Analysis of California Condor (Gymnogyps californianus) Use of Six Management Units Using Location Data from Global Positioning System Transmitters, Southern California, 2004-09_Initial Report

Open-File Report 2010-1287 



\section{Analysis of California Condor (Gymnogyps californianus) Use of Six Management Units Using Location Data from Global Positioning System Transmitters, Southern California, 2004-09_Initial Report}

By Matthew Johnson, Jeffrey Kern, and Susan M. Haig

Open-File Report 2010-1287

U.S. Department of the Interior

U.S. Geological Survey 


\section{U.S. Department of the Interior \\ KEN SALAZAR, Secretary}

\section{U.S. Geological Survey \\ Marcia K. McNutt, Director}

U.S. Geological Survey, Reston, Virginia: 2010

For more information on the USGS-the Federal source for science about the Earth, its natural and living resources, natural hazards, and the environment, visit $h t t p: / / w w w . u s g s . g o v$ or call 1-888-ASKUSGS.

For an overview of USGS information products, including maps, imagery, and publications, visit http://www.usgs.gov/pubprod

To order this and other USGS information products, visit http://store.usgs.gov

Suggested citation:

Johnson, Matthew, Kern, Jeffrey, and Haig, S.M., 2010, Analysis of California Condor (Gymnogyps californianus) use of six management units using location data from global positioning system transmitters, southern California, 2004-09-Initial report: U.S. Geological Survey Open-File Report 2010-1287, 64 p.

Any use of trade, product, or firm names is for descriptive purposes only and does not imply endorsement by the U.S. Government.

Although this report is in the public domain, permission must be secured from the individual copyright owners to reproduce any copyrighted material contained within this report. 


\section{Contents}

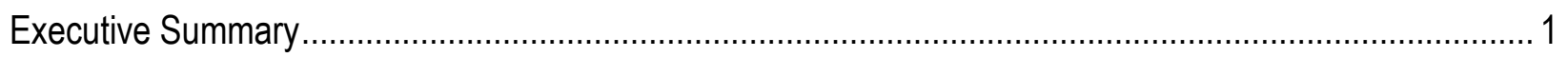

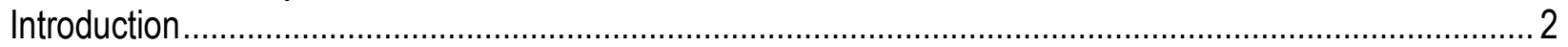

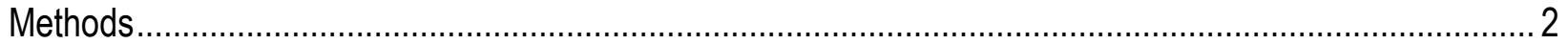

Management Units and Ecoregion Data ....................................................................................... 3

Global Positioning System Transmitter Data............................................................................. 3

Home Range, Utilization Distribution, and Relative Concentration of Use Estimates................................ 4

California Condor Use of Management Units and Ecoregions by Year ................................................ 5

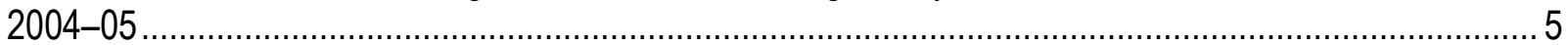

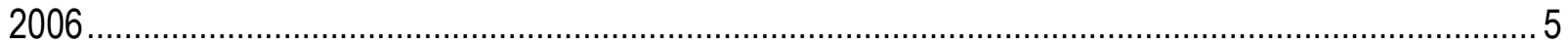

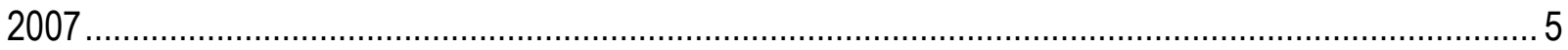

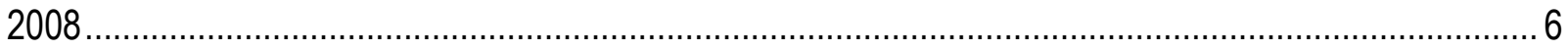

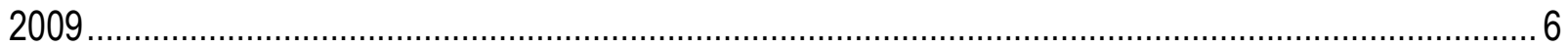

Analysis of California Condor Use of Management Units ……………........................................... 7

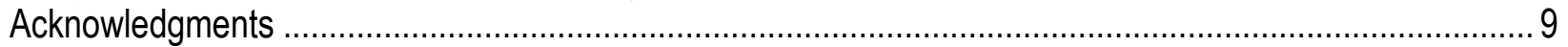

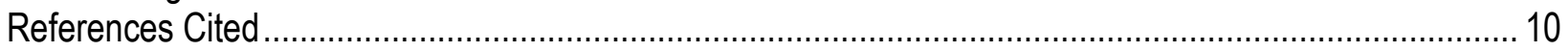

Appendix A.-Analysis of California Condor (Gymnogyps californianus) Use of Six Management Units Using Location Data from Global Positioning System Transmitters, Southern California, 2004-09-Initial

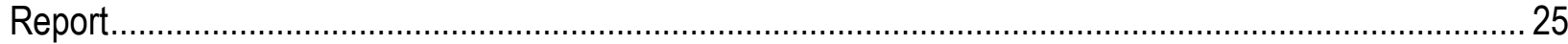

\section{Figures}

Figure 1. Map showing historical range of the California Condor, management units, foraging zones, and Federal lands within the range, and designated Critical Habitat for the species.

Figure 2. Map showing Geographic Information System data for six management units in southern

California

Figure 3. Illustrative example of methods used to quantify California Condor space use within the southern

California population

Figure 4. Map showing ecological subregion Geographic Information System data used to derive ecologically relevant areas of interest for spatial analyses of California Condors in the southern California population

Figure 5. Map showing final Geographic Information System data layer depicting the six management units and seven ecoregions used in the spatial analyses of California Condors in the southern California population

Figure 6. Maps showing average relative concentration of use of six management units and seven ecoregions within the annual (2006-09) home range of California Condors in the southern California population

Figure 7. Bar graphs showing relative concentration of use of six management units and seven ecoregions within the annual home range of California Condors in the southern California population (panel A, 2006) and mean occurrence of each management unit and ecoregion within the home range (panel B)...

Figure 8. Bar graphs showing relative concentration of use of six management units and seven ecoregions within the annual home range of California Condors in the southern California population (panel A, 2007) and mean occurrence of each management unit and ecoregion within the home range (panel B).. 
Figure 9. Bar graphs showing relative concentration of use of six management units and seven ecoregions within the annual home range of California Condors in the southern California population (panel A, 2008) and mean occurrence of each management unit and ecoregion within the home range (panel B)..

Figure 10. Bar graphs showing relative concentration of use of six management units and seven ecoregions within the annual home range of California Condors in the southern California population (panel A, 2009) and mean occurrence of each management unit and ecoregion within the home range (panel $\mathrm{B})$.

Figure 11. Bar graph showing mean difference in relative concentration of use of six management units and seven ecoregions within the annual home range of California Condors in the southern California population

\section{Table}

Table 1. Global Positioning System (GPS) location data for 21 California Condors.

\section{Conversion Factors and Datum}

\section{Conversion Factors}

SI to Inch/Pound

\begin{tabular}{lll}
\hline \multicolumn{1}{c}{ Multiply } & \multicolumn{1}{c}{ By } & \multicolumn{1}{c}{ To obtain } \\
\hline kilometer $(\mathrm{km})$ & 0.6214 & mile $(\mathrm{mi})$ \\
$\operatorname{meter}(\mathrm{m})$ & 3.281 & foot $(\mathrm{ft})$ \\
kilogram $(\mathrm{kg})$ & 2.205 & pound avoirdupois $(\mathrm{lb})$ \\
\hline
\end{tabular}

\section{Datum}

Horizontal coordinate information is referenced to the North American Datum of 1983 (NAD 83) 


\section{Analysis of California Condor (Gymnogyps californianus) Use of Six Management Units Using Location Data from Global Positioning System Transmitters, Southern California, 2004-09-Initial Report}

By Matthew Johnson, Jeffrey Kern, and Susan M. Haig

\section{Executive Summary}

This report provides an analysis of California Condor (Gymnogyps californianus) space use of six management units in southern California (Hopper Mountain and Bitter Creek National Wildlife Refuges, Wildlands Conservancy_-Wind Wolves Preserve, Tejon Mountain Village Specific Plan, California Condor Study Area, and the Tejon Ranch excluding Tejon Mountain Village Specific Plan and California Condor Study Area). Space use was analyzed to address urgent management needs using location data from Global Positioning System transmitters. The U.S. Fish and Wildlife Service provided the U.S. Geological Survey with location data (200409) for California Condors from Global Positioning System transmitters and Geographic Information System data for the six management units in southern California.

We calculated relative concentration of use estimates for each management unit for each California Condor $(n=21)$ on an annual basis $(n=39$ annual home ranges $)$ and evaluated resource selection for the population each year using the individual as our sampling unit. The most striking result from our analysis was the recolonization of the Tejon Mountain Village Specific Plan, California Condor Study Area, and Tejon Ranch management units during 2008. During 2004-07, the home range estimate for two (25 percent) California Condors overlapped the Tejon Mountain Village Specific Plan, California Condor Study Area, and Tejon Ranch management units $(\mathrm{n}=8)$, and use within the annual home range generally was bimodal and was concentrated on the Bitter Creek and Hopper Mountain National Wildlife Refuges. However, 10 (77 percent) California Condor home ranges overlapped the Tejon Mountain Village Specific Plan, California Condor Study Area, and Tejon Ranch management units during $2008(\mathrm{n}=13)$, and by 2009, the home range of every condor carrying a Global Positioning System transmitter $(n=14)$ overlapped these management units. Space use was multimodal within the home range during 2008-09 and was concentrated on Hopper Mountain Refuge in the south, Bittercreek Refuge and the Wind Wolves Preserve in the northwest, and the Tejon Mountain Village Specific Plan, California Condor Study Area, and Tejon Ranch management units in the northeast. Recolonization of the Tejon Mountain Village Specific Plan, California Condor Study Area, and Tejon Ranch management units reestablished traditional condor movement and foraging patterns in southern California and provides the travel corridor (approximately 20 kilometers wide) for recolonization of the northeastern part of the species historical range. 


\section{Introduction}

The Federally Endangered California Condor (Gymnogyps californianus) is the largest land bird in North America weighing approximately $8.5 \mathrm{~kg}$ with a $2.8 \mathrm{~m}$ wingspan (Snyder and Schmitt, 2002). California Condors are obligate scavengers with a life history characterized by delayed maturity, low productivity, and relatively high adult survivorship (Koford, 1953). Although the California Condor's historical range was across much of the United States, northern Mexico, and southern Canada during the Pleistocene age, by 1982, the California Condor's range was limited to a small area surrounding the southern San Joaquin Valley, California, with a population size of 22 birds (fig. 1; Wilbur, 1976; Snyder and Snyder, 2000). A captive flock was established to stave off extinction in 1982, and by 1987, the last wild condor was brought into captivity (U.S. Fish and Wildlife Service, 2010]. Captive breeding efforts have been successful since 1988 with reintroduction to the wild beginning in 1992. Since that time, free-flying California Condor populations have been re-established at five release sites in the western United States (southern California-Hopper Mountain National Wildlife Refuge Complex; northern Arizona_-Vermilion Cliffs; central California-Big Sur and Pinnacles National Monument) and in Baja California, Mexico - Sierra San Pedro de Mártir National Park (U.S. Fish and Wildlife Service, 2010).

The U.S. Geological Survey (USGS) and the U.S. Fish and Wildlife Service (USFWS) California Condor Recovery Program are undertaking a research program to model California Condor movement patterns and habitat use in historical and reintroduced populations. The goal of this research program is to better inform and enhance the management strategies at current condor release sites, identify and evaluate potential future release sites, and develop a metapopulation structure throughout the condor's historical range that will ensure sufficient connectivity among populations to maintain genetic variation and self-sustaining demographic rates over the long term. During early stages of this collaborative effort, USFWS requested that USGS provide a preliminary report focused on California Condor use of six management units in southern California to address urgent management needs (figs. 1 and 2). The objective of this report is to present analyses of California Condor use of these management units by the southern California Condor population to fulfill that request.

\section{Methods}

We used California Condor Global Positioning System (GPS) transmitter data to quantify condor use of six management units and seven ecoregions in southern California by calculating a relative concentration of use (RCU) estimate for each management unit and ecoregion (Neatherlin and Marzluff, 2004; Marzluff and others, 2004; Millspaugh and others, 2006). We calculated resource selection within the 99-percent fixed-kernel estimate of individual condor home ranges (Worton, 1987) by estimating the utilization distribution (UD, probability density function, Silverman, 1986) through the fixed-kernel procedure (Worton, 1989) with an automatic bandwidth selection method (reference or normal method, $h_{\text {ref }}$ ). The UD of an individual, or population of animals, can be used to estimate the probability and intensity of use for specific habitats or sites within an area of interest (for example, home range, Van Winkle, 1975; Marzluff and others, 2001, 2004). The total likelihood of use in a particular habitat or site is the total volume of the UD associated with that habitat or site, and concentration of use is the ratio of this volume (that is, probability of occurrence) to the availability of the habitat within the home range (fig. 3; Neatherlin and Marzluff, 2004; Marzluff and others, 2004; Millspaugh and others, 2006). 
Concentration of use corresponds to other selection coefficients that relate resource use to availability (Manly and others, 2002; Marzluff and others,2004), and improves on traditional selection coefficients because it integrates relative selectivity as a continuous probabilistic process throughout the area of interest (for example, home range), appropriately uses individual animals as the sampling unit (Otis and White, 1999), and accounts for the unit sum constraint (Aebischer and others, 1993).

\section{Management Units and Ecoregion Data}

USFWS provided USGS with Geographic Information System (GIS) data for six management units (fig. 2). USGS supplemented these data with U.S. Department of Agriculture (USDA) GIS data (fig. 4; U.S. Forest Service ecological subregions, Cleland and others, 2007). It was necessary to supplement the GIS data provided by USFWS (fig. 2) to fully quantify condor resource selection within annual home ranges, as condor home ranges extended beyond the six management units of interest. We used USDA GIS data (fig. 4) because these data allowed us to delineate more ecologically relevant regions (that is, at an appropriate scale for analyzing California Condor movements) relative to other available GIS data for the region. We coalesced the 42 ecological subregions delineated within our study area (fig. 4) into seven ecologically relevant regions, and then merged these data with the GIS data provided by USFWS (fig. 2) to produce our base GIS map that contained six management units and seven ecoregions (fig. 5). Analyses were conducted using ArcMap 9.2 (ESRI, 2007).

\section{Global Positioning System Transmitter Data}

USFWS provided the USGS with GPS-transmitter (Argos/GPS PTT; Microwave

Telemetry, Inc. ${ }^{(}$, Columbia, Maryland) location data (hourly locations, 05:00-20:00 PST) for the California Condor population in southern California. USGS also requested USFWS provide data on GPS-transmitter attachment dates and individual California Condor case histories to ensure data accuracy and utility. The original dataset contained 155,543 GPS locations for 35 individual condors (June 15, 2004-December 31, 2009). Of these, 5,342 locations were obtained while a condor was in captivity (for example, in a flight-pen prior to release or in a trap for periodic management activities). These location data (that is, data from captive birds) did not contribute to our understanding of California Condor space use and were not included in the analyses. Examination of the relevant condor GPS-transmitter location dataset (150,201 location points, $n$ $=35$ individuals) revealed that individual condors carried GPS transmitters for varying periods of time (length of time individual condors continuously carried a GPS transmitter ranged from 135 months), that 18 condors (51 percent) carried transmitters during multiple calendars years, and that 14 condors ( 40 percent) carried a transmitter for less than 6 months during a calendar year (June 15, 2004-December 31, 2009).

We produced annual home range, UD, and RCU estimates for individual California Condors that were equipped with GPS transmitters for a minimum of 6 consecutive months during any 1 calendar year (table $1 ; 2004-09 ; \mathrm{n}=21$ individuals; 127,931 GPS locations) to quantify condor resource selection using an objective measure of resource availability during an explicit period of time (that is, annual home range). This data selection method reduced biases associated with comparing condor resource selection between bird's carrying GPS transmitters for a small portion of the annual cycle (for example, 1-3 months) and those carrying transmitters throughout the annual cycle, and it ameliorated potential biases in condor behavior associated with birds becoming acclimated to carrying a GPS transmitter. In our final GPS-transmitter 
location dataset (table 1), nearly one-half of all condors carried GPS transmitters during multiple years (10 of 21 condors). We therefore calculated home range, UD and RCU estimates for each condor on an annual basis and modeled resource selection for the population each year using the individual as our sampling unit. However, as only two California Condors carried GPS transmitters during 2004-05 (table 1), we report and discuss space use during this period for each individual.

\section{Home Range, Utilization Distribution, and Relative Concentration of Use Estimates}

We evaluated two commonly used automatic bandwidth-selection methods (reference or normal method, $h_{\text {ref; }}$ and least squares cross-validation, LSCV) to produce 99-percent fixedkernel home range estimates and estimate UDs (39 UD estimates for 21 individual California Condors, 2004-09, fig. 3, table 1, appendix A). The bandwidth, or smoothing parameter, controls the neighborhood size within which observed locations contribute to the density estimate at a point (Silverman, 1986). The LSCV bandwidth selection method is frequently used in wildlife home range studies and often outperforms the $h_{\text {ref }}$ bandwidth selection method (Silverman, 1986; Manly, 2002; Amstrup and others, 2004). However, we predicted that the $h_{\text {ref }}$ bandwidth selection method would more realistically estimate California Condor home ranges as condors are a wide-ranging and highly mobile species, and the LSCV bandwidth selection method tends to select overly small bandwidth values when there is clustering in the data, even with large datasets, as is the case with the California Condor GPS-transmitter dataset (Silverman, 1986; Amstrup and others, 2004). California Condors routinely return to perch and roost at the same distinct locations throughout the annual cycle, and GPS location data for individual condors therefore contain numerous overlapping location points at these sites. The LSCV algorithm failed as a result of these overlapping data points; it failed to minimize the mean integrated squared error function during the fixed-kernel density estimation procedure because of discretization errors (that is, division by zero error). We attempted to overcome this obstacle and evaluate the LSCV bandwidth selection method by randomly shifting overlapping points (100$300 \mathrm{~m}$ ) or deleting overlapping points prior to running the algorithm; however, the LSCV algorithm continued to fail after overlapping points were randomly shifted or deleted. We were unable to evaluate the LSCV method further; instead we used the $h_{\text {ref }}$ smoothing parameter to estimate 99-percent fixed-kernel home ranges and UDs $(n=39)$ for individual condors $(n=21)$ and produced RCU estimates for all management units $(n=6)$ and ecoregions $(n=7)$ for each GPS-tagged condor annually (table 1, fig. 5, appendix A). We used HRT [Home Range Tools for ArcGIS (Rodgers and others, 2005)] to estimate $h_{\text {ref }}$ (the smoothing parameter) and Hawth's Analysis Tools for ArcGIS (Beyer, 2004) to estimate the 99-percent fixed-kernel home range and UD for individual condors (grid cell size $=100 \mathrm{~m}$ ). We calculated RCU estimates within each management unit and ecoregion using ArcMap 9.2 (Neatherlin and Marzluff, 2004; ESRI, 2007; Kertson and Marzluff, 2009).

We compared relative concentration of use (RCU) among all management units and ecoregions within condor annual home ranges using individual condors as the sampling unit in a population-level analysis. We also summed the total area of each management unit and ecoregion within condor home ranges to estimate occurrence so that selectivity could be viewed in the context of availability (Neatherlin and Marzluff, 2004). Although spatial autocorrelation arises through the use of a fixed-kernel procedure to construct the UD, by using individual condors as the sampling unit in a population-level model, we may ignore spatial autocorrelation in the individual locations because individual model coefficients are unbiased even when 
autocorrelation is present (Liang and Zeger, 1986; McCullagh and Nelder, 1989; Aebischer and others, 1993; Neter and others, 1996; Erickson And others, 2001). We compared annual RCU estimates for the six management units (fig. 2) for seven California Condors that carried a GPS transmitter during 2008 and 2009 using a Wilcoxon signed rank test—a nonparametric test for paired data (Wilcoxon, 1945; SAS Institute, 2008).

\section{California Condor Use of Management Units and Ecoregions by Year}

\section{4-05}

Both California Condors tracked during 2004-2005 concentrated use within the annual home range on the HOP management unit and in the SOUTH ecoregion (appendix A). Condor use in the SOUTH management unit generally was on or near several communication towers where field personnel documented condors airborne and roosting (U.S. Fish and Wildlife Service, 2010). Condor SB161 predominantly used the HOP management unit and to a lesser extent the SOUTH and SRTM ecoregions during 2004-05; however, its home range also overlapped the NTR and SYSM ecoregions and the TMV management unit, but these areas rarely were used (appendix A). Similarly, condor SB192 predominantly used the HOP management unit and surrounding ecoregions (NTR, SOUTH, SRTM, SYSM) during 2004-05; however, condor SB192 also used the CSA, TEJON, and TMV management units during both years (appendix A). The home range of condor SB192 also overlapped the WEST ecoregion during 2004-05, but this area rarely was used (appendix A).

\section{6}

Two of three California Condors (SB021 and SB192) tracked in 2006 were paired, and the other individual (condor SB112) also attempted reproduction (table 1), but neither the condor pair nor condor SB112 successfully fledged offspring in 2006 (U.S. Fish and Wildlife Service, 2010). Space use within the annual home range was bimodal for the condor pair and was concentrated on the BC management unit in the north and the HOP management unit in the south, whereas adjacent management unit (WW) and ecoregions (SRTM, WEST) were used less frequently (figs. 6 and 7, appendix A). In contrast, the home range for condor SB112 did not overlap the BC management unit in 2006 (fig. 7, appendix A). Rather, condor SB112 concentrated use in the HOP management unit and the adjacent SRTM ecoregion (appendix A). All three condors tracked during 2006 used the SOUTH ecoregion generally on or near several communication towers where field personnel previously documented condors airborne and roosting (U.S. Fish and Wildlife Service, 2010).

\section{7}

All five California Condors tracked during 2007 generally exhibited a bimodal UD (fig. 8, appendix A). Space use within the annual home range was concentrated on the $\mathrm{BC}$ and $\mathrm{HOP}$ management units, and intervening or adjacent management unit (WW) and ecoregions (NTR, SOUTH, SRTM, SYSM, WEST) were used less frequently (figs. 6 and 8, appendix A). The average likelihood of condor occurrence on the HOP and BC management units was 35 and 29 percent, respectively (fig. $8 A$ ) despite these management units comprising less than 1 (HOP) and less than 4 percent $(\mathrm{BC}$ ) of the annual home range (fig. $8 B$ ). Although ecoregions adjacent to 
HOP and BC were used relatively more frequently during 2007 compared to other ecoregions (for example, SRTM = 10 percent, figs. 6 and 8A); unlike HOP and BC management units, these ecoregions generally constituted a larger portion of the home range (for example, SRTM $=32$ percent, fig. 8B). California Condor use of the SOUTH ecoregion in 2007 was concentrated on or near several communication towers where field personnel previously documented condors airborne and roosting (U.S. Fish and Wildlife Service, 2010).

\section{8}

Overall, UD estimates indicated California Condors exhibited a multimodal distribution in 2008 (fig. 9, appendix A). Condor use within the annual home range was concentrated on the HOP management unit in the south, $\mathrm{BC}$ and WW management units in the northwest, and on CSA, TEJON, and TMV management units in the northeast (10 of 13 condors tracked during 2008, figs. 6 and 9, appendix A). The average likelihood of condor occurrence was highest in the BC (31 percent) and HOP (26 percent) management units (fig. 9A, appendix A) despite these management units comprising less than 3 (BC) and less than 1 percent (HOP) of the annual home range (fig. 9B). The WW management unit and four ecoregions (NTR, SYSM, SRTM, and WEST) also were within the home range of all 13 condors tracked during 2008 (figs. 6 and 9 , appendix A). The average likelihood of condors using the WW management unit was 6 percent during 2008, and this management unit accounted for 7 percent of the annual home range. The average likelihood of condors using the four ecoregions used by all GPS-tagged condors in 2008 was similar to that of the WW management unit (average likelihood of use: NTR $=5$ percent, SRTM $=8$ percent, SYSM $=5$ percent, WEST $=7$ percent; fig. 9A); however, NTR and SRTM ecoregions constituted 3-4 times more of the annual home range than the WW management unit (fig. 9B). Most condors tracked during 2008 also used the CSA (77 percent, $\mathrm{n}=10$ ), TEJON (77 percent, $\mathrm{n}=10$ ), and TMV (85 percent, $\mathrm{n}=11$ ) management units (figs. 6 and 9; appendix A). Nearly all (92 percent) condor UD estimates for 2008 also included the SOUTH ecoregion (fig. 9, appendix A) where use was concentrated on or near several communication towers where field personnel previously documented condors airborne and roosting (U.S. Fish and Wildlife Service, 2010).

\section{9}

Annual home range estimates for the 14 California Condors tracked during 2009 overlapped all management units and ecoregions (figs. 6 and 10, appendix A). California Condor UD estimates from 2009 indicated a multimodal distribution with use concentrated on HOP management unit in the south, BC and WW management units in the northwest, and on the CSA, TEJON, and TMV management units in the northeast (figs. 6 and 10, appendix A). The average likelihood of condor occurrence during 2009 was highest on the BC (21 percent), CSA (14 percent), and HOP (23 percent) management units and within the SRTM (9 percent) ecoregion (fig. 10A, appendix A). The HOP, BC, and CSA management units comprised less than 1, 2, and 4 percent of the annual home range, respectively; whereas the relative contribution of the SRTM ecoregion to the annual home range was 17 percent (fig. 10B). The average likelihood of condor use ranged from 4 to 6 percent for three other management units (TEJON, TMV, WW) and two ecoregions (SYSM, WEST), and these areas constituted between 2 and 11 percent of the annual home range (fig. 10). The average likelihood of occurrence for California Condors tracked during 2008 and $2009(n=7)$ was statistically different between years in three of the six management units (fig. 11). Wilcoxon signed rank tests indicated that California Condor use of 
CSA and TEJON management units was higher in 2009 than in 2008; whereas, the likelihood of condors use of the BC management unit was lower in 2009 (fig. 11).

\section{Analysis of California Condor Use of Management Units}

The most striking result from our analysis was the recolonization of the CSA, TEJON, and TMV management units during 2008. During 2004-07, California Condor use within the annual home range generally was bimodal and use was concentrated on the $\mathrm{BC}$ and HOP management units, and the home range estimate for 2 (25 percent) California Condors overlapped the CSA, TEJON, and TMV management units $(n=8)$. However, 10 (77 percent) California Condor home ranges overlapped these management units during $2008(\mathrm{n}=13)$, and by 2009 , the home range of every GPS-tagged condor $(n=14)$ overlapped the CSA, TEJON, and TMV management units, and space use was multimodal within the home range and use was concentrated on the HOP management unit in the south, BC and WW management units in the northwest, and CSA, TEJON, and TMV management units in the northeast.

Extensive use of the BC and HOP management units during 2004-07 was likely related to condors being released from captivity and proffered food at these sites. California Condors previously were released from captivity on the HOP management unit $(<2004)$, and the current release site in southern California is on the $\mathrm{BC}$ management unit $(>2005$, no new releases in southern California 2004-05; U.S. Fish and Wildlife Service, 2010). Food was previously proffered on the HOP management unit and currently is provided on the BC and WW management units (U.S. Fish and Wildlife Service, 2010). Although a steady supply of proffered food was historically (Wilbur and others, 1974; Wilbur, 1978; Meretsky and Snyder, 1992) and is currently available to condors in southern California, California Condor foraging patterns and feeding events are not necessarily limited by proffered food availability (Meretsky and Snyder, 1992). For example, California Condors have recolonized traditional foraging habitat (CSA, TEJON, and TMV) despite consistent food provisioning on the $\mathrm{BC}$ and $\mathrm{WW}$ management units. Non-proffered food (carcasses) availability in traditional condor foraging habitat most likely encouraged condor use of these areas and may maintain condor use despite consistent provisioning efforts elsewhere. The home range for six ( 75 percent) condors tracked during 2004-07 ( $\mathrm{n}=8)$ also included several communication towers where condors have been documented roosting in the SOUTH ecoregion, and to the northwest, the home range for condors SB161 and SB192 extended into Santa Barbara, San Luis Obispo, and Monterey Counties. Both California Condors tracked during 2004-05 were released in central California near Big Sur (condor SB161 in 1997, condor SB192 in 1998) before dispersing to southern California and first attempting reproduction in 2004 (U.S. Fish and Wildlife Service, 2010), which likely explains their use of these areas.

During 2008, California Condor space use within the annual home range generally shifted from a bimodal to a multimodal distribution and was concentrated on the HOP management unit in the south, BC and WW management units in the northwest, and CSA, TEJON, and TMV management units in the northeast (figs. 6 and 9). Home range and UD estimates during 2008 were similar in all but three cases (condors SB107, SB328, SB428). The home range for these three condors did not appreciably overlap the CSA, TEJON, and TMV management units. In one case, breeding condor SB107 exhibited a bimodal UD predominantly using the BC and HOP management units during 2008 (appendix A). Breeding did not likely limit use of the CSA, TEJON, and TMV management units by condor SB107, as five other condors tracked during 2008, including its mate (that is, condor SB161), fledged offspring and 
exhibited a multimodal UD that included these management units (figs. 6 and 9, table 1, appendix A). In the second case, condor SB328 hatched in the wild in April 2004, but was brought into captivity in August 2004 because of a broken wing, and was not released into the wild again until October 2007 (U.S. Fish and Wildlife Service, 2010). Space use primarily was unimodal within the home range for condor SB328 during 2008, and use was focused on the BC and WW management units and NTR ecoregion, with other areas (HOP management unit and SRTM, SYSM, WEST ecoregions) used less frequently (appendix A). Lastly, condor SB428 hatched in 2007 and was the youngest condor tracked during 2008. Condor SB428 predominantly used the BC, HOP, and WW management units during 2008, and intervening or adjacent management units and ecoregions (WEST, NTR, SRTM) were used less frequently (appendix A). Although home range estimates for these three condors (SB328, SB428, SB107) did not appreciably overlap the CSA, TEJON, or TMV management units during 2008, the home range estimate for more than 75 percent of GPS-tagged California condors did overlap (figs. 6 and 9). Furthermore, by 2009 every GPS-tagged condor's home range $(n=14)$ overlapped the CSA, TEJON, TMV management units, including immature condor SB428.

During 2009, all California Condor home range and UD estimates indicated a multimodal distribution, and use generally was concentrated on the HOP management unit in the south, BC and WW management units in the northwest, and CSA, TEJON, and TMV management units in the northeast (figs. 6 and 10). California Condors initially recolonized the CSA, TEJON, and TMV management units in 2008 (figs. 6 and 9) and relative concentration of use of these management units continued to increase in 2009 (fig. 11). The CSA, TEJON, and TMV, management units historically were used by California Condors (Meretsky and Snyder, 1992), and portions of these management units were designated as critical habitat (fig. 1, U.S. Fish and Wildlife Service, 1976). Recolonization of historical foraging and roosting sites within the CSA, TEJON, and TMV management units reestablished traditional condor movement and foraging patterns in southern California, particularly for breeding condors. Prior to extirpation from the wild, California Condor movement patterns were analyzed in six foraging zones (dashed lines in figure 1, Meretsky and Snyder, 1992). Historically, California Condors used all these foraging zones during the annual cycle, with unpaired and immature condors exhibiting the broadest movement patterns, capable of moving between any two points within the species' range in a single day (Meretsky and Snyder, 1992). Breeding pairs in southern California typically did not forage more than 50-70 km from their nest site historically; however, breeding birds did forage over considerably longer distances (more than $150 \mathrm{~km}$; Meretsky and Snyder, 1992). California Condors that historically nested near and to the east of Hooper Mountain NWR more frequently used the CSA, TEJON, and TMV management units (Tehachapi foraging zone of Meretsky and Snyder, 1992) during the breeding season compared to any other foraging area (fig. 1; Meretsky and Snyder, 1992). Reintroduced condors nesting on and near the HOP management unit predominantly used $\mathrm{BC}$ and HOP management units prior to 2008. Condor pairs near the HOP management unit routinely traveled to proffered food on the $\mathrm{BC}$ management unit before 2008 (55-66 km from nest sites). This foraging pattern, nesting near the HOP management unit and foraging on or near the $\mathrm{BC}$ management unit, did not match well with the foraging pattern exhibited by the historical population. Although adult condors were historically familiar with all major foraging zones used by the population, condors historically breeding near the HOP management unit most frequently foraged on and near the CSA, TEJON, and TMV management units (24-36 km from nest sites, Tehachapi foraging zone of Meretsky and Snyder, 1992). Prior movement analyses (Meretsky and Snyder, 1992) were conducted on the behavior of the remnant 
population of California Condors ( $n=23$ individuals) and may not necessarily be indicative of condor movement patterns before the precipitous population decrease of the 20th century. However, Meretsky and Snyder's (1992) work is the only published research that consistently tracked individual California Condors prior to extirpation. Regardless, reintroduced California Condors have recolonized the CSA, TEJON, and TMV management units, and this behavior is consistent with that exhibited by the population prior to extirpation. Furthermore, California Condors use of the CSA, TEJON, and TMV management units will likely increase if condors recolonize their historical range to the northeast.

Nesting, foraging, and roosting habitat in the Sierra Nevada mountain range has not yet been recolonized; however, the CSA, TEJON, and TMV management units provide the only corridor (approximately $20 \mathrm{~km}$ wide) that permits condor movement between the northeastern and southern parts of the historical range (fig. 1). Historically, California Condors traveled through these management units and adjacent foothills and mountains surrounding the San Joaquin Valley, and reintroduced condors will most likely use this area to move between the northeastern and southern parts of the range given that a prior study reported that condors did not typically fly directly across the San Joaquin Valley (Meretsky and Snyder, 1992). As scavengers, California Condors must cope with a food supply that is spatially and temporally unpredictable, and maintaining familiarity with food availability throughout the foraging range is likely adaptive (Meretsky and Snyder, 1992). California Condors that travel widely, throughout their range, not only acquire greater information on food availability compared to conspecifics that forage over a more limited area, but wide-ranging condors also have the opportunity to acquire greater information on predator and competitor (black bear, Ursus americanus; coyote, Canis latrans; Golden Eagle, Aquila chrysaetos) densities throughout the range (Meretsky and Snyder, 1992). Incorporating prior information on food, predator, and competitor densities into foraging behavior increases the probability of locating food, decreases the amount of time required to locate food, and may reduce the probability of encountering both predator and competitor, all of which can impact survival and reproduction.

Overall, the data indicated that California Condors in southern California recolonized the CSA, TEJON, and TMV management units. Annual home range estimates generally did not include the CSA, TEJON and TMV management units during 2004-07, and space use within the annual home range was bimodal and was concentrated on HOP management unit in the south and $\mathrm{BC}$ and WW management units in the northwest. However, 10 of 13 California Condor home ranges overlapped these management units during 2008, and the home range of all 14 condors tracked in 2009 overlapped the CSA, TEJON, and TMV management units. Furthermore, space use within the annual home range generally was multimodal and was concentrated on the HOP management unit in the south, BC and WW management units in the northwest, and CSA, TEJON, and TMV management units in the northeast. Recolonization of the CSA, TEJON, and TMV management units reestablished traditional condor movement and foraging patterns in southern California and provides the travel corridor (approximately $20 \mathrm{~km}$ wide) for recolonization of the northeastern part of the species' historical range.

\section{Acknowledgments}

We thank H. Beyer, B.N. Kertson, J.M. Marzluff, and A.R. Rodgers for technical assistance and J. Brandt, B. Massey, and J. Burnett for providing data. We also thank K. Jenkins and D. Wiens for comments that improved the manuscript. 


\section{References Cited}

Aebischer, N.J., Robertson, P.A., and Kenward, R.E., 1993, Compositional analysis of habitat use from animal radio-tracking data: Ecology, v. 74, p. 1313-1325.

Amstrup, S.C., McDonald, T.L., and Durner, G.M., 2004, Using satellite radiotelemetry data to delineate and manage wildlife populations: Wildlife Society Bulletin, v. 32, no. 3, p. 661-679.

Beyer, H., 2005, Hawth's Analysis Tools for ArcGIS: Accessed November 1, 2010, at http://www.spatialecology.com/htools/.

Cleland, D.T., Freeouf, J.A., Keys, J.E., Jr., Nowacki, G.J., Carpenter, C.A., and McNab, W.H., 2007, Ecological Subregions: Sections and Subsections of the Conterminous United States [1:3,500,000] [CD-ROM]. Sloan, A.M., cartographer, Gen. Tech. Report WO-76. Washington, DC: U.S. Department of Agriculture, Forest Service.

Erickson, W.P., McDonald, T.L., Gerow, K.G., Howlin, S., and Kern, J.W., 2001, Statistical issues in resource selection studies with radio-marked animals: in Millspaugh, J.J., and Marzluff, J.M., eds., Radio Tracking and Animal Populations: Academic Press, San Diego, California, p. 211-242.

ESRI, 2007, ArcGIS, Version 9.2: Earth Systems Research Institute, Inc., Redlands, CA.

Kertson, B.N., and Marzluff, J.M., 2009, Animal movement, home range, and resource utilization function (ruf) analysis in ArcMap 9.3: School of Forest Resources, University of Washington, Seattle, $30 \mathrm{p}$.

Koford, C.B., 1953, The California Condor: National Audubon Society Research Report number 4, $154 \mathrm{p}$.

Liang, K.Y., and Zeger, S.L., 1986, Longitudinal data analysis using generalized linear models: Biometrika, v. 73, p. 13-22.

Manly, B.F.J., McDonald, L.L., Thomas, D.L., McDonald, T.L., and Erickson, W.P., 2002, Resource Selection by Animals, Second edition: Kluwer Academic, Boston, MA.

Marzluff, J.M., S.T. Knick, S.T., and J.J. Millspaugh, J.J., 2001, High-tech behavioral ecology: modeling the distribution of animal activities to better understand wildlife space use and resource selection, in Millspaugh, J.J., and Marzluff, J.M., eds., Radio Tracking and Animal Populations: Academic Press, San Diego, California, p. 310-326.

Marzluff, J.M., Millspaugh, J.J., Hurvitz, P., and Handcock, M.S., 2004, Relating resources to a probabilistic measure of space use: forest fragments and Steller's Jays: Ecology, v. 85, p. 1411-1427.

McCullagh, P., and Nelder, J.A., 1989, Generalized linear models, Second edition, Monographs on statistics and applied probability \#37: Chapman and Hall, London, UK.

Meretsky, V.J., and Snyder, N.F.R., 1992, Range use and movements of California Condors: Condor, v. 94, p. 313-335.

Millspaugh, J.J., Nielson, R.M., McDonald, L., Gitzen, R.A., Rittenhouse, C.D., Hubbard, M.W., and Sheriff, S.L., 2006, Analysis of resource selection using utilization distributions: Journal of Wildlife Management, v. 70, p. 384-395.

Neatherlin, E.A., and Marzluff, J.M., 2004, Campgrounds enable American crows to colonize remote native forests: Journal of Wildlife Management, v. 68, p. 708-718.

Neter, J., Kutner, M.H., Nachtsheim, C.J., and Wasserman, W., 1996, Applied linear statistical models: McGraw-Hill, Boston, MA.

Otis, D.L., and White, G.C., 1999, Autocorrelation of location estimates and the analysis of radiotracking data: Journal of Wildlife Management, v. 63, p. 1039-1044. 
Rodgers, A.R., Carr, A.P., Smith, L., Kie, J.G., 2005, HRT: home range tools for ArcGIS: Ontario Ministry of Natural Resources, Centre for Northern Forest Ecosystem Research, Thunder Bay, Ontario, Canada, accessed November 1, 2010, at http://www.blueskytelemetry.com/downloads.asp.

SAS Institute, 2008, Version 9.2, SAS Institute Inc.: Cary, NC, ESRI, 2007.

Silverman, B.W., 1986, Density estimation for statistics and data analysis: Chapman and Hall, London, UK.

Snyder, N.F.R., and Schmitt, N.J., 2002, California Condor (Gymnogyps californianus), in Poole A., and Gill, F., eds., The Birds of North America, No. 610. The Birds of North America, Inc., Philadelphia, PA.

Snyder, N.F.R., and Snyder, H., 2000, The California Condor: A Saga of Natural History and Conservation: Academic Press, San Diego.

U.S. Fish and Wildlife Service, 1976, Part 17-Endanered and Threatened Wildlfie and Plants. Federal Register, Vol.41, No. 187-Friday, September 24, 1976. pp. 41914-441916.

U.S. Fish and Wildife Service, 1996, California Condor Recovery Plan, Third Revision. Portland, Oregon.

U.S. Fish and Wildlife Service, 2010, Hopper Mountain National Wildlife Refuge Complex, California Condor Recovery Program: accessed November 2, 2010, at http://www.fws.gov/hoppermountain/CACORecoveryProgram/CACondorRecoveryProgram.ht $\mathrm{ml}$.

Van Winkle, W., 1975, Comparison of several probabilistic home-range models: Journal of Wildlife Management. v. 39, p. 118-123.

Wilbur, S.R., Carrier, W., and Borneman, J., 1974, Supplemental feeding program for California Condors: Journal of Wildlife Management, v. 38, p. 343-346.

Wilbur, S.R., 1976, Status of the California Condor, 1972-1975: American Birds, v. 30, p. 789790.

Wilbur, S.R., 1978, Supplemental feeding of California Condors, in Temple, S.A., ed., Endangered birds: management techniques for preserving threatened species: University of Wisconsin Press, Madison, WI, p. 135-140.

Wilcoxon, F., 1945, Individual comparisons by ranking methods: Biometrics Bulletin, v. 1, p. $80-83$.

Worton, B.J., 1987, A review of models of home range for animal movements: Ecological Modeling, v. 38, p. 277-298.

Worton, B.J., 1989, Kernel method for estimating the utilization distribution in home-range studies: Ecology. v. 70, p. 164-168. 


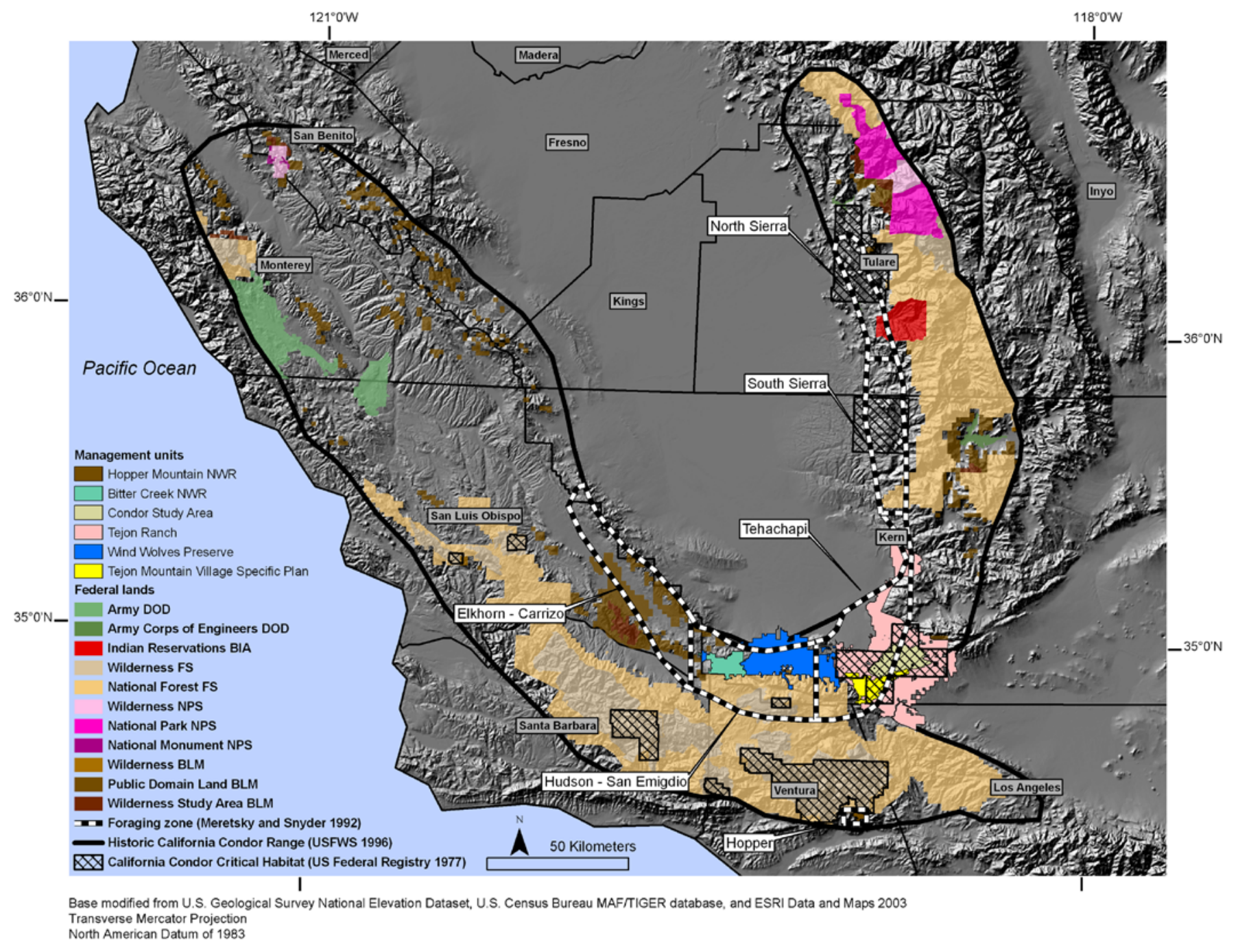

Figure 1. Map showing historical range of the California Condor (Recovery Plan for the California Condor, U.S. Fish and Wildlife Service 1996), management units, foraging zones, and Federal lands within the range, and designated Critical Habitat for the species (U.S. Fish and Wildlife Service, 1976). 


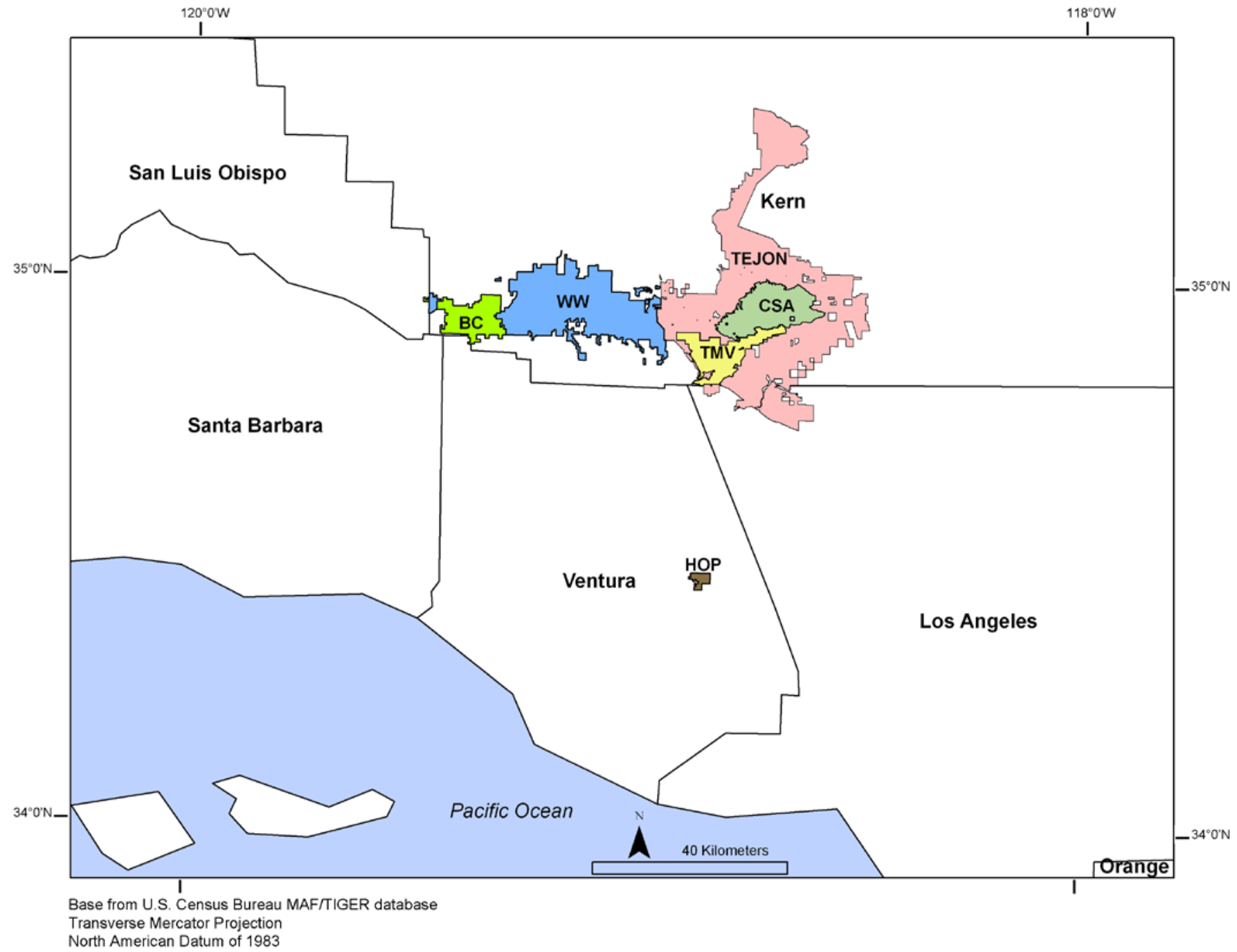

Figure 2. Map showing Geographic Information System data for six management units in southern California.

\section{Abbreviations for management units:}

BC Bitter Creek National Wildlife Refuge

CSA California Condor Study Area

HOP Hopper Mountain National Wildlife Refuge

TEJON Tejon Ranch excluding the TMV and the CSA

TMV Tejon Mountain Village Specific Plan

WW Wildlands Conservancy-Wind Wolves Preserve 
- location data

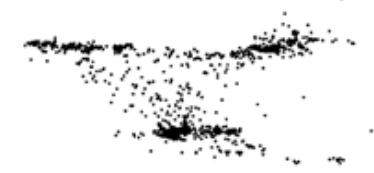

Fixed-kernel home range
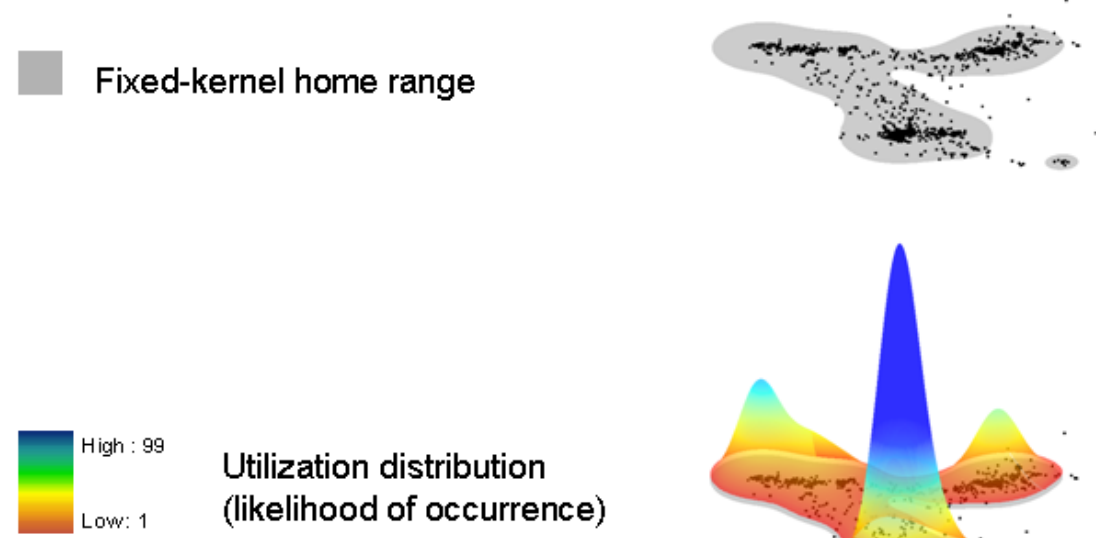

Utilization distribution (likelihood of occurrence)
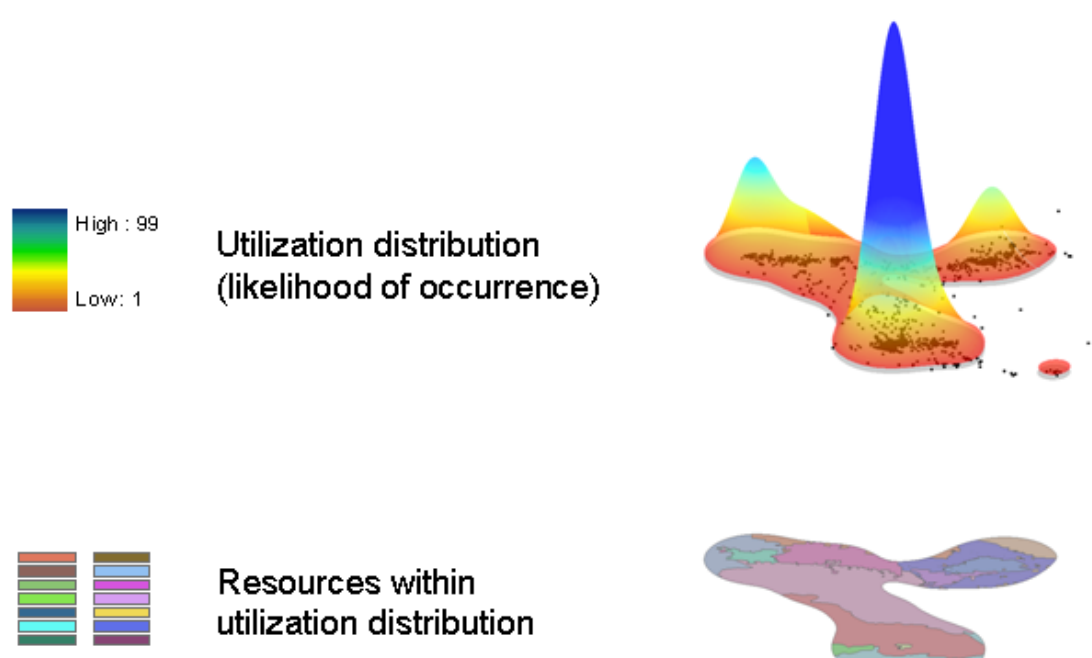

Resources within utilization distribution

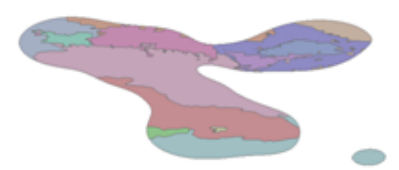

Relate utilization distribution to resources

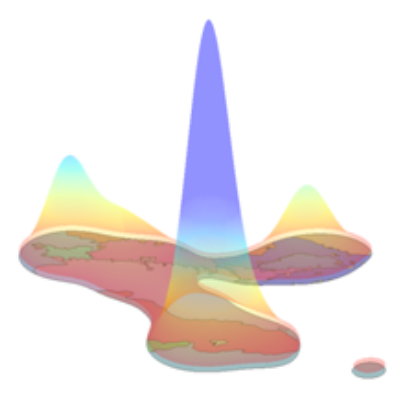

Figure 3. Illustrative example of methods used to quantify California Condor space use within the southern California population. First, the fixed-kernel home range and utilization distribution (UD) for each condor were estimated using Global Positioning System (GPS) location data. Greater heights of the UD indicate greater condor use, as inferred from regions of concentrated GPS locations. Then, resource attributes are measured within the area covered by the UD. Lastly, the height of the UD (a measure of relative use) is then related to resource attributes within each condor's home range. 


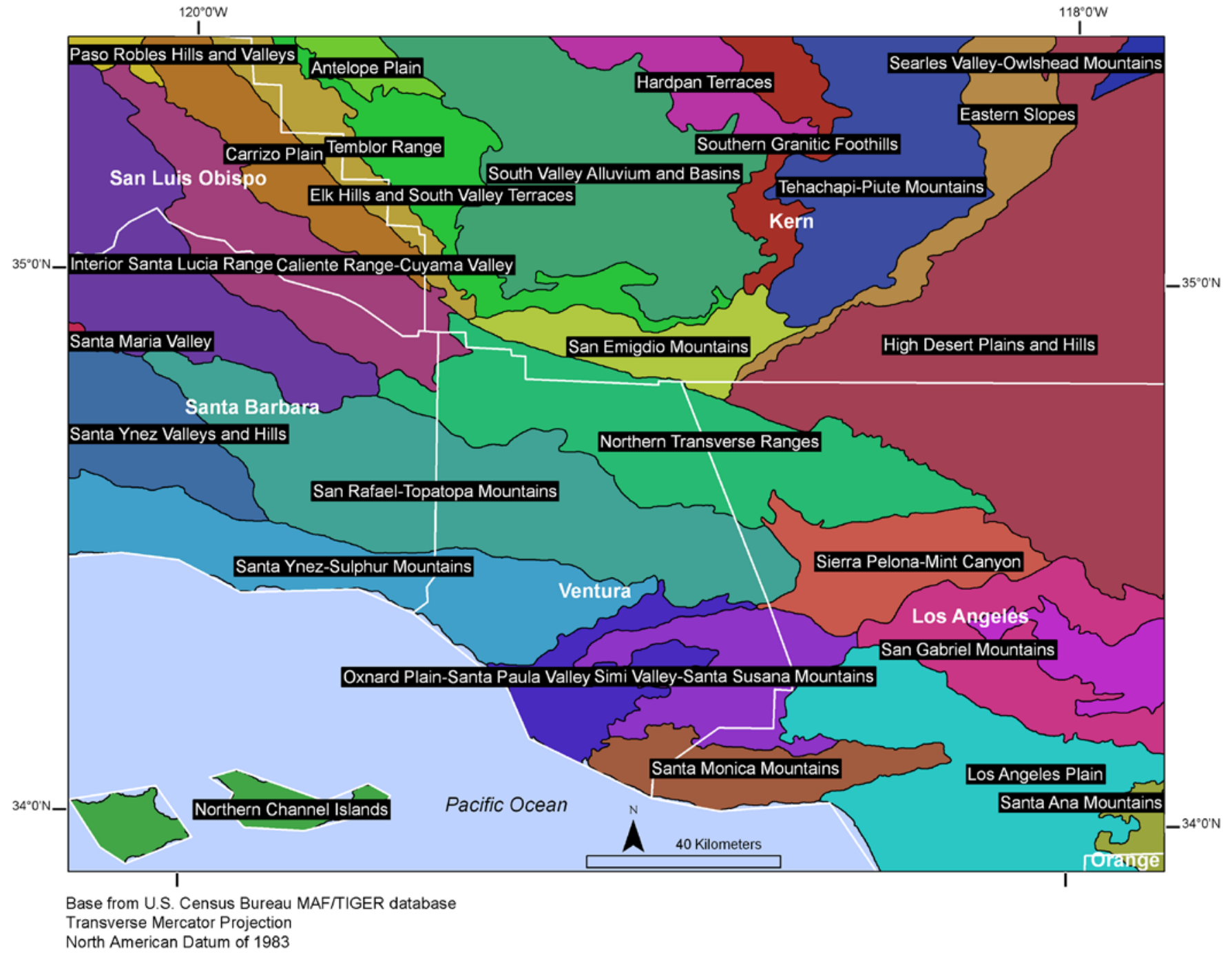

Figure 4. Map showing ecological subregion $(n=42)$ Geographic Information System data used to derive ecologically relevant areas of interest for spatial analyses of California Condors in the southern California population (USDA Forest Service, EcoregionsCalifornia07_3, Cleland and others, 2007). 


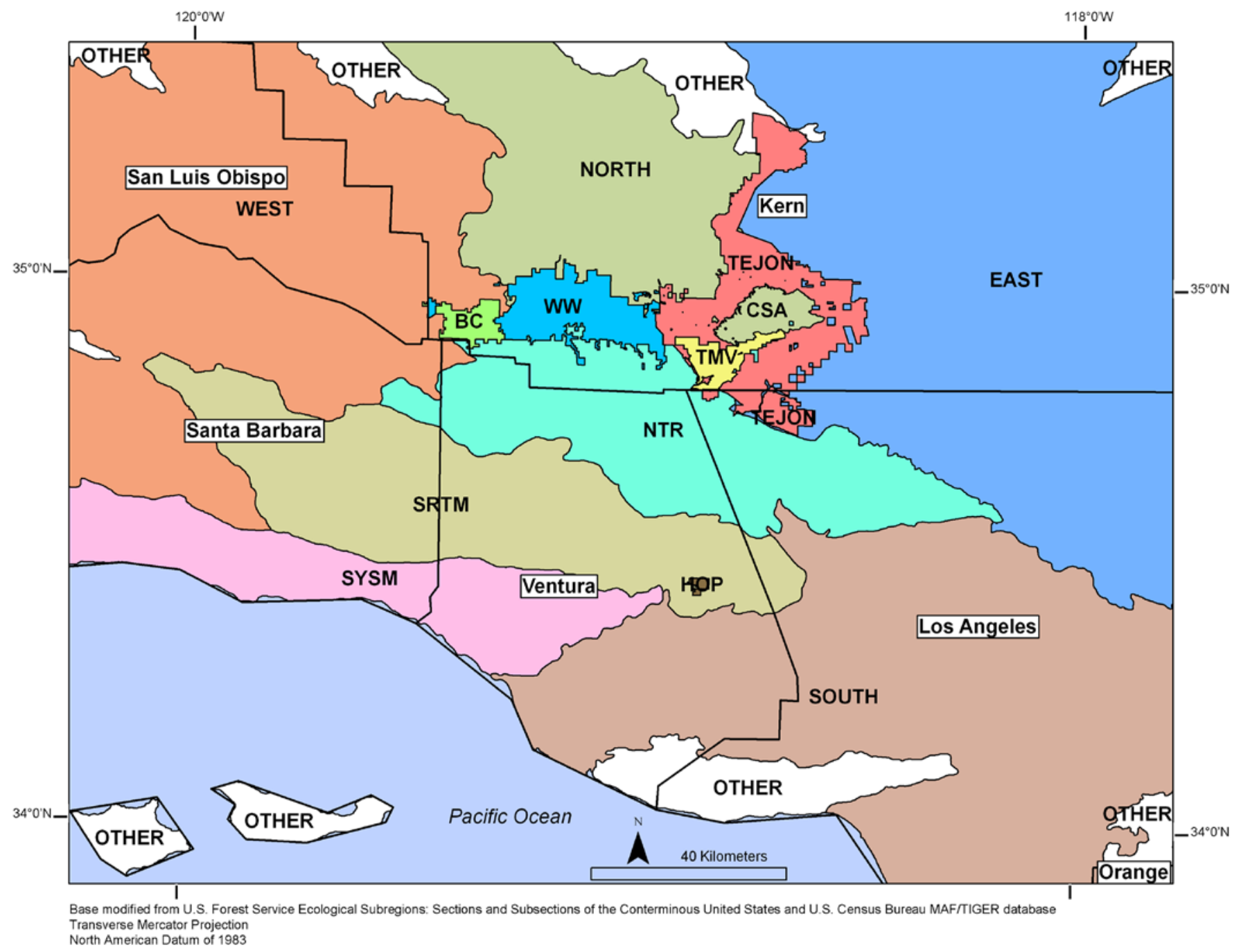

Figure 5. Map showing final Geographic Information System data layer depicting the six management units and seven ecoregions used in the spatial analyses of California Condors in the southern California population.

\begin{tabular}{ll} 
& \multicolumn{1}{c}{ Abbreviations for man } \\
BC & Bitter Creek National Wildlife Refuge \\
CSA & California Condor Study Area \\
HOP & Hopper Mountain National Wildlife Refuge \\
TEJON & Tejon Ranch excluding the TMV and the CSA \\
TMV & Tejon Mountain Village Specific Plan \\
WW & Wildlands Conservancy-Wind Wolves Preserve
\end{tabular}

Abbreviations for ecoregions:

EAST Southern Granitic Foothills, Tehachapi Piute Mountains, Eastern Slopes, High Desert Plains and Hills, eastern portions of San Emigdio Mountains

NORTH South Valley Alluvium and Basins, eastern portions of Elk Hills and South Valley Terraces;

NTR Northern Transverse Ranges \& western portions of San Emigdio Mountains

SOUTH Oxnard Plain Santa Paula Valley, Simi Valley Santa Susana Mountains, Los Angeles Plain, San Gabriel Mountains, Upper San Gabriel Mountains, Sierra Pelona Mint Canyon

SRTM San Rafael Topatopa Mountains

SYSM Santa Ynez Sulphur Mountains

WEST Interior Santa Lucia Range, Caliente Range, Cuyama Valley, Carrizo Plain, Temblor Range, Santa Ynez Valleys and Hills, western portions of Elk Hills and South Valley Terraces 


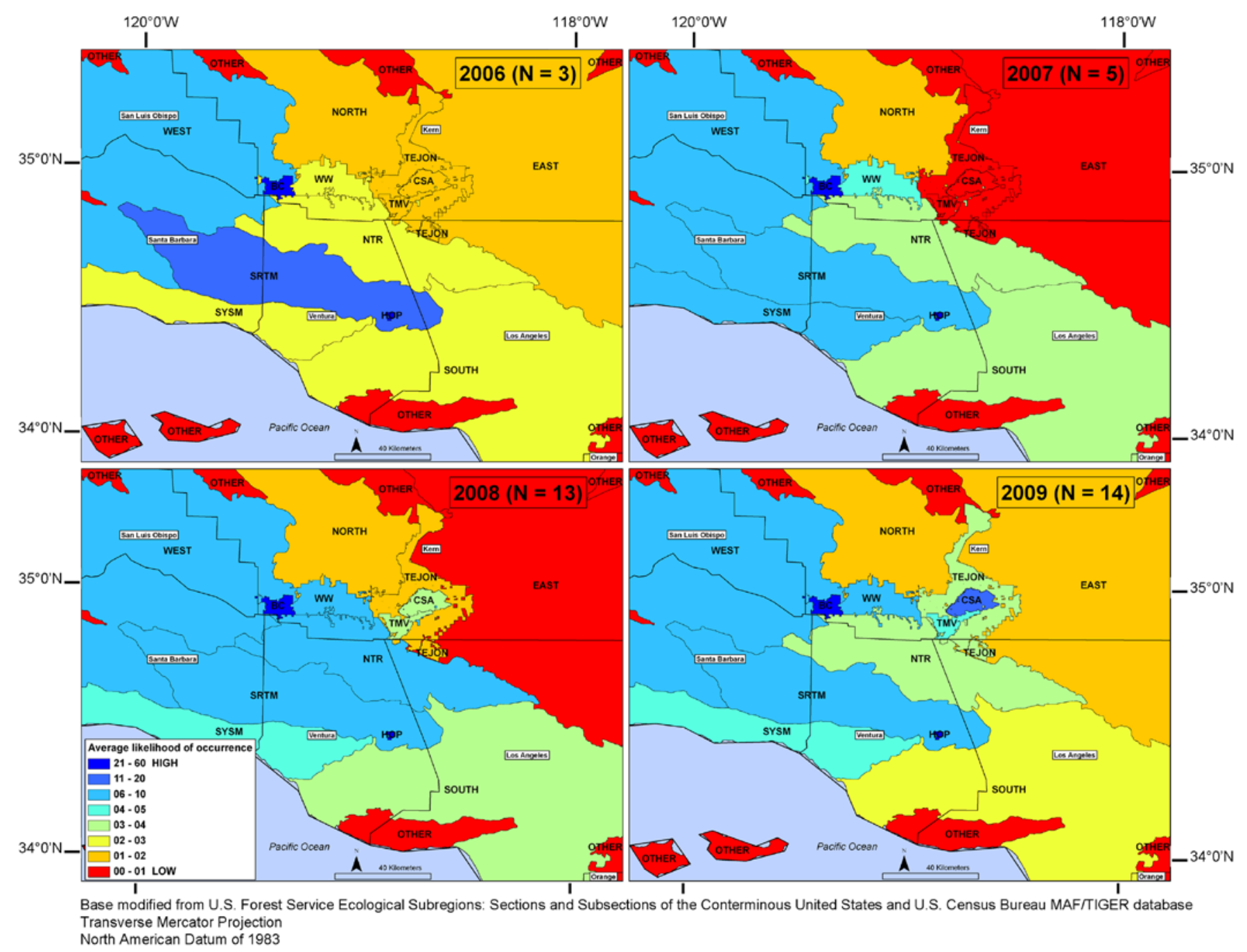

Figure 6. Maps showing average relative concentration of use of six management units and seven ecoregions within the annual (2006-09) home range of California Condors in the southern California population. Relative concentration of use is the ratio of a condors' total likelihood of occurrence in a specific management unit or ecoregion (volume of utilization distribution associated with the management unit or ecoregion) divided by total occurrence (availability) of that management unit or ecoregion in the home range. See figure 5 for definitions of abbreviations for management units and ecoregions. 

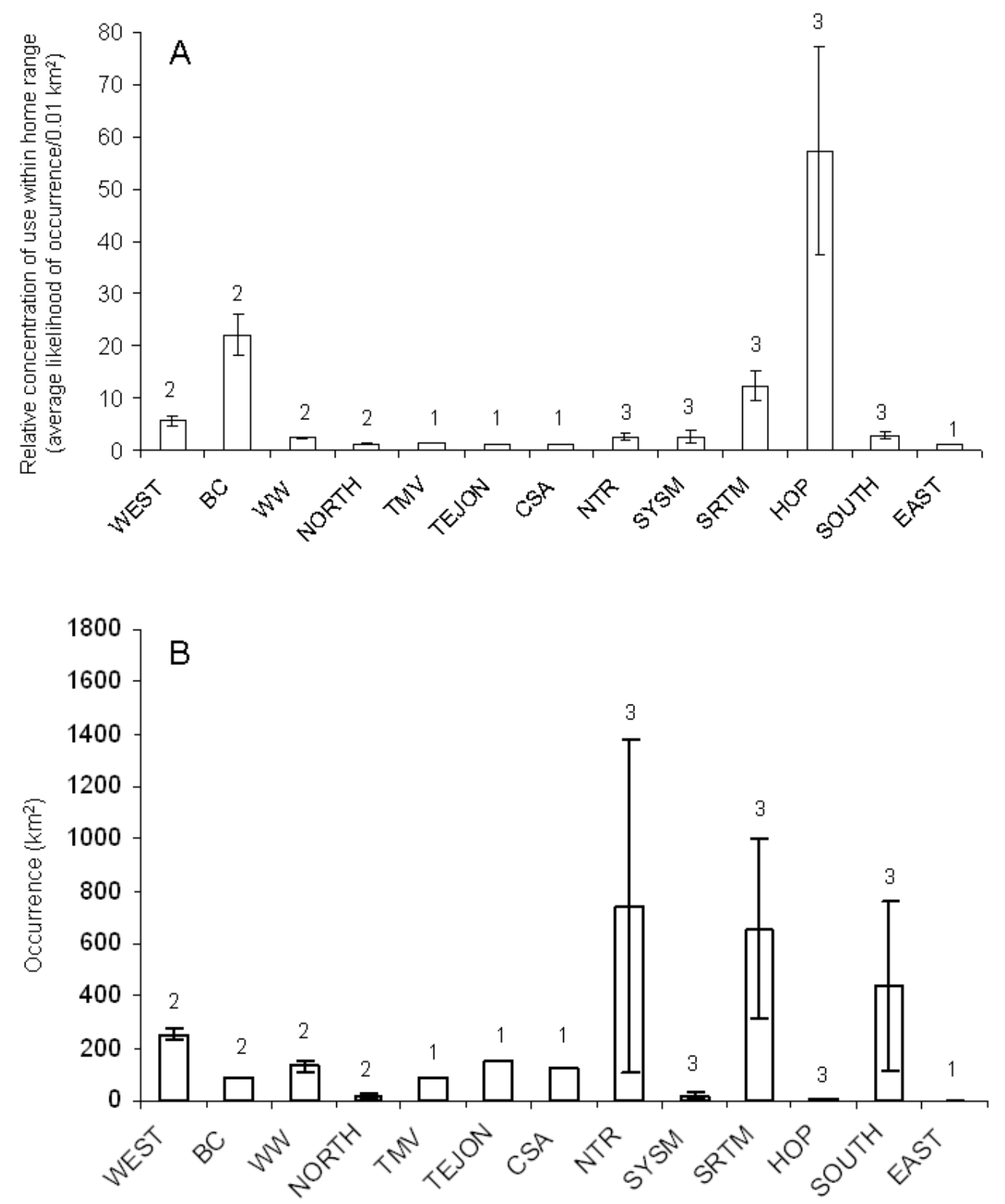

Figure 7. Bar graphs showing relative concentration of use of six management units and seven ecoregions within the annual home range of California Condors in the southern California population (panel A, 2006, $n$ $=3$ ). Concentration of use is the ratio of a condors' total likelihood of occurrence in a specific management unit or ecoregion (volume of utilization distribution associated with the management unit or ecoregion) divided by total occurrence (availability) of that management unit or ecoregion in the home range. As resource availability influences this measure of selection (relative concentration of use), we also present mean occurrence of each management unit and ecoregion within the home range (panel B). Numbers above bars indicate sample size and error bars provide standard deviation. See figure 5 for definitions of abbreviations for management units and ecoregions. 

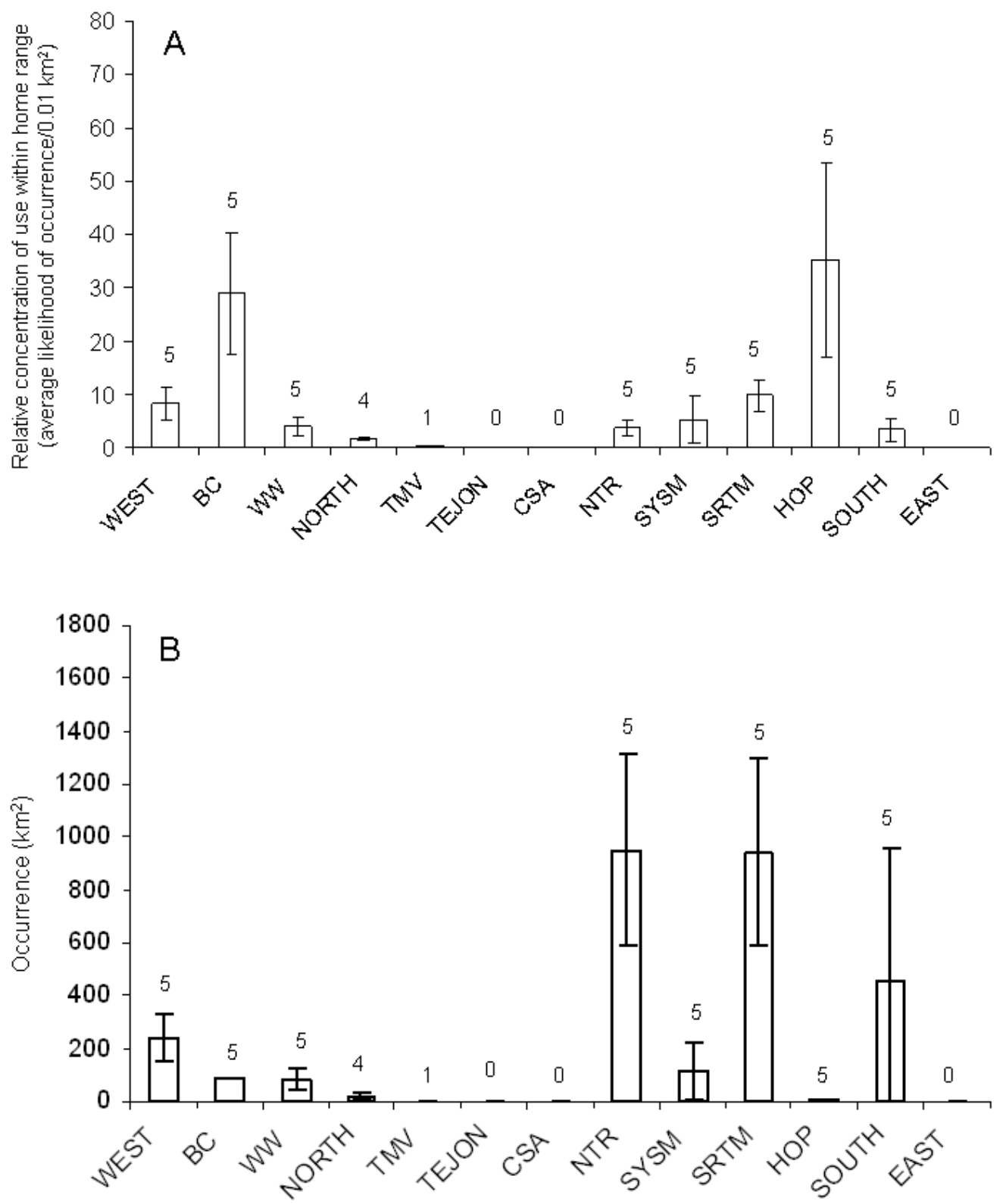

Figure 8. Bar graphs showing relative concentration of use of six management units and seven ecoregions within the annual home range of California Condors in the southern California population (panel A, 2007, $n$ $=5$ ). Concentration of use is the ratio of a condors' total likelihood of occurrence in a specific management unit or ecoregion (volume of utilization distribution associated with the management unit or ecoregion) divided by total occurrence (availability) of that management unit or ecoregion in the home range. As resource availability influences this measure of selection (relative concentration of use), we also present mean occurrence of each management unit and ecoregion within the home range (panel B). Numbers above bars indicate sample size and error bars provide standard deviation. See figure 5 for definitions of abbreviations for management units and ecoregions. 

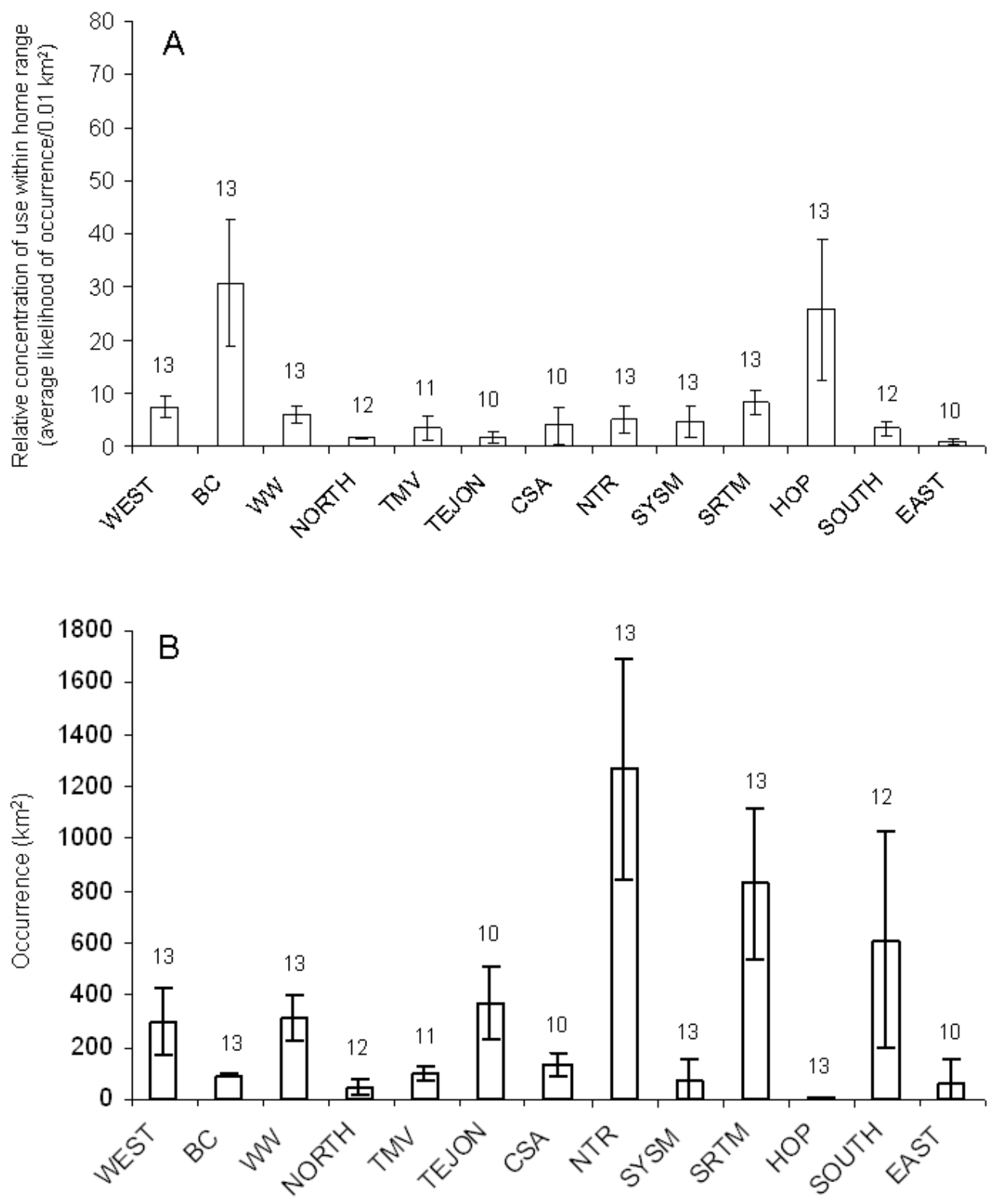

Figure 9. Bar graphs showing relative concentration of use of six management units and seven ecoregions within the annual home range of California Condors in the southern California population (panel A, 2008, $n$ $=13$ ). Concentration of use is the ratio of a condors' total likelihood of occurrence in a specific management unit or ecoregion (volume of utilization distribution associated with the management unit or ecoregion) divided by total occurrence (availability) of that management unit or ecoregion in the home range. As resource availability influences this measure of selection (relative concentration of use), we also present mean occurrence of each management unit and ecoregion within the home range (panel B). Numbers above bars indicate sample size and error bars provide standard deviation. See figure 5 for definitions of abbreviations for management units and ecoregions. 

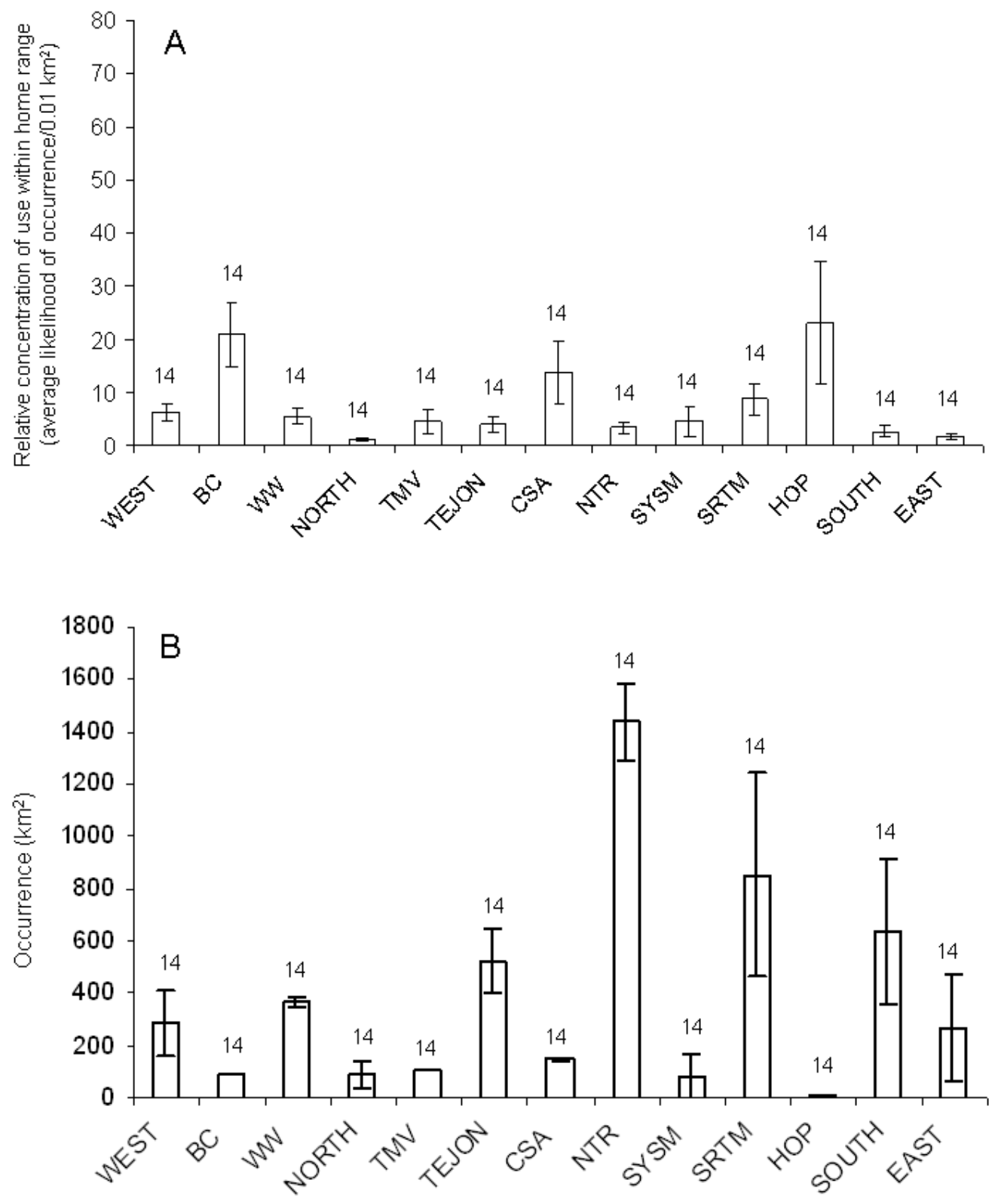

Figure 10. Bar graphs showing relative concentration of use of six management units and seven ecoregions within the annual home range of California Condors in the southern California population (panel A, 2009, $n=14$ ). Concentration of use is the ratio of a condors' total likelihood of occurrence in a specific management unit or ecoregion (volume of utilization distribution associated with the management unit or ecoregion) divided by total occurrence (availability) of that management unit or ecoregion in the home range. As resource availability influences this measure of selection (relative concentration of use), we also present mean occurrence of each management unit and ecoregion within the home range (panel B). Numbers above bars indicate sample size and error bars provide standard deviation. See figure 5 for definitions of abbreviations for management units and ecoregions. 


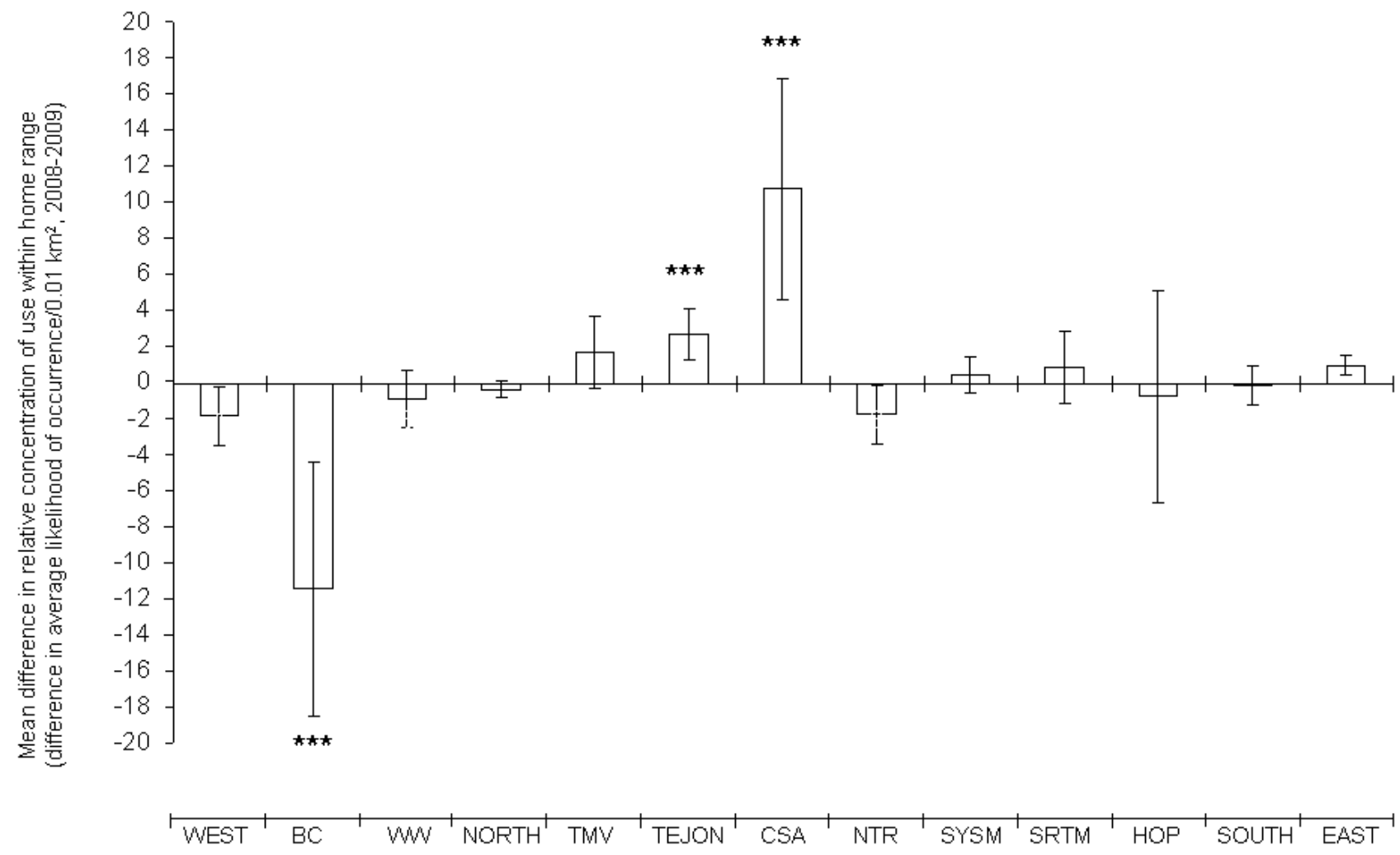

Figure 11. Bar graph showing mean difference in relative concentration of use of six management units and seven ecoregions within the annual home range of California Condors in the southern California population ( $\mathrm{n}=7$ individuals; ${ }^{* * *}$ indicates significant Wilcoxon signed rank test, $p=0.02$ ). Concentration of use is the ratio of a condors' total likelihood of occurrence in a specific management unit or ecoregion (volume of utilization distribution associated with the management unit or ecoregion) divided by total occurrence (availability) of that management unit or ecoregion in the home range. Error bars provide standard deviation. See figure 5 for definitions of abbreviations for management units and ecoregions. 
Table 1. Global Positioning System (GPS) location data for 21 California Condors in southern California.

[Studbook No. = individual bird ID. The number of GPS locations collected annually for each condor is provided in yearly columns (2004-09) and the length of time (months) each condor carried a GPS transmitter is given in parentheses. Data from breeding condors are in bold]

\begin{tabular}{|c|c|c|c|c|c|c|c|c|}
\hline \multirow{2}{*}{$\begin{array}{c}\text { Studbook } \\
\text { No. }\end{array}$} & \multirow[b]{2}{*}{ Sex } & \multirow{2}{*}{$\begin{array}{c}\text { Hatch } \\
\text { year }\end{array}$} & \multicolumn{6}{|c|}{ Year } \\
\hline & & & 2004 & 2005 & 2006 & 2007 & 2008 & 2009 \\
\hline 021 & Male & 1980 & & & $1,780(12)$ & & & $2527(10.5)$ \\
\hline 079 & Female & 1992 & & & & $2,657(6)$ & $3,123(10)$ & $3,963(12)$ \\
\hline 107 & Male & 1994 & & & & $3,499(10)$ & $3,706(12)$ & $3,729(12)$ \\
\hline 112 & Female & 1994 & & & $1,155(6)$ & & & \\
\hline 156 & Female & 1997 & & & & & $3,996(12)$ & \\
\hline 161 & Female & 1997 & $1,522(6)$ & $640(9)$ & & & 3,331 (10) & $3,696(12)$ \\
\hline 180 & Female & 1998 & & & & & & $4,544(12)$ \\
\hline 192 & Female & 1998 & $1,807(6)$ & 3,109 (12) & 4,869 (12) & $3,096(10)$ & $4,156(11)$ & $3,843(12)$ \\
\hline 213 & Male & 2000 & & & & $3,607(10)$ & $4,137(12)$ & \\
\hline 214 & Female & 2000 & & & & & $3,080(10)$ & \\
\hline 237 & Male & 2001 & & & & & 3,029 (10) & $4,033(12)$ \\
\hline 247 & Male & 2001 & & & & & 3,581 (11) & 4,331 (12) \\
\hline 255 & Female & 2001 & & & & & & $2,253(9)$ \\
\hline 262 & Male & 2001 & & & & & & $3,224(8.5)$ \\
\hline 289 & Female & 2002 & & & & & $3,147(9.5)$ & \\
\hline 326 & Male & 2004 & & & & & & $3,857(10)$ \\
\hline 328 & Male & 2004 & & & & & $4,767(11)$ & \\
\hline 369 & Male & 2005 & & & & & & $4,481(12)$ \\
\hline 412 & Male & 2006 & & & & $2,174(7)$ & $4,179(10.5)$ & \\
\hline 428 & Female & 2007 & & & & & $2,748(7)$ & $4,545(12)$ \\
\hline 462 & Male & 2008 & & & & & & $2,010(6)$ \\
\hline \multicolumn{2}{|c|}{ Total females } & & 2 & 2 & 2 & 2 & 7 & 6 \\
\hline \multicolumn{2}{|c|}{ Breeding females } & & 2 & 1 & 2 & 1 & 4 & 4 \\
\hline \multicolumn{2}{|c|}{ Total males } & & 0 & 0 & 1 & 3 & 6 & 8 \\
\hline \multicolumn{2}{|c|}{ Breeding males } & & 0 & 0 & 1 & 1 & 3 & 3 \\
\hline Total con & lors & & 2 & 2 & 3 & 5 & 13 & 14 \\
\hline
\end{tabular}


This page left intentionally blank 


\title{
Appendix A.-Analysis of California Condor (Gymnogyps californianus) Use of Six Management Units Using Location Data from Global Positioning System Transmitters, Southern California, 2004-09-Initial Report
}

\author{
Utilization distribution estimates $(n=39)$ for 21 California Condors from the southern \\ California population (2004-09). Individual condor identifications and year are indicated on each \\ map in the upper right corner in white lettering. California Condor Global Positioning System \\ transmitter data $(127,931$ locations) were used to estimate the utilization distribution (that is, \\ probability density function) for individual California Condors within the 99-percent fixed- \\ kernel estimate of their annual home range (Worton, 1987, 1989, smoothing parameter $=h_{\text {ref, }}$ \\ grid cell size $=100 \mathrm{~m}$ ). The utilization distribution of an individual, or population of animals, \\ can be used to estimate the probability and intensity of use for specific habitats or sites within an \\ area of interest (for example, home range) as a function of relocation points (Van Winkle, 1975; \\ Marzluff and others, 2001, 2004). HRT: Home Range Tools for ArcGIS (Rodgers and others, \\ 2005) was used to estimate $h_{\text {ref }}$ (the smoothing parameter) and Hawth's Analysis Tools for \\ ArcGIS (Beyer, 2004) was used to estimate the 99-percent fixed-kernel home range and \\ utilization distribution for individual condors (ESRI, 2007).
}

\author{
Abbreviations for management units: \\ BC Bitter Creek National Wildlife Refuge \\ CSA California Condor Study Area \\ HOP Hopper Mountain National Wildlife Refuge \\ TEJON Tejon Ranch excluding the TMV and the CSA \\ TMV Tejon Mountain Village Specific Plan \\ WW Wildlands Conservancy-Wind Wolves Preserve \\ Abbreviations for ecoregions: \\ EAST Southern Granitic Foothills, Tehachapi Piute Mountains, Eastern Slopes, High Desert Plains \\ and Hills, eastern portions of San Emigdio Mountains \\ NORTH South Valley Alluvium and Basins, eastern portions of Elk Hills and South Valley Terraces; \\ NTR Northern Transverse Ranges \& western portions of San Emigdio Mountains \\ SOUTH Oxnard Plain Santa Paula Valley, Simi Valley Santa Susana Mountains, Los Angeles Plain, San \\ Gabriel Mountains, Upper San Gabriel Mountains, Sierra Pelona Mint Canyon \\ SRTM San Rafael Topatopa Mountains \\ SYSM Santa Ynez Sulphur Mountains \\ WEST Interior Santa Lucia Range, Caliente Range, Cuyama Valley, Carrizo Plain, Temblor Range, \\ Santa Ynez Valleys and Hills, western portions of Elk Hills and South Valley Terraces
}




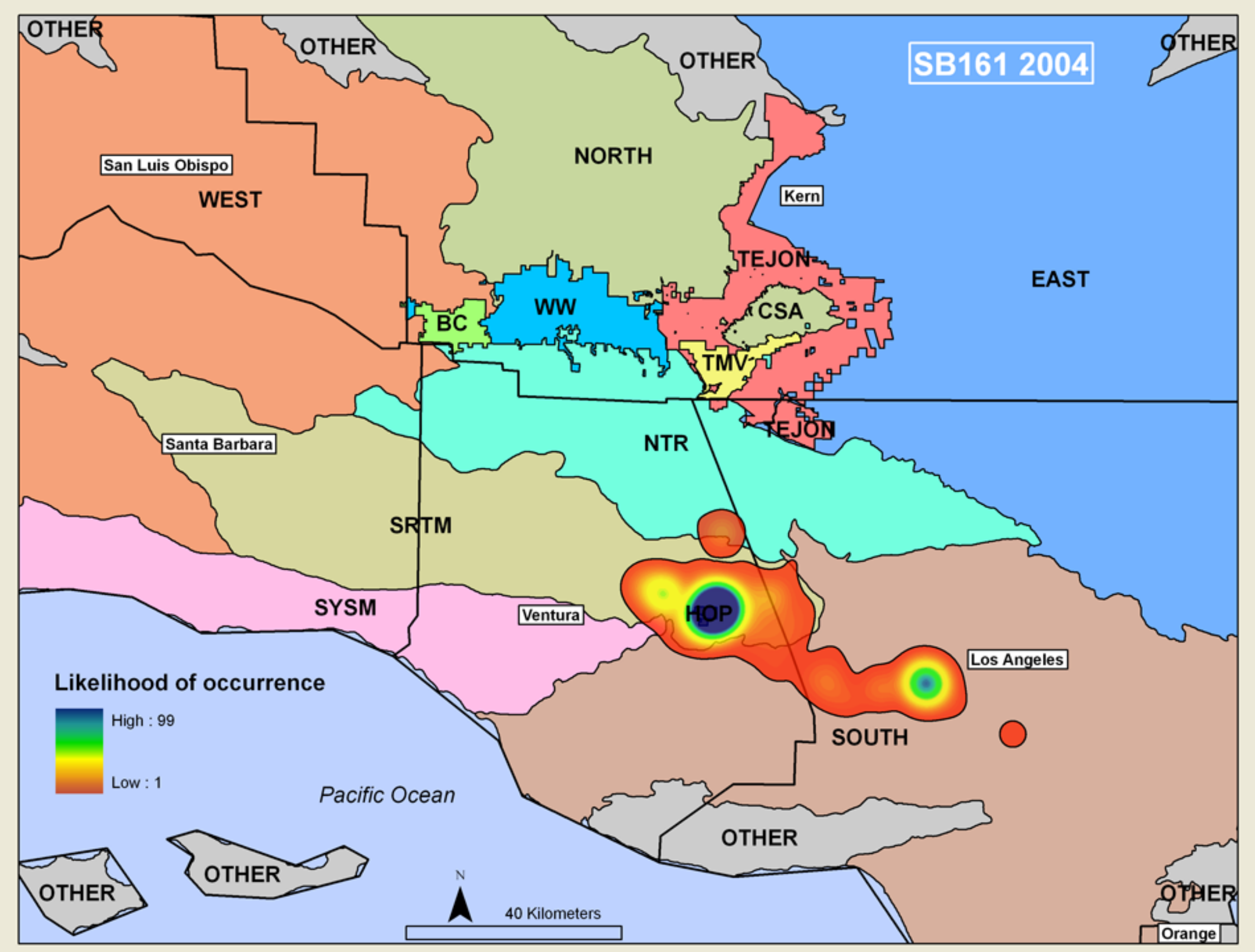




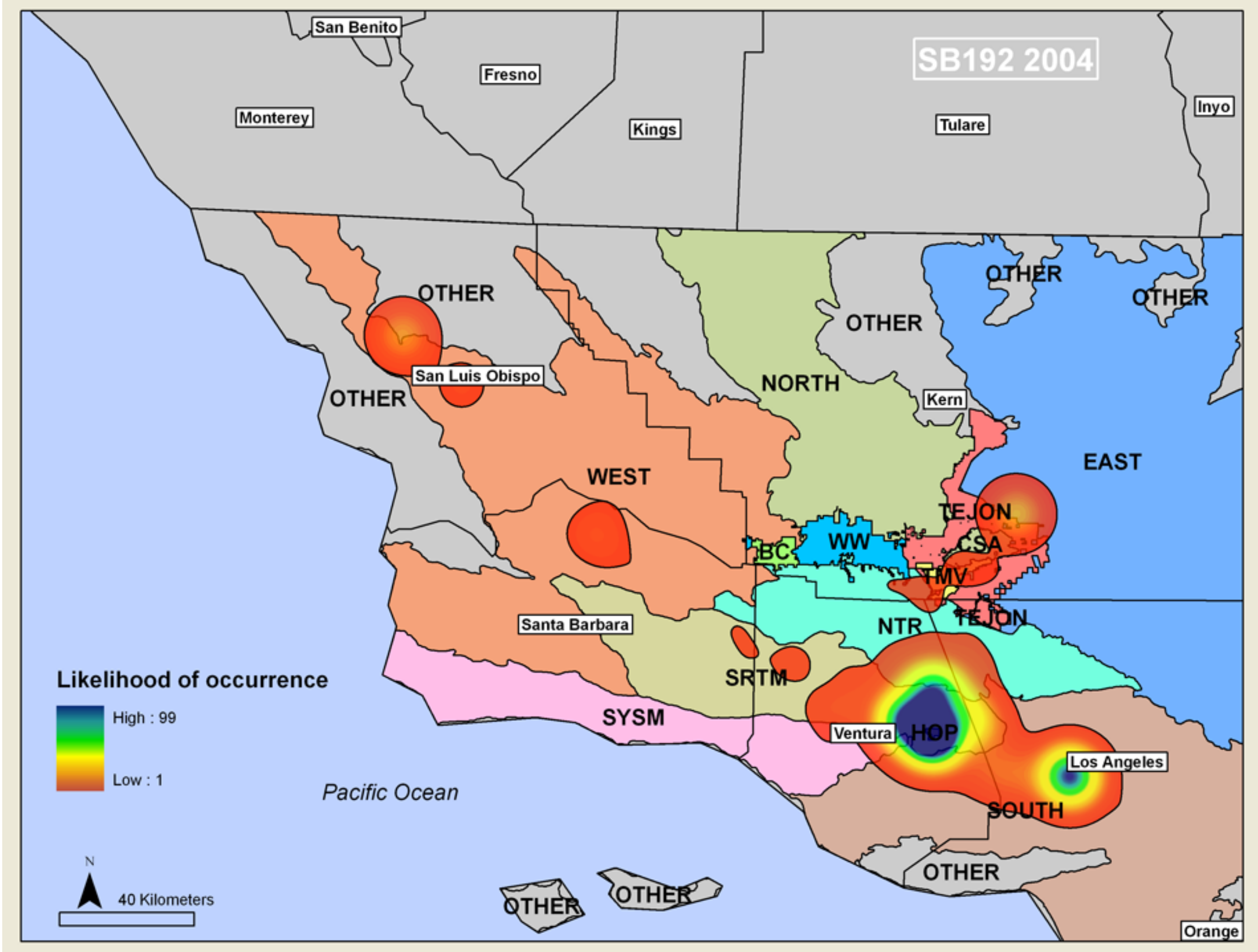




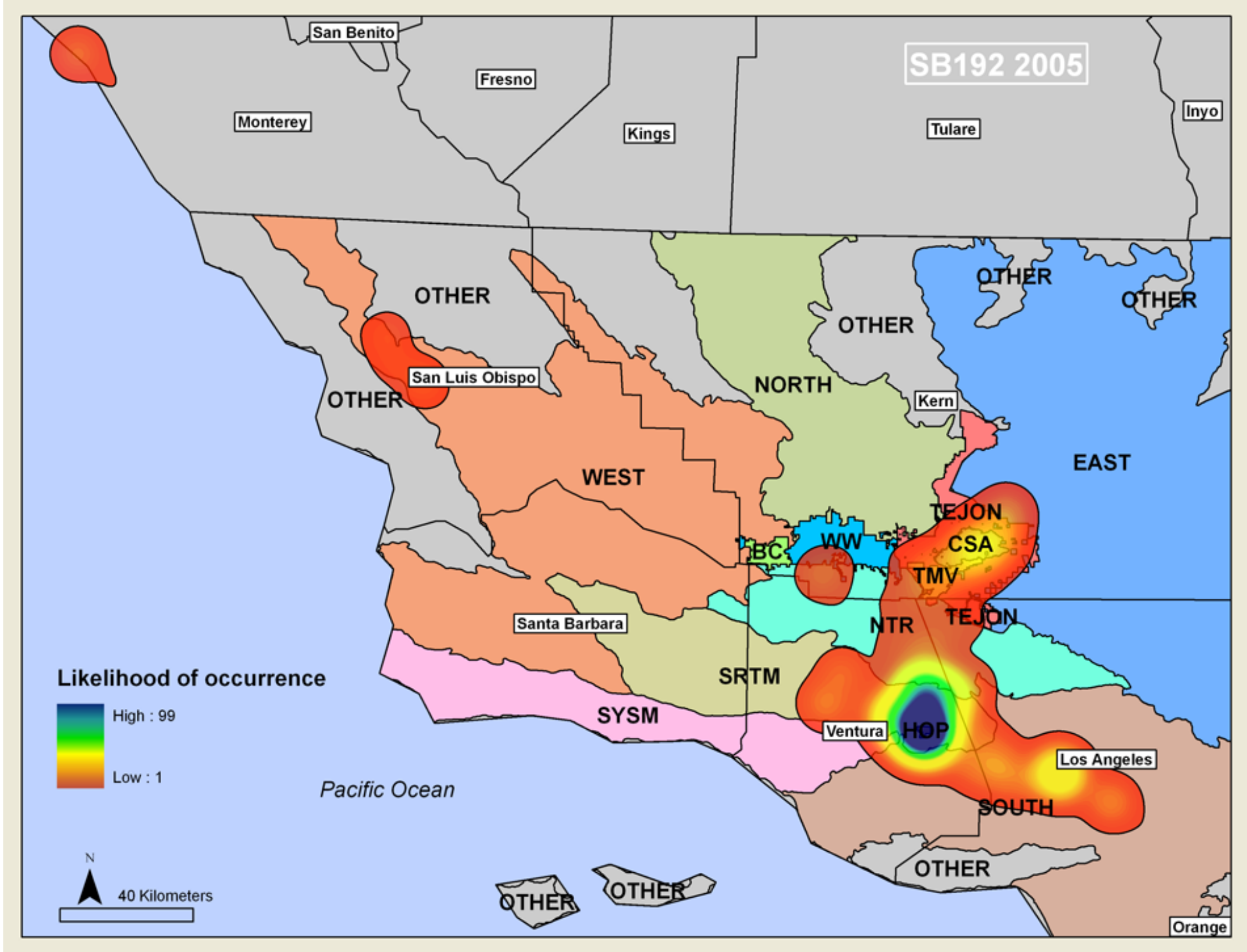




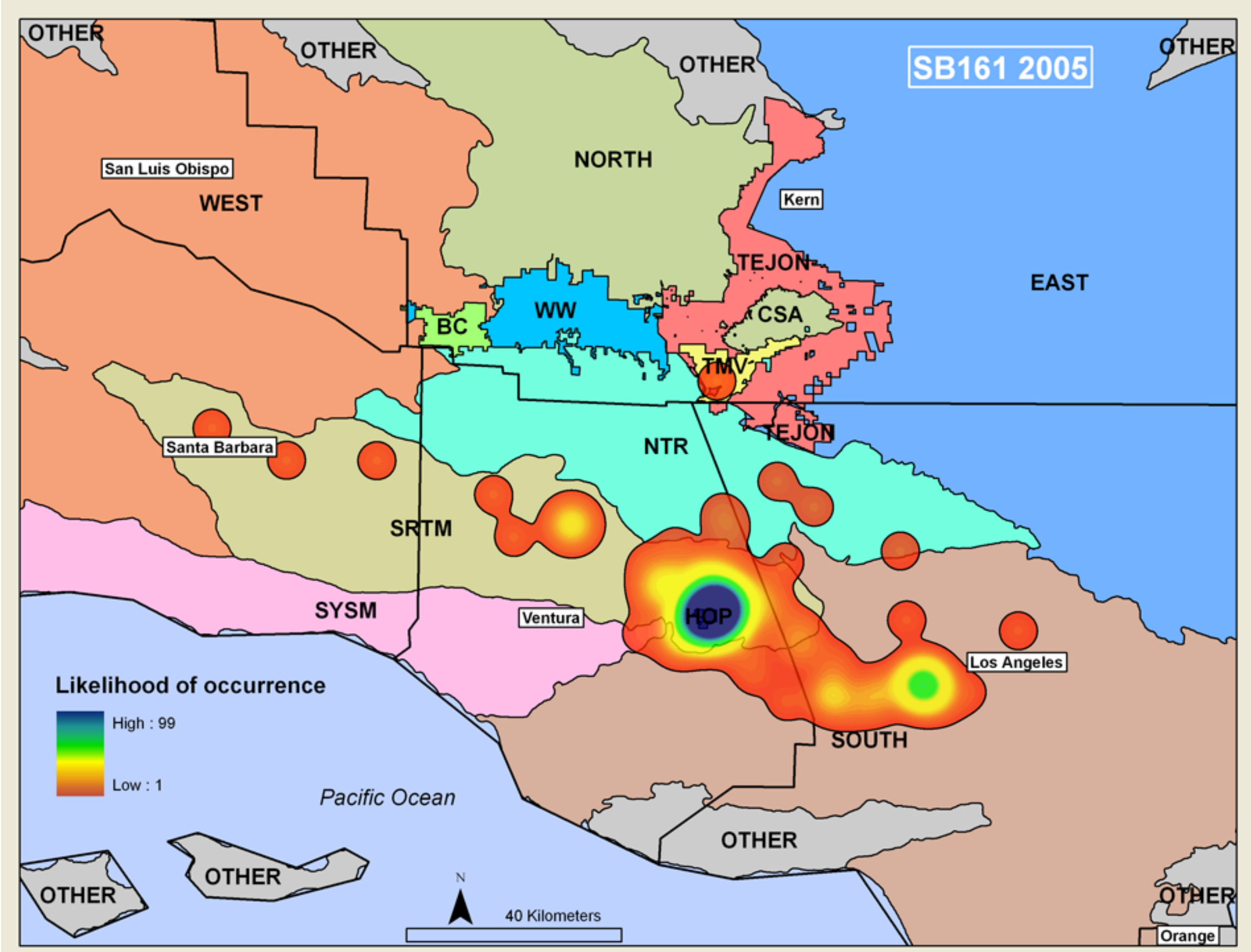




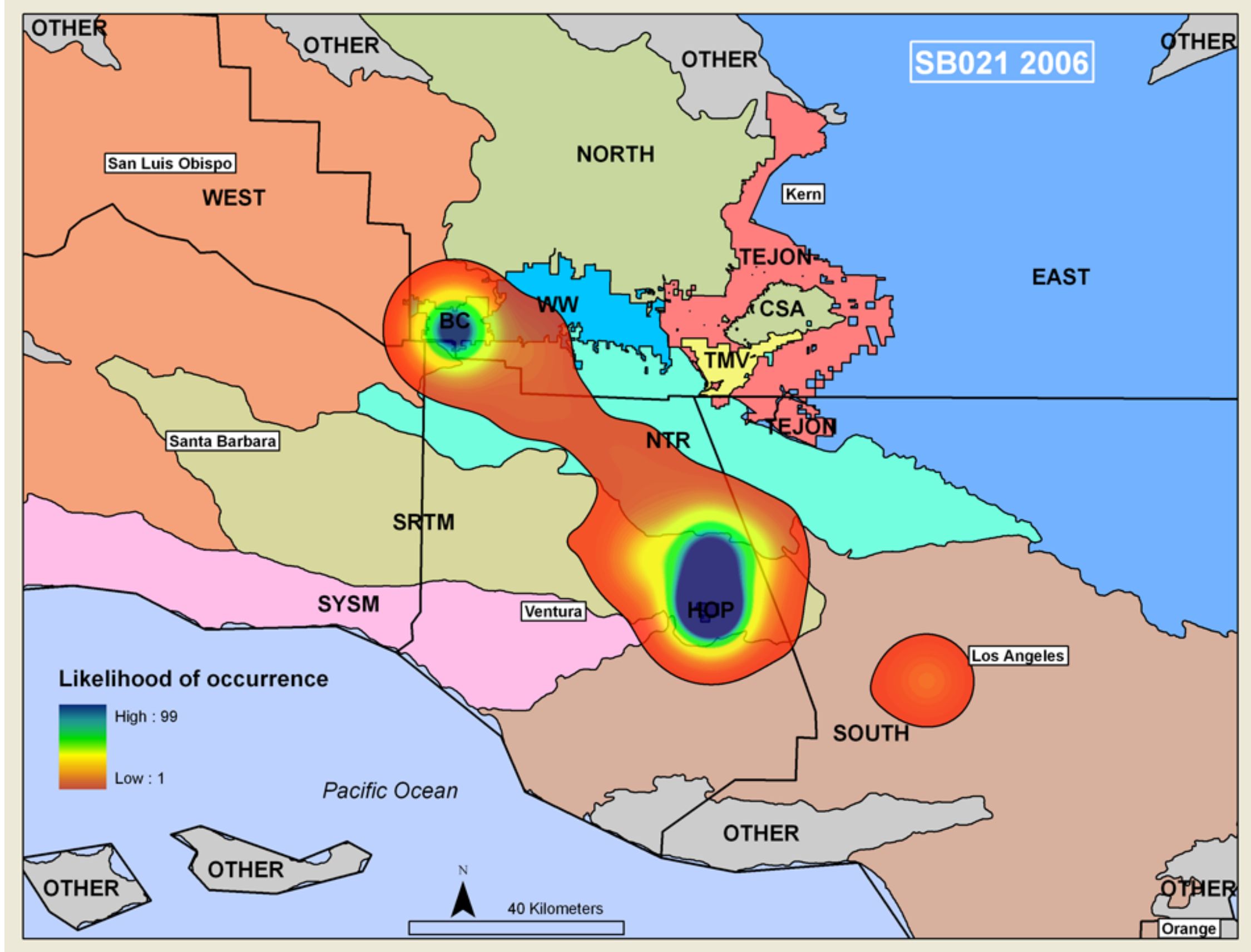




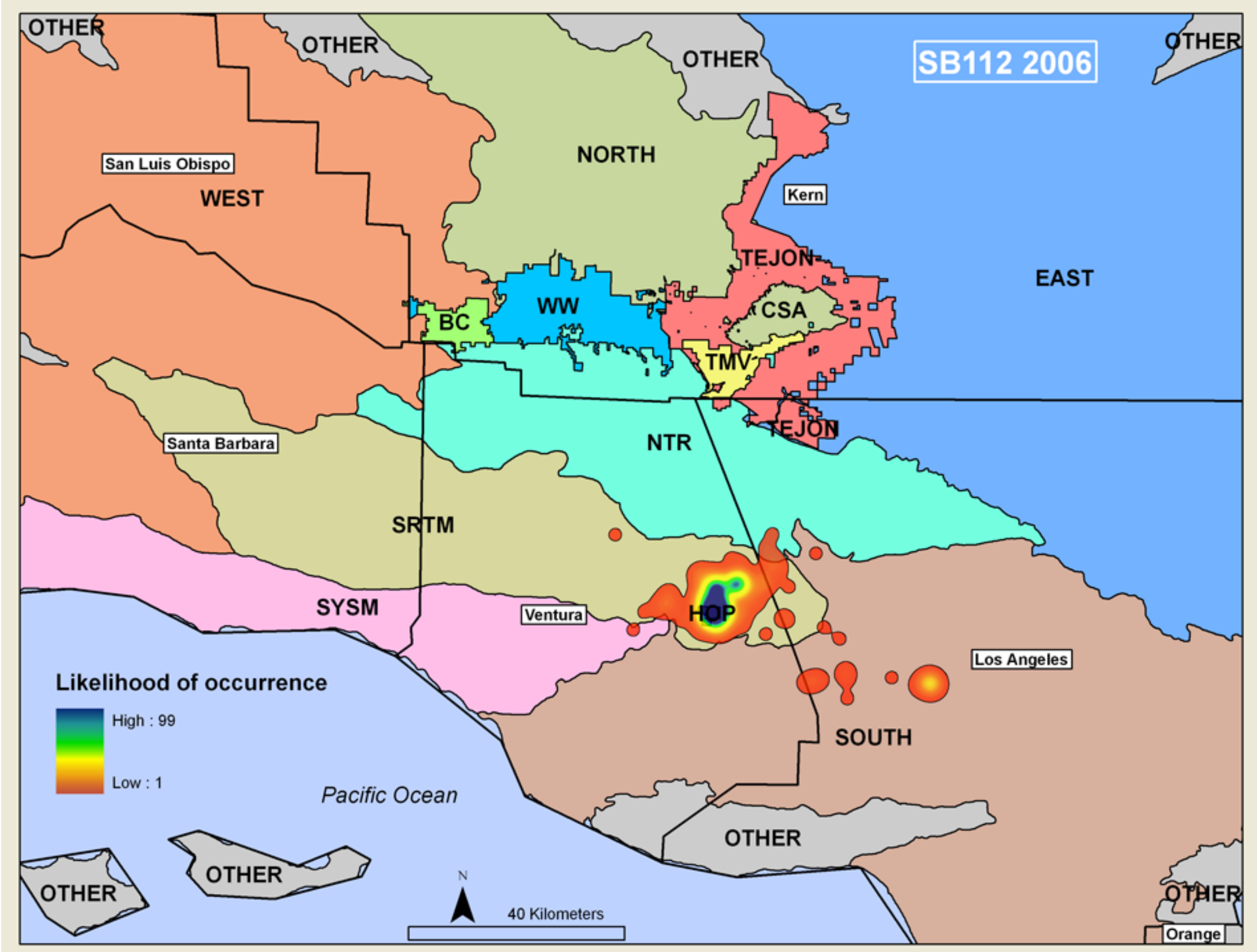




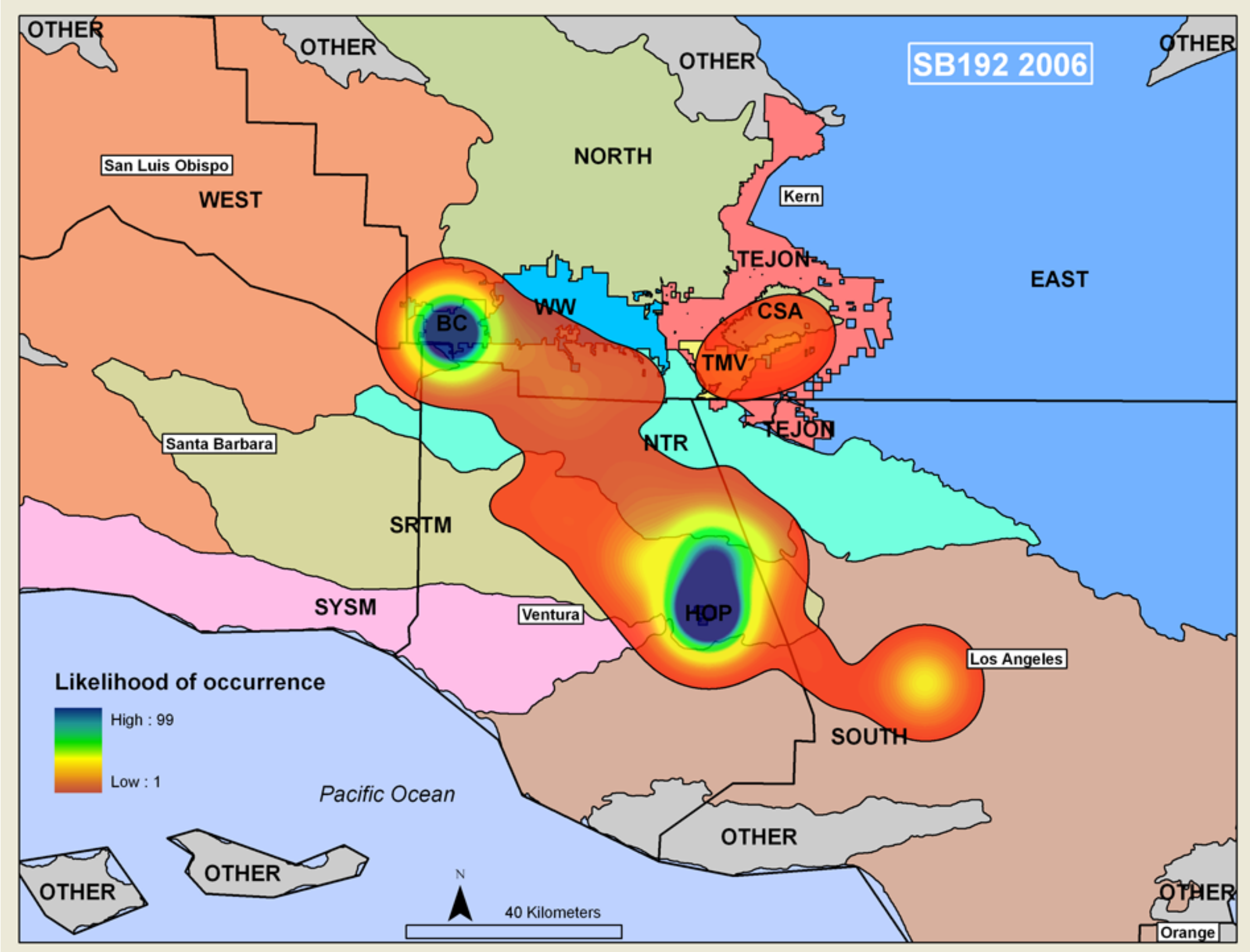




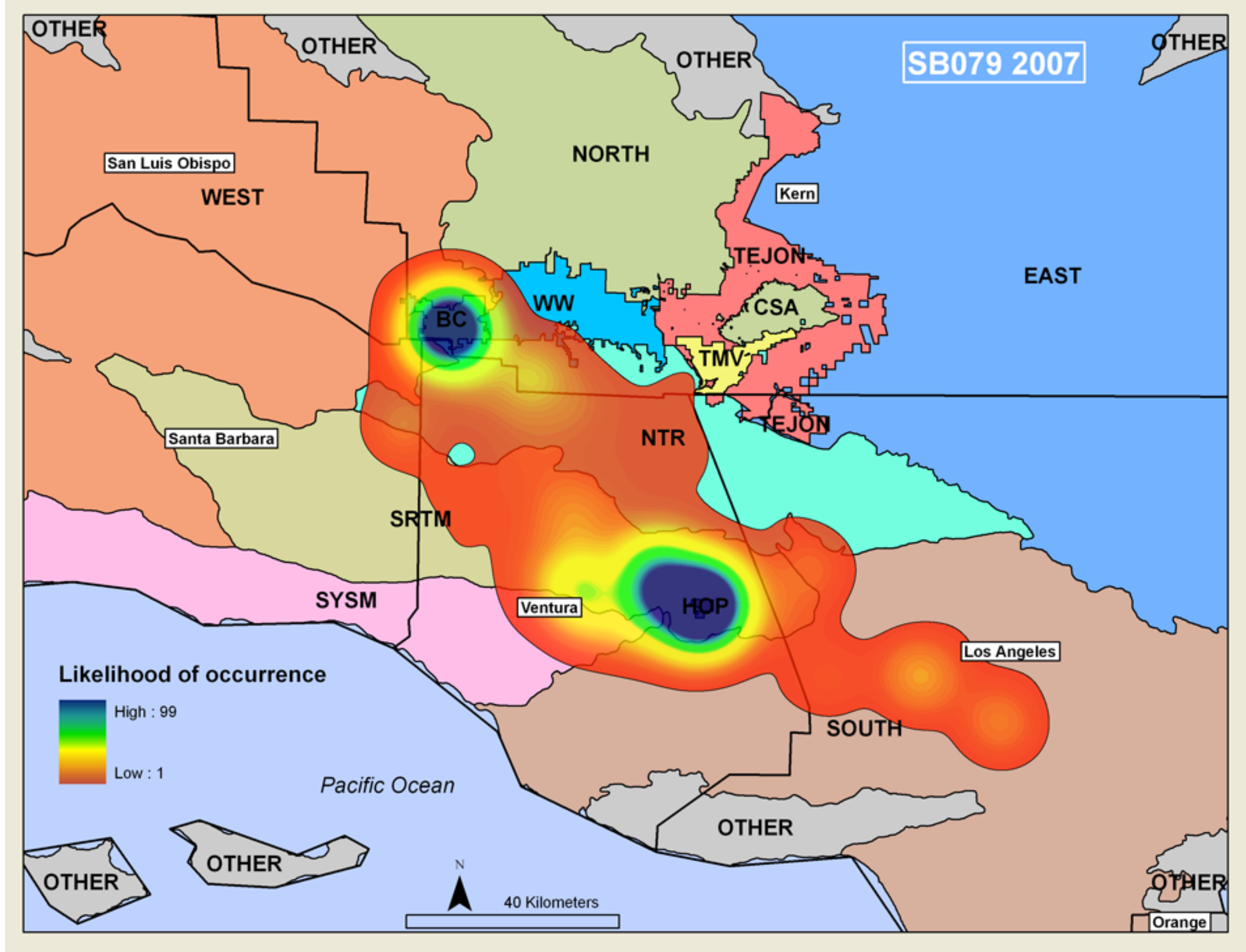




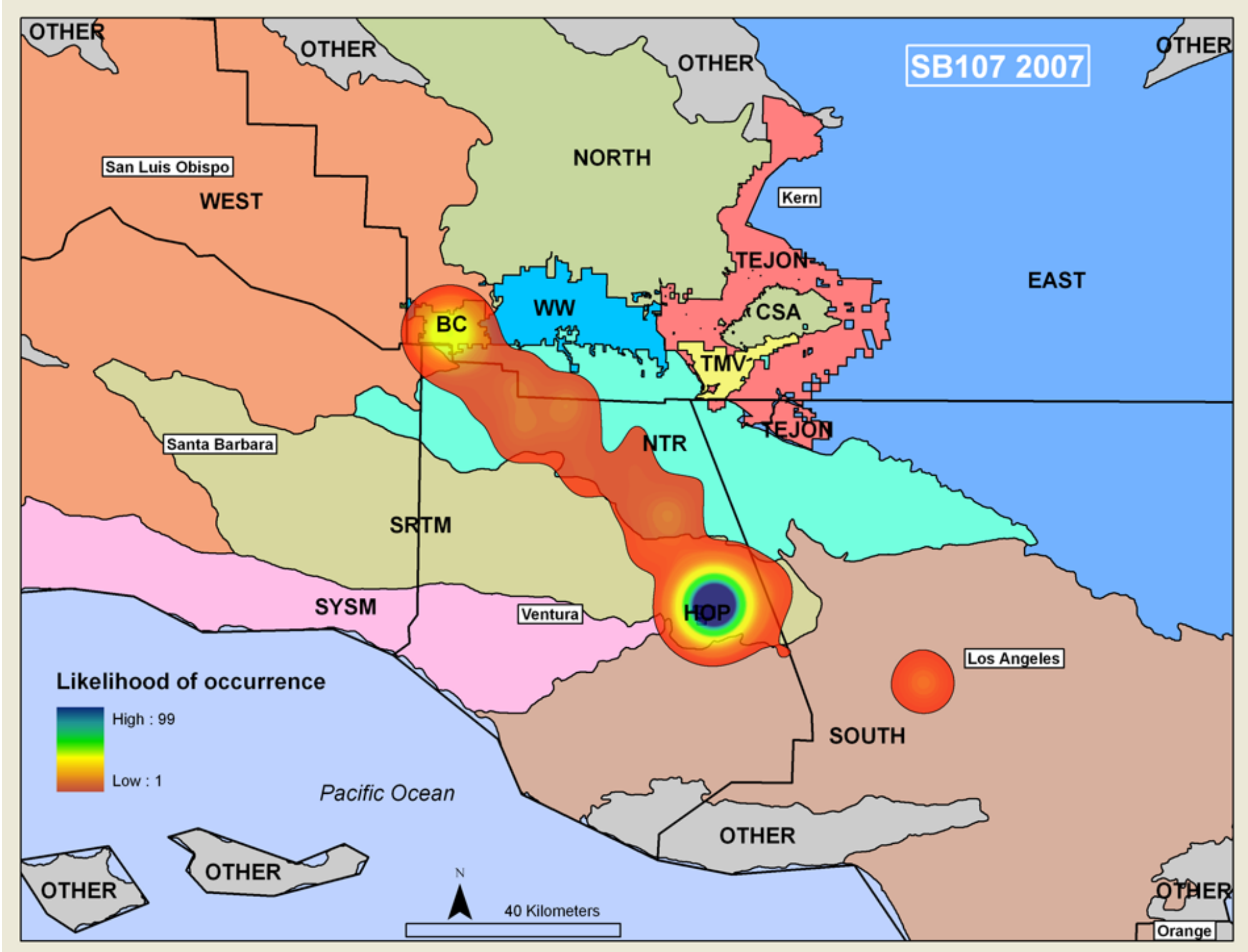




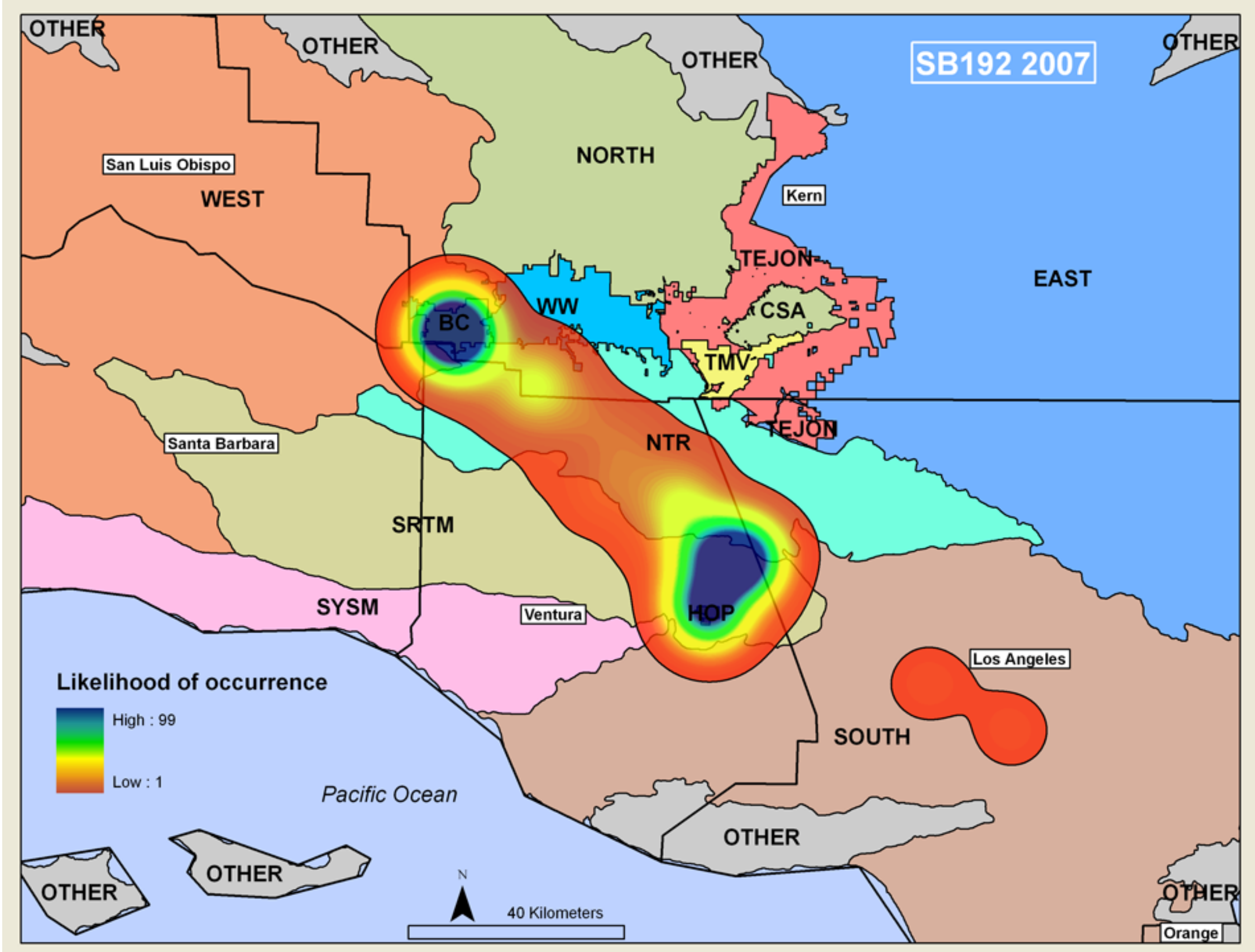




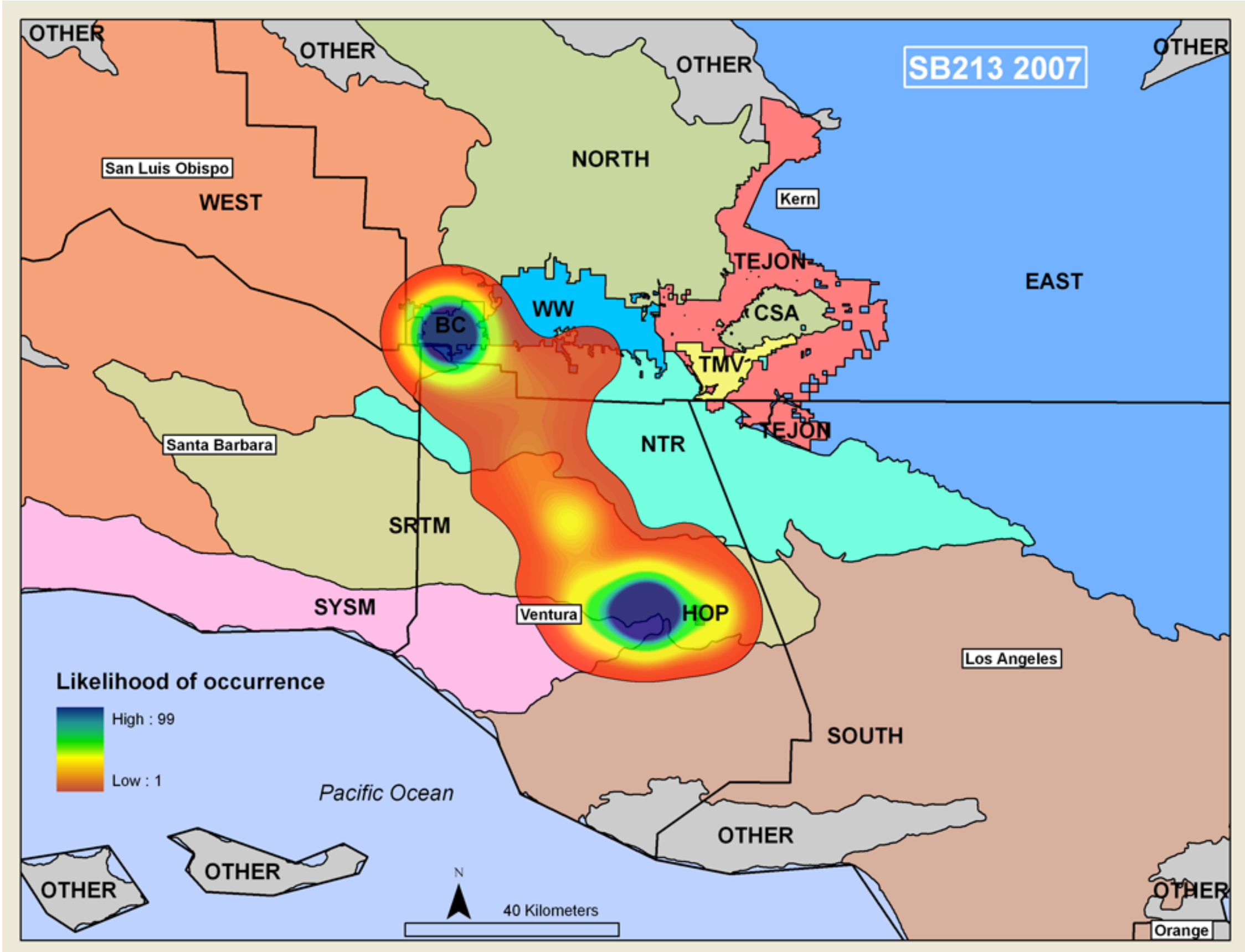




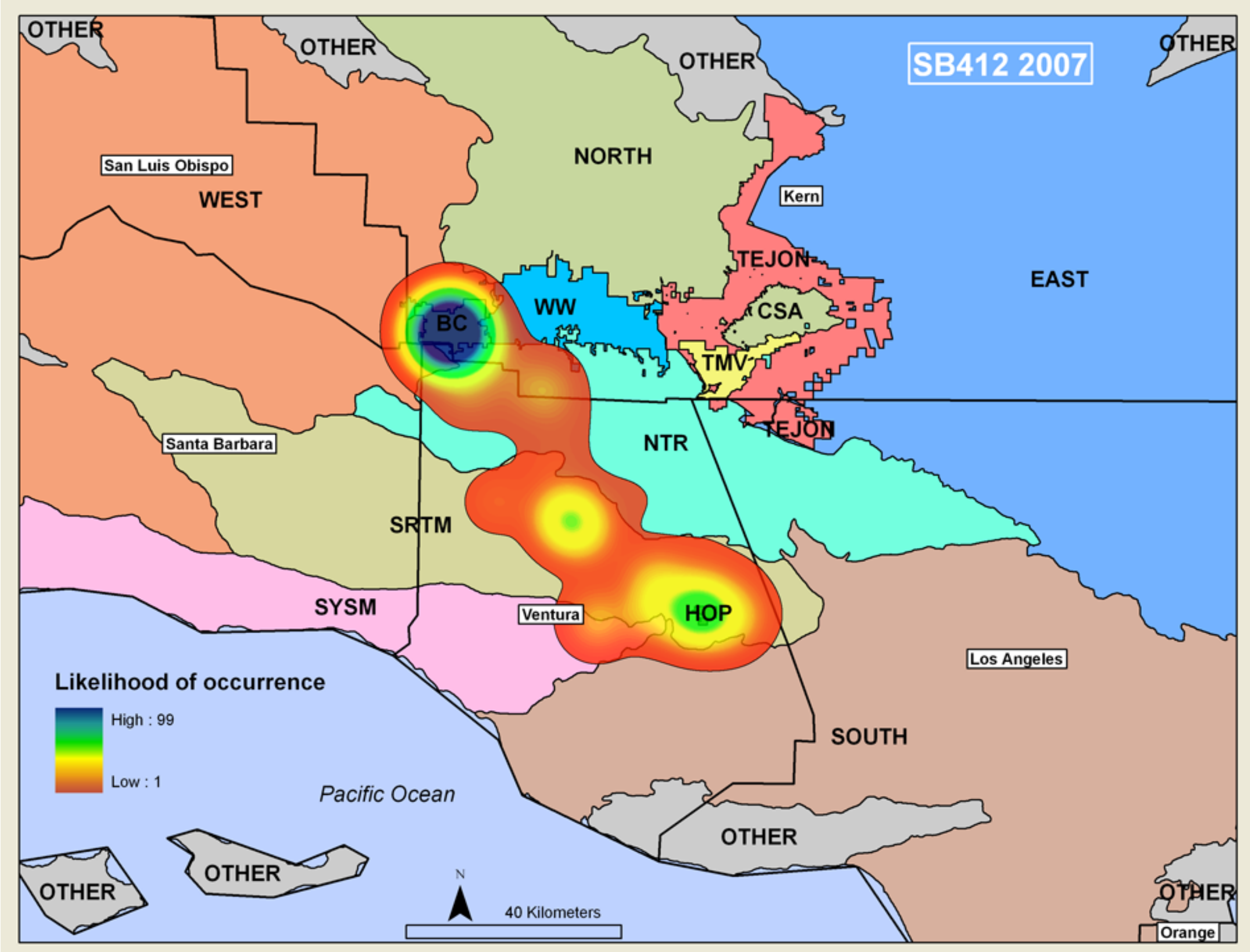




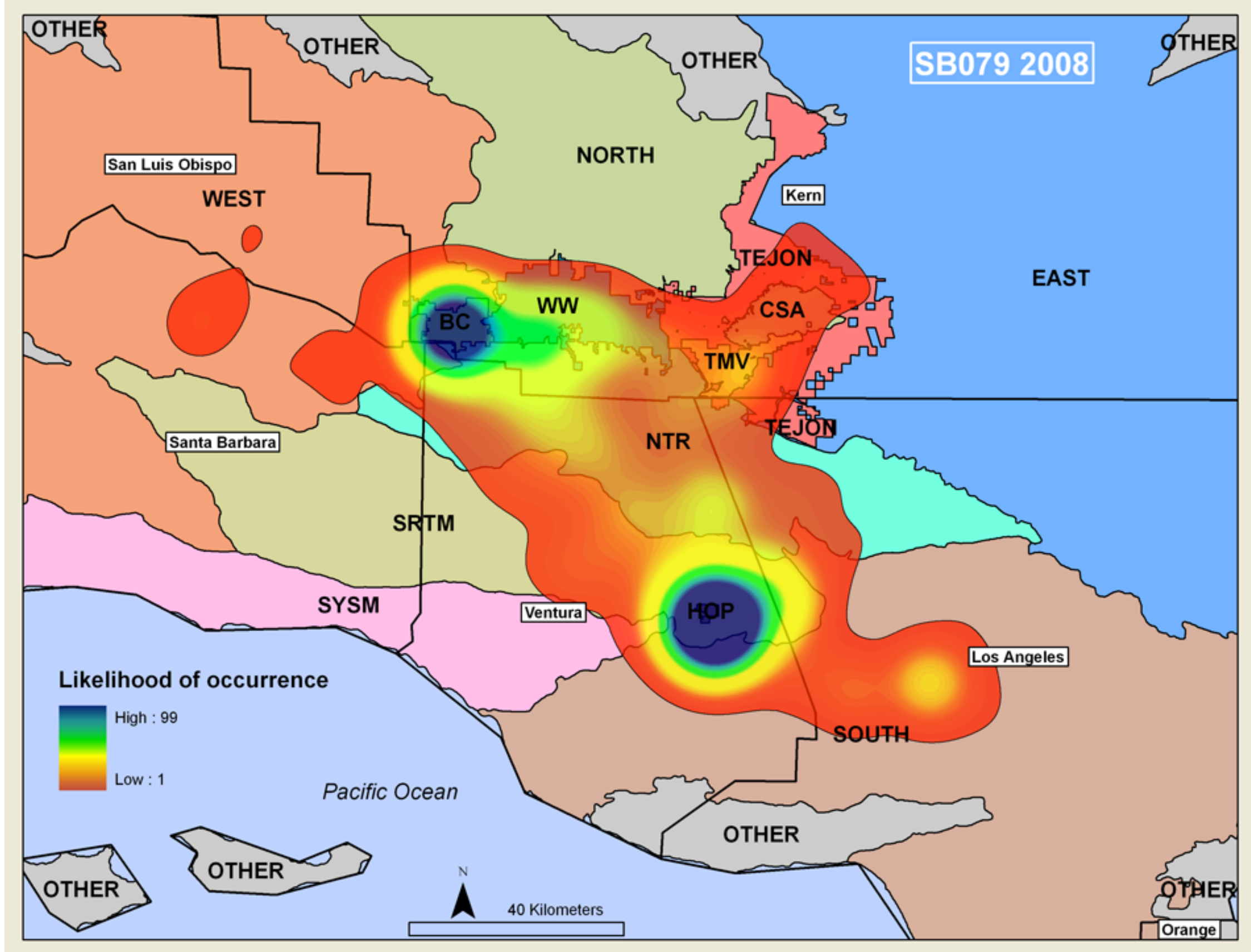




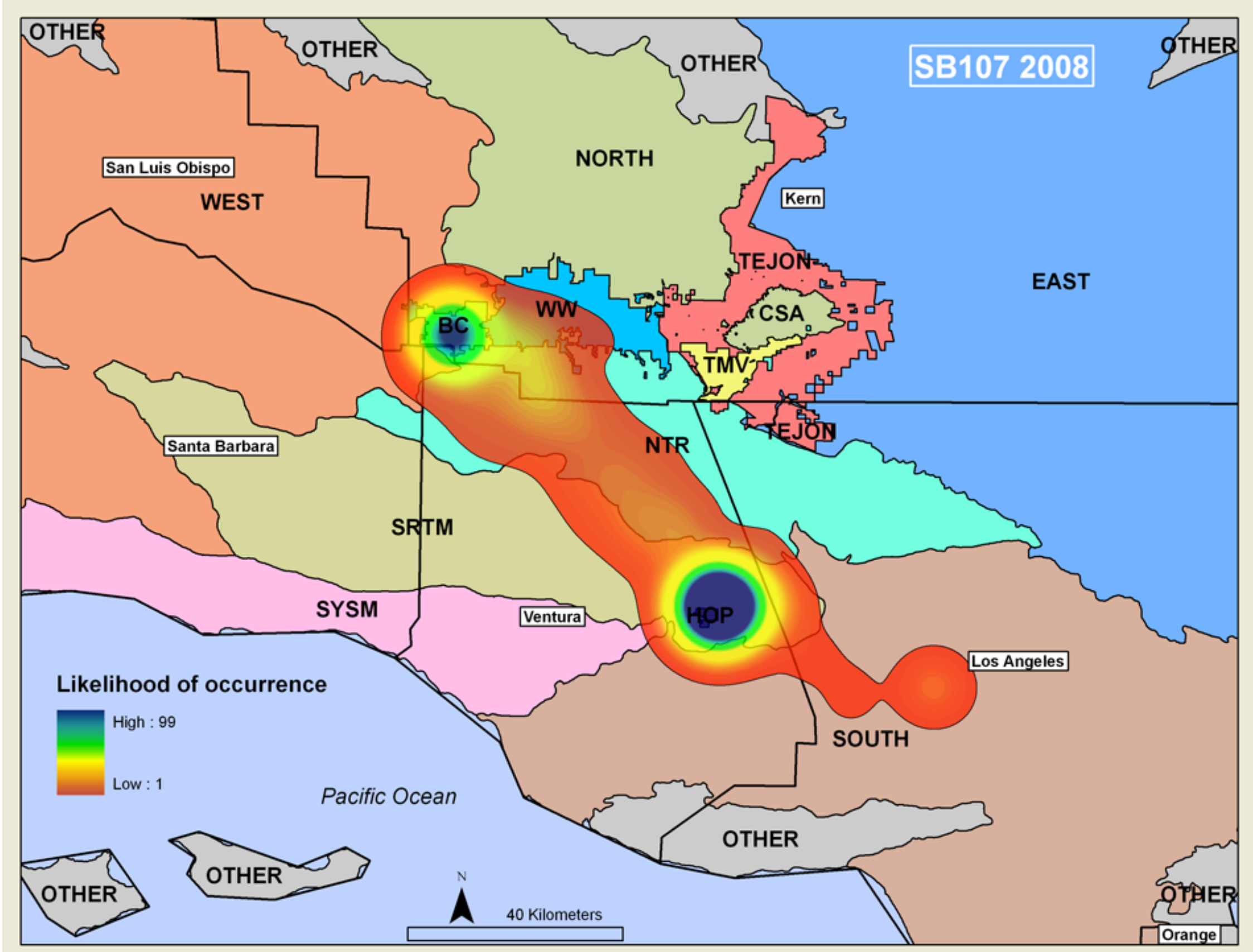




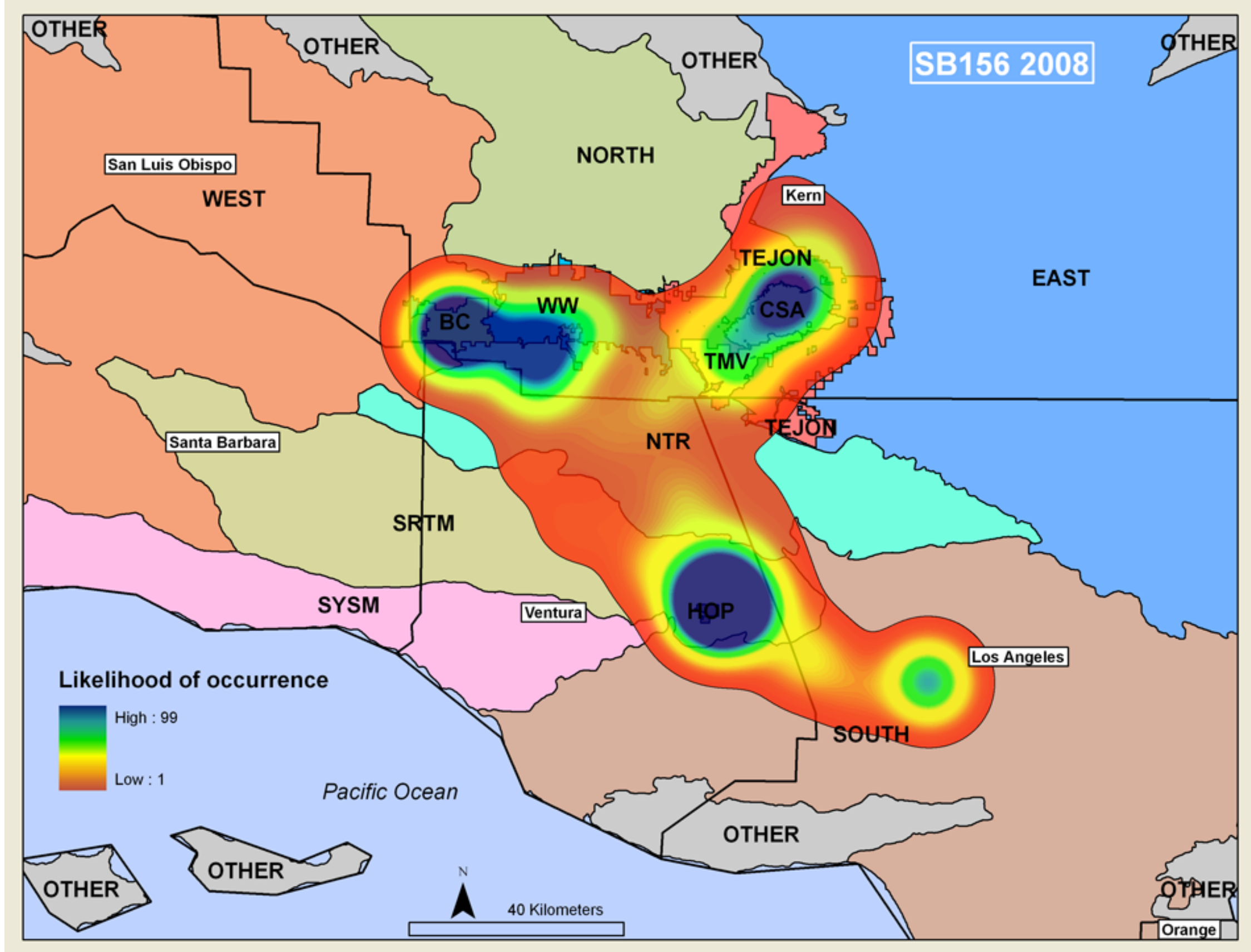




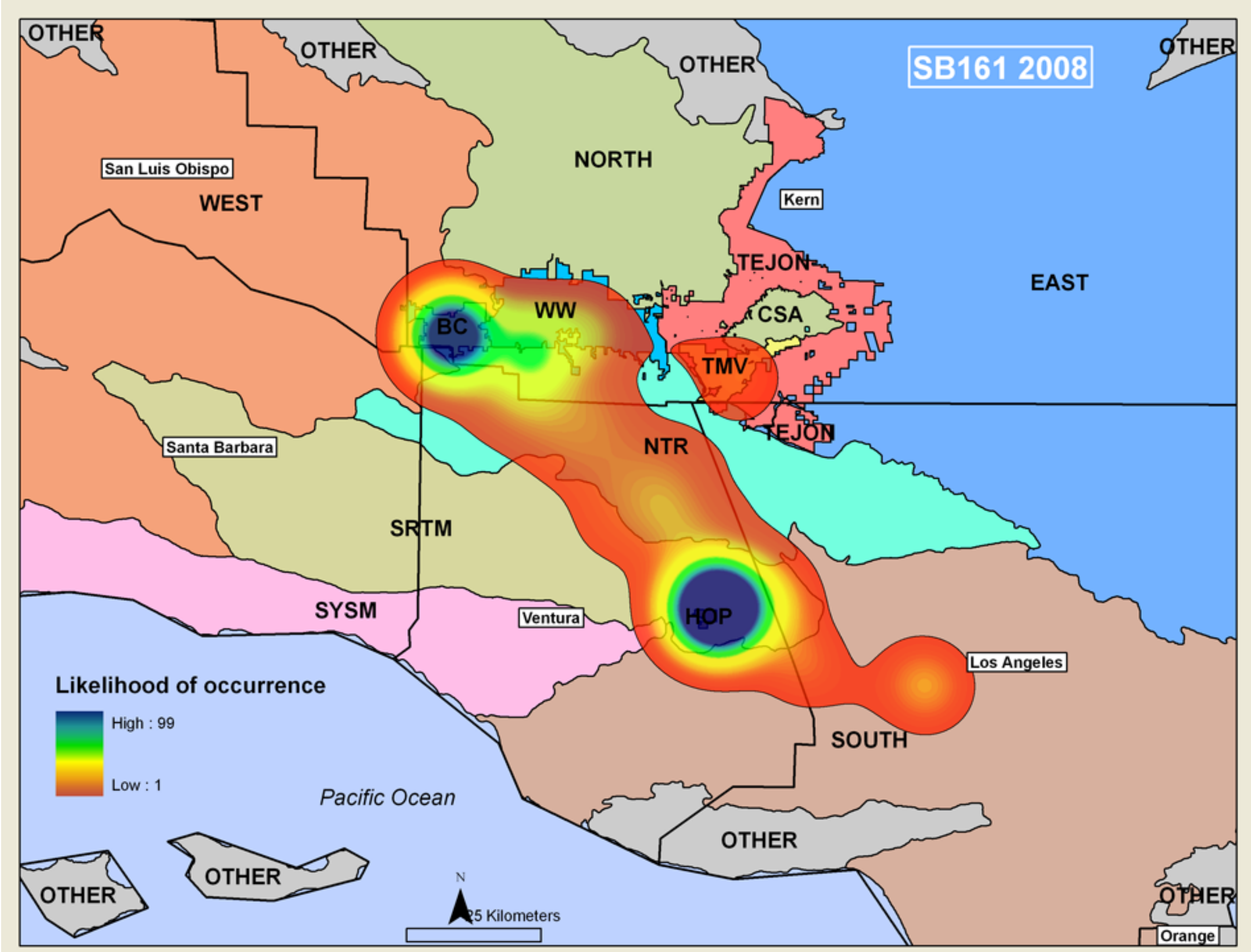




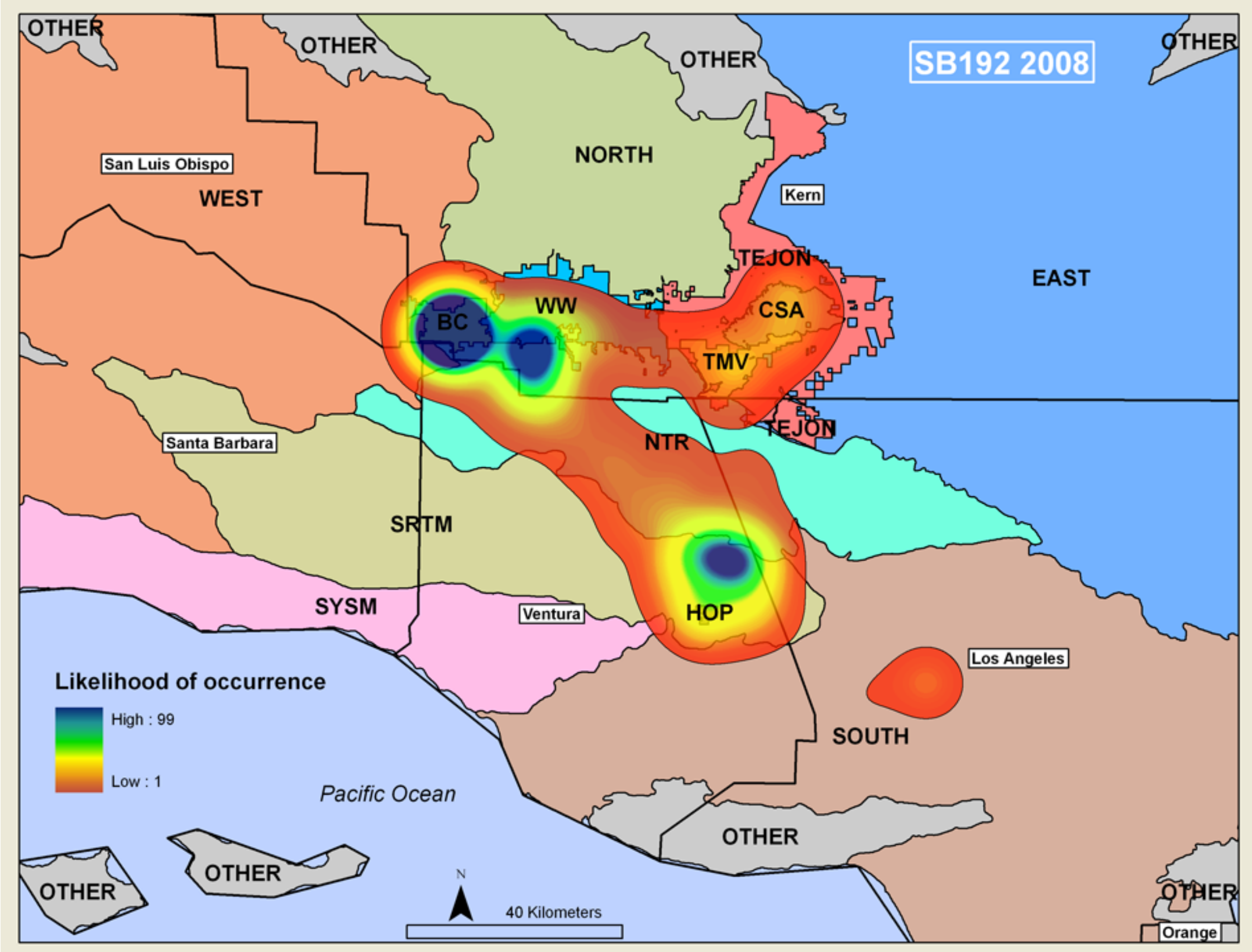




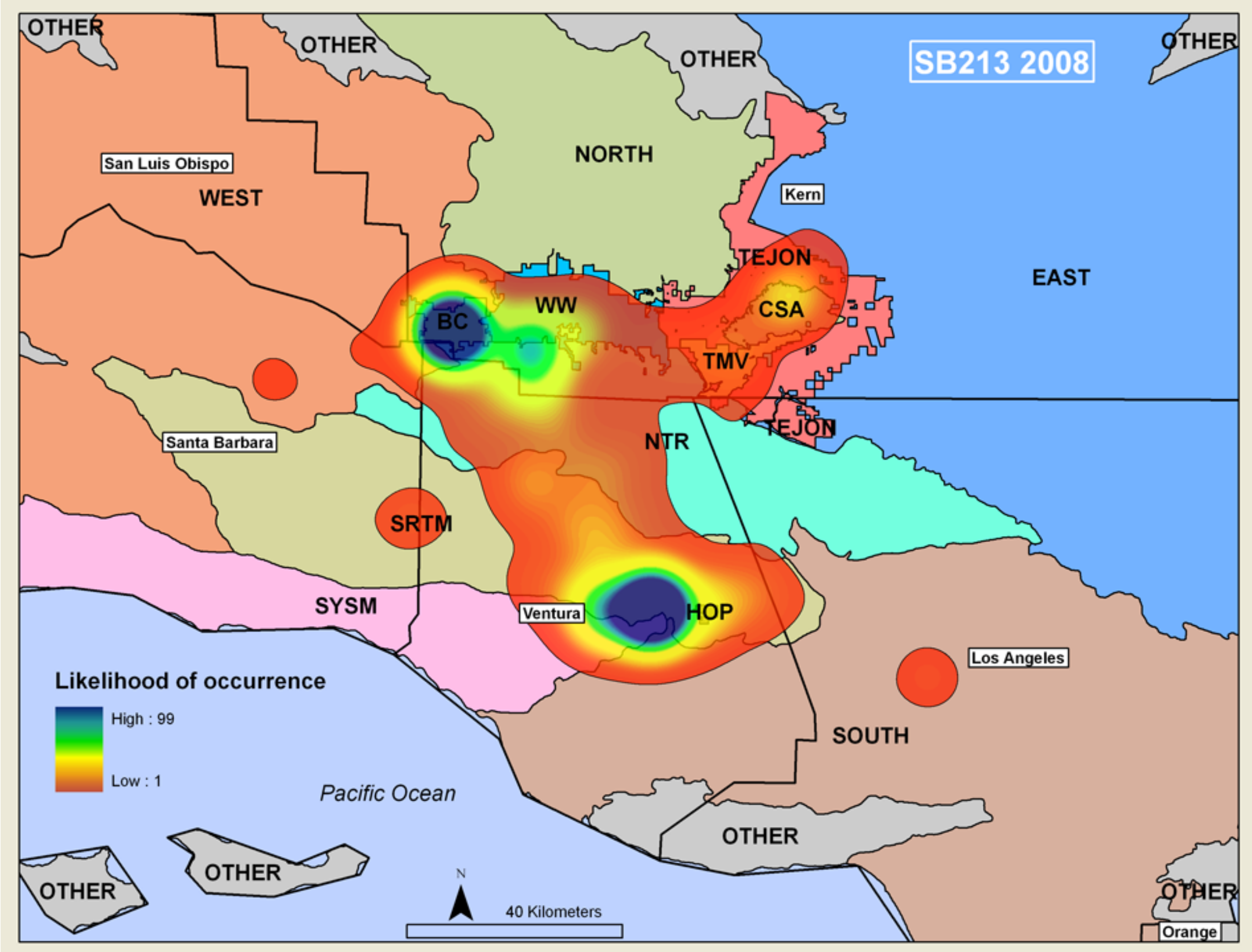




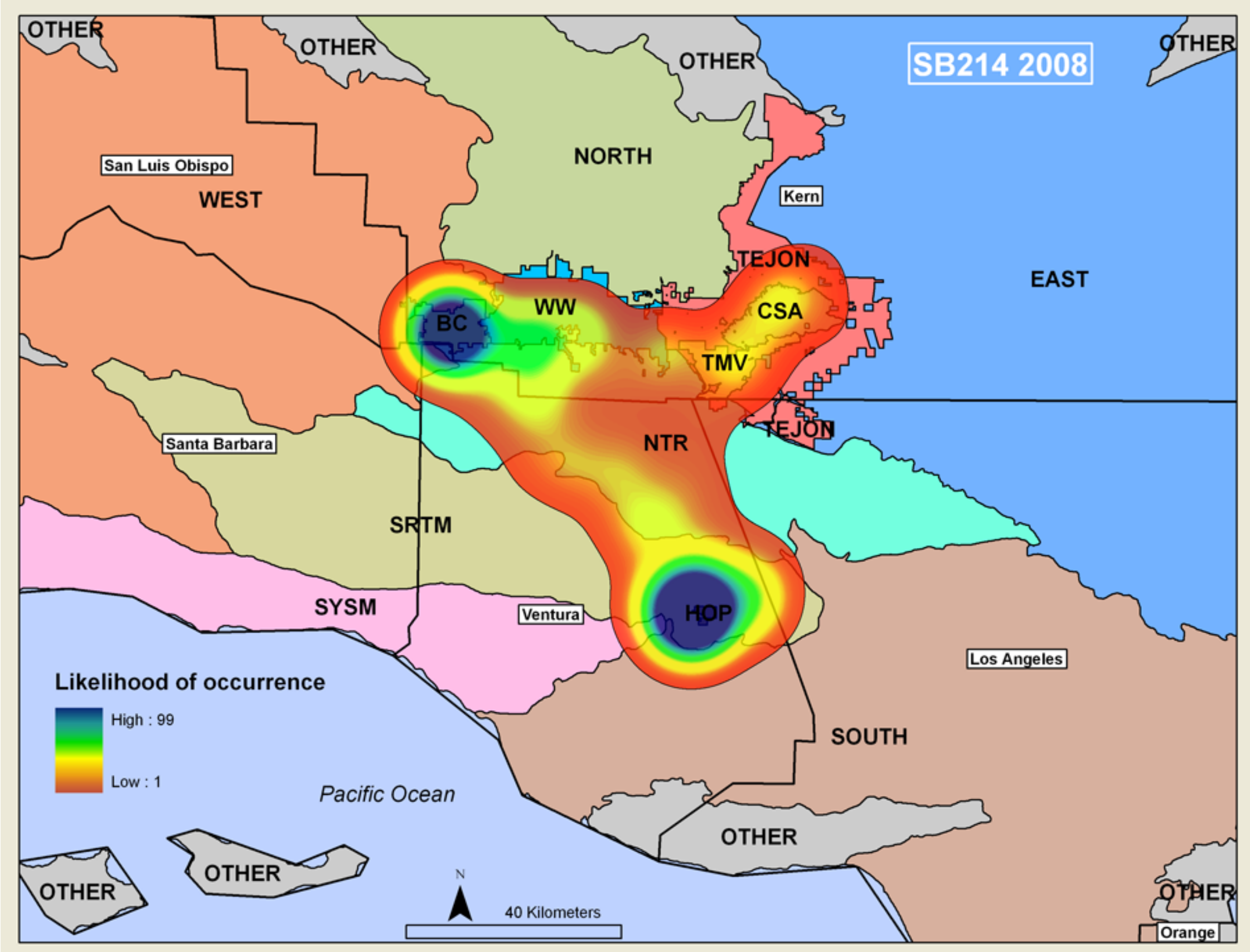




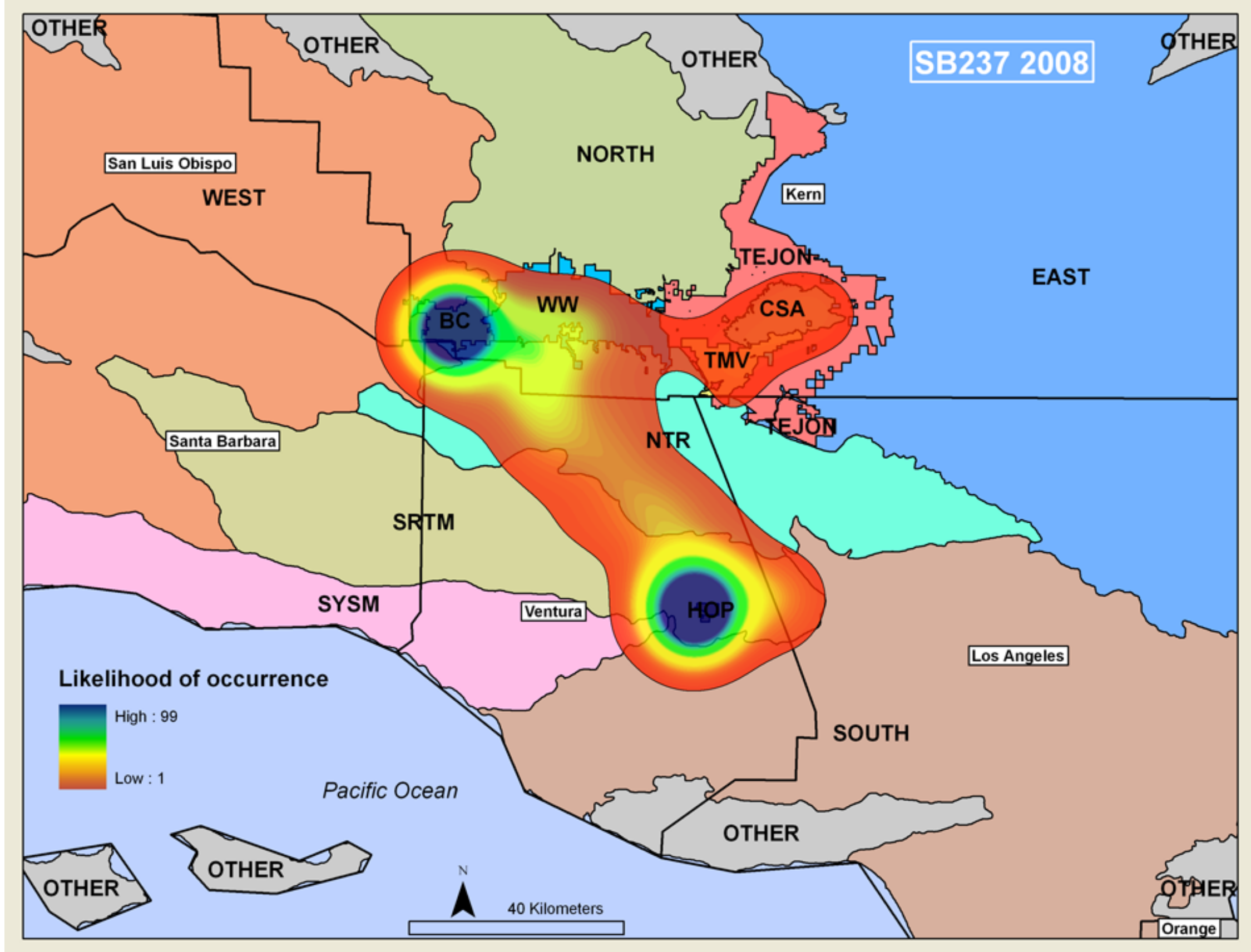




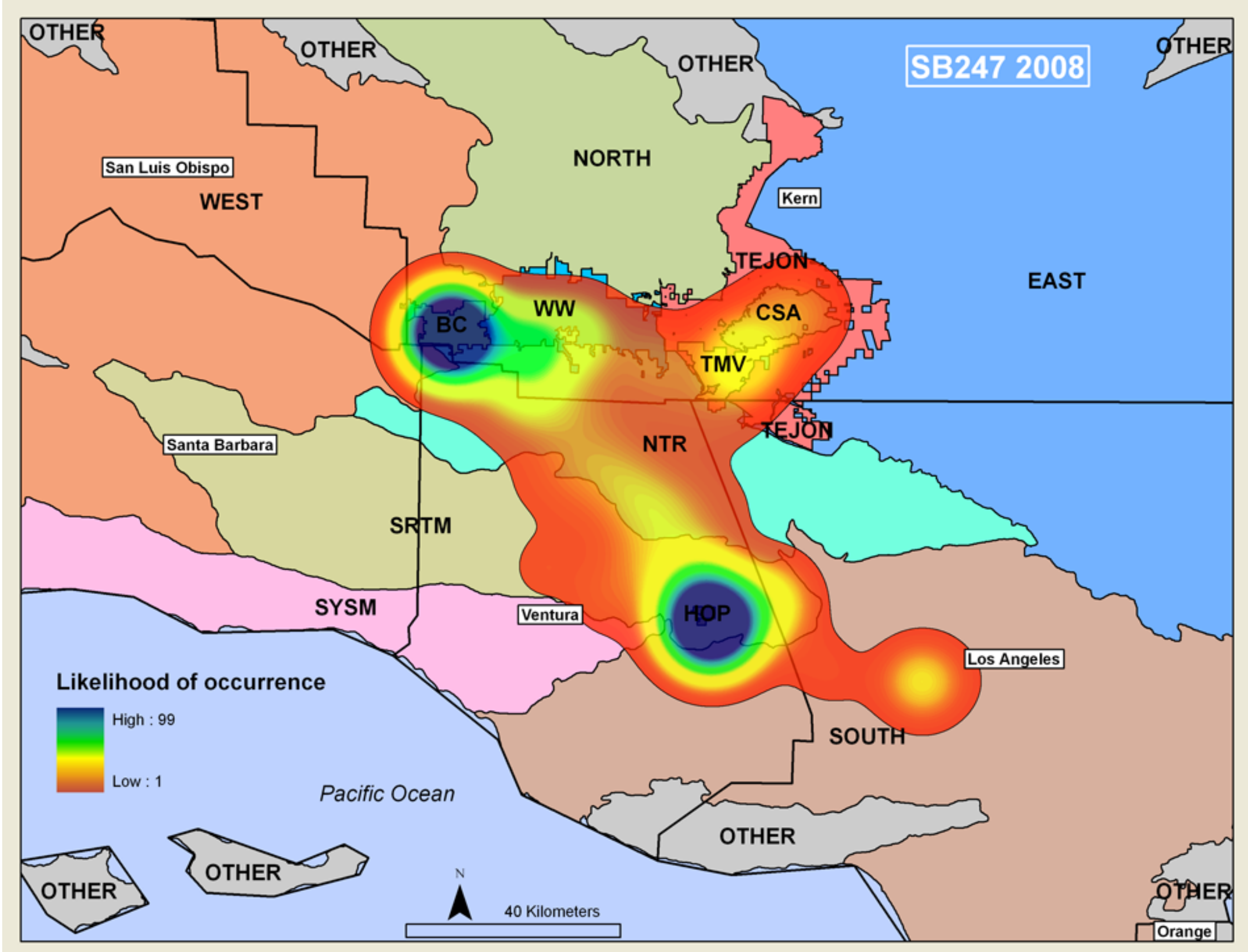




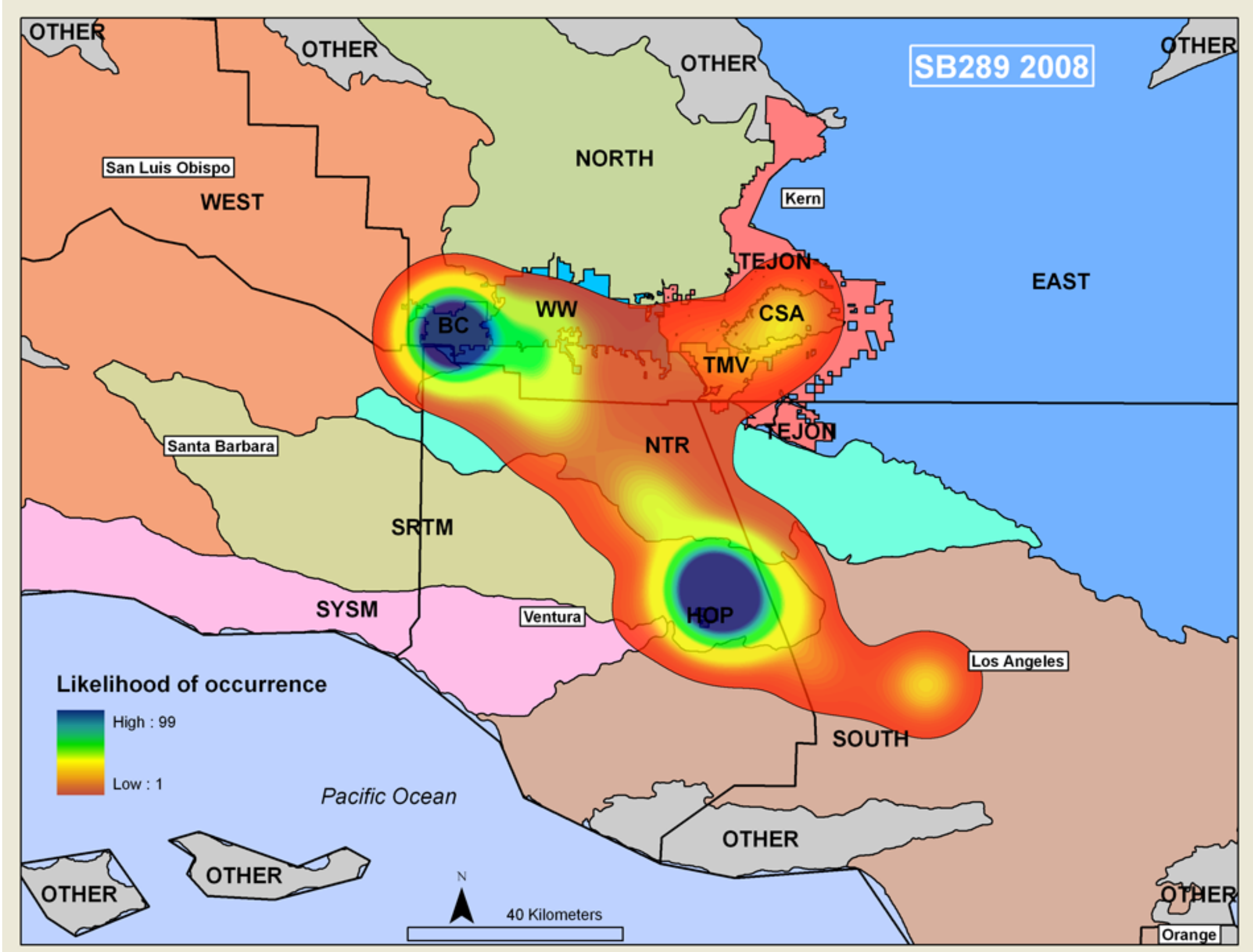




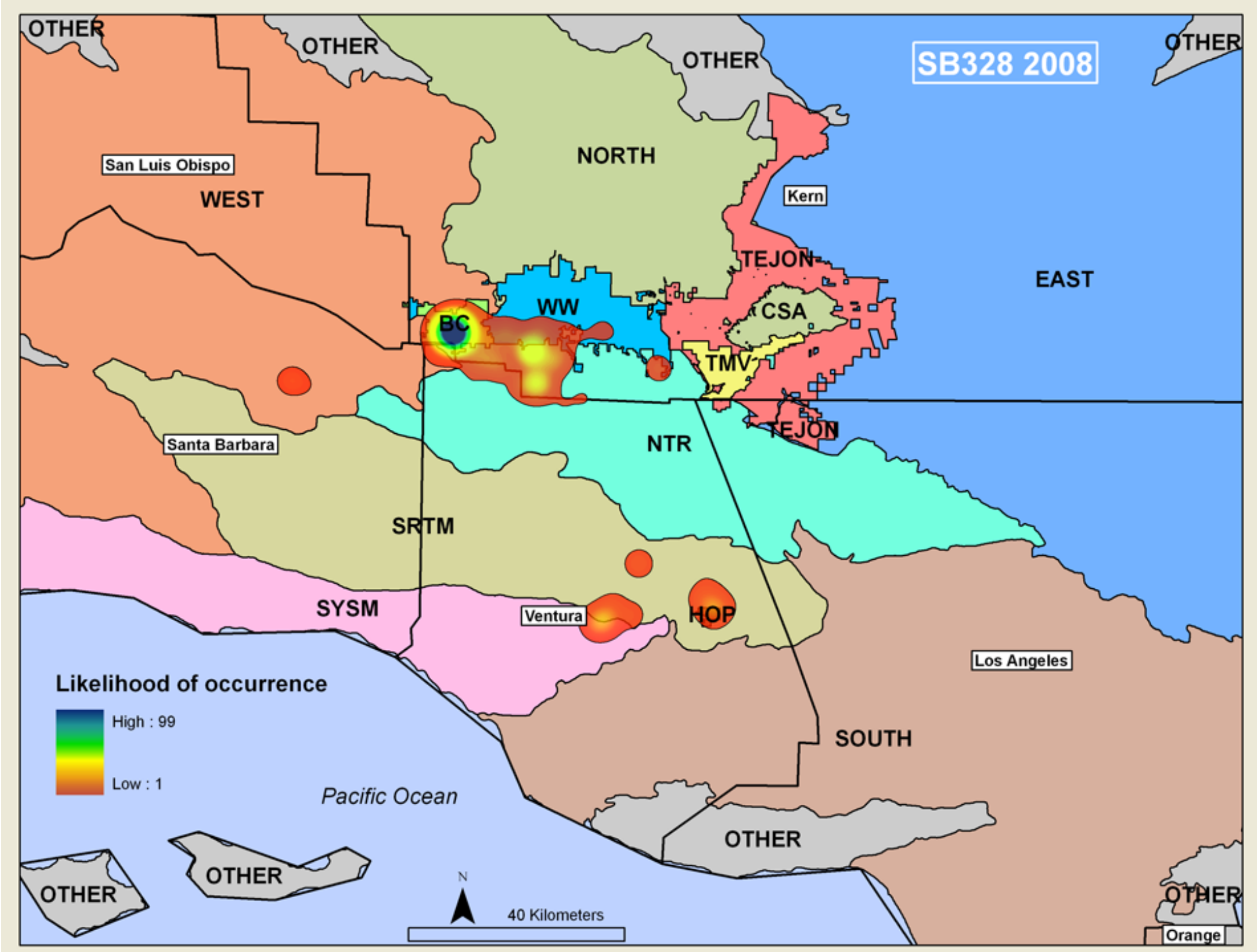




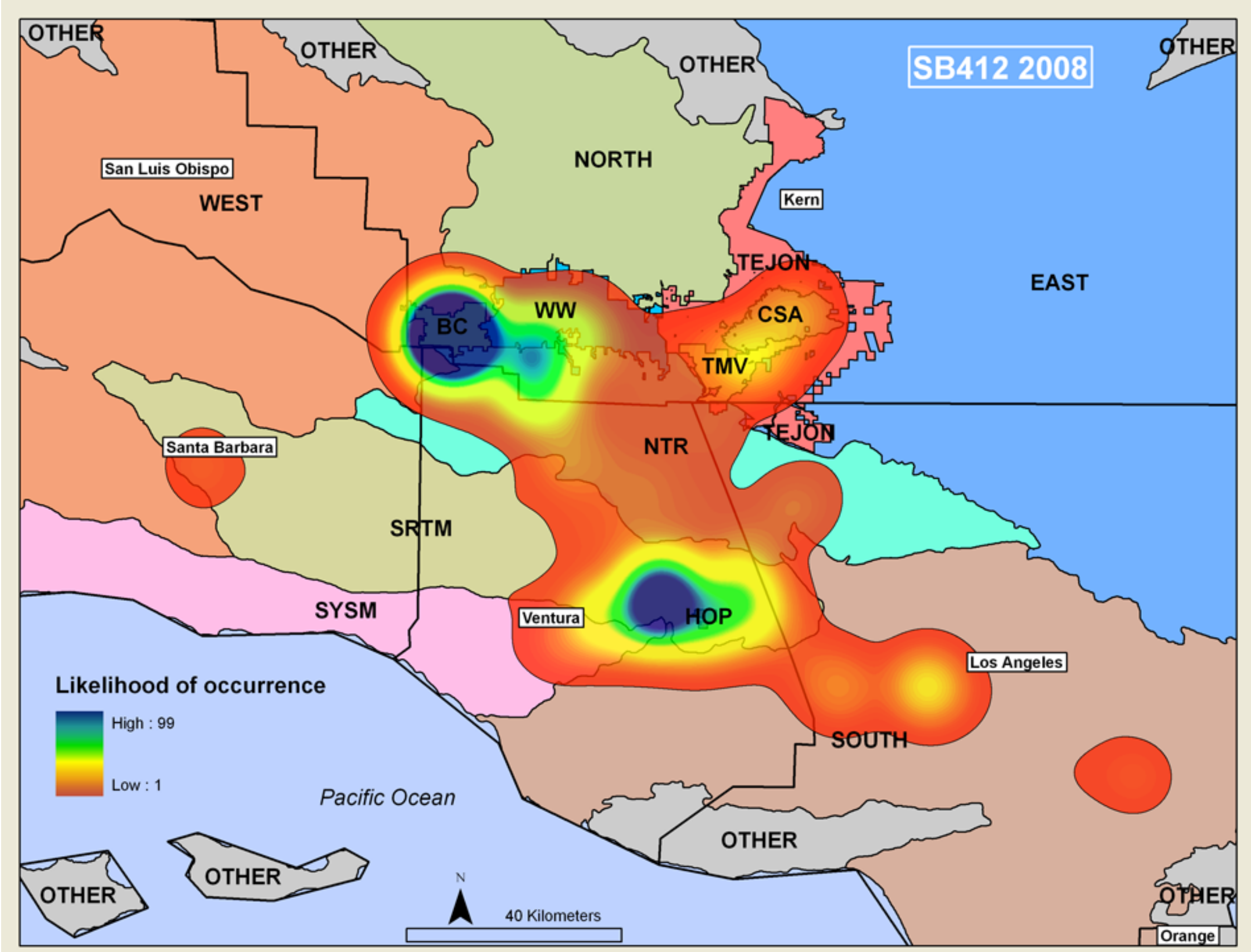




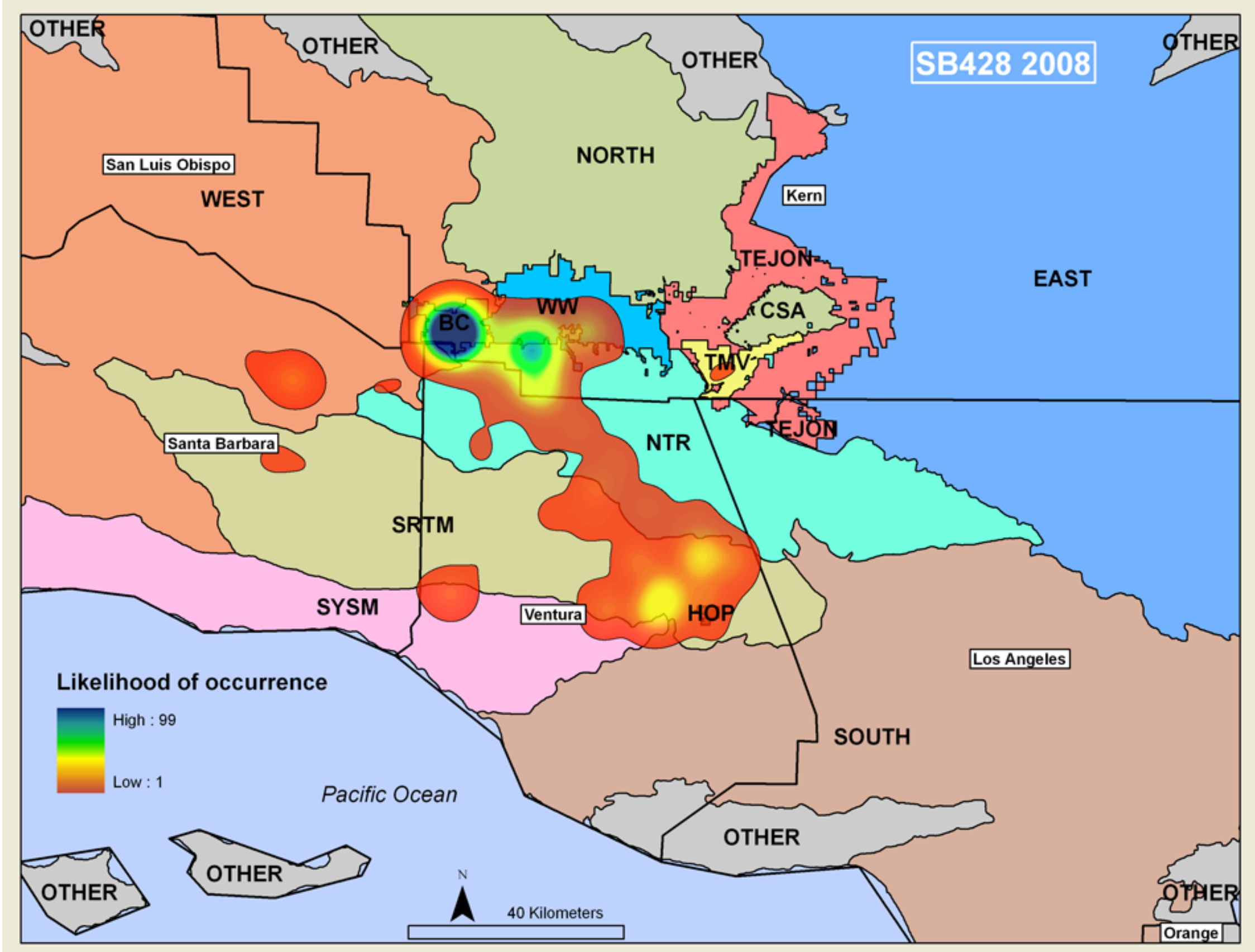




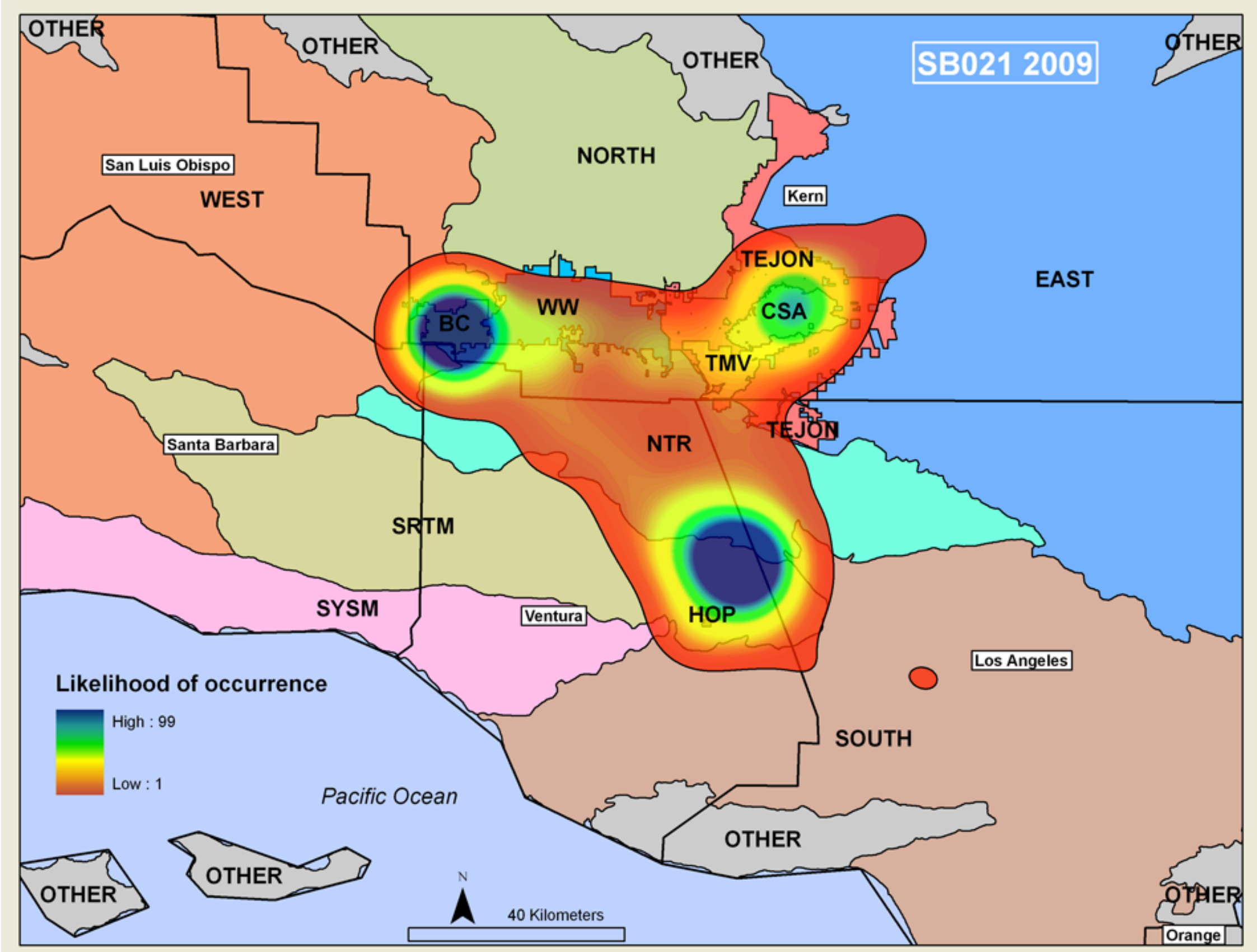




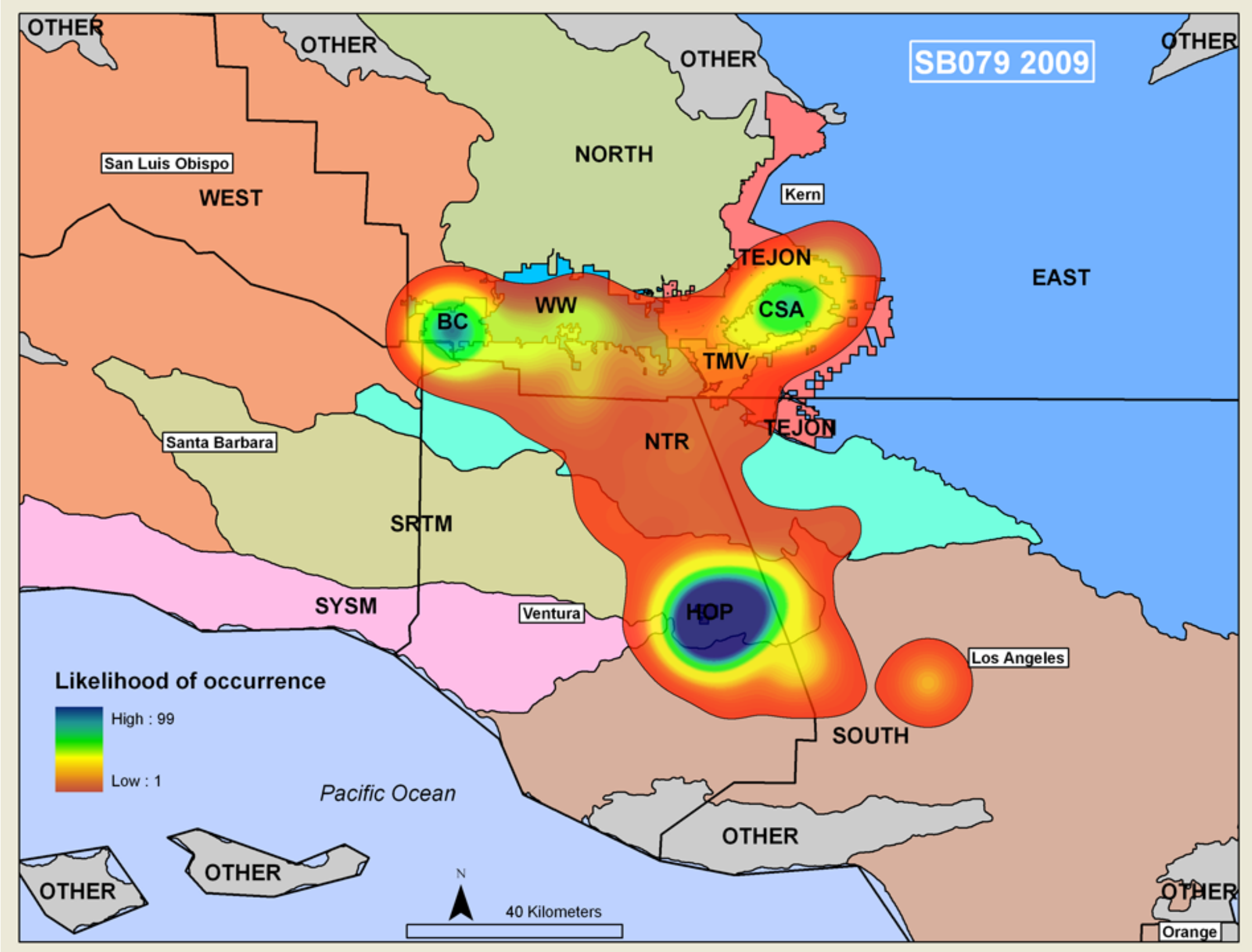




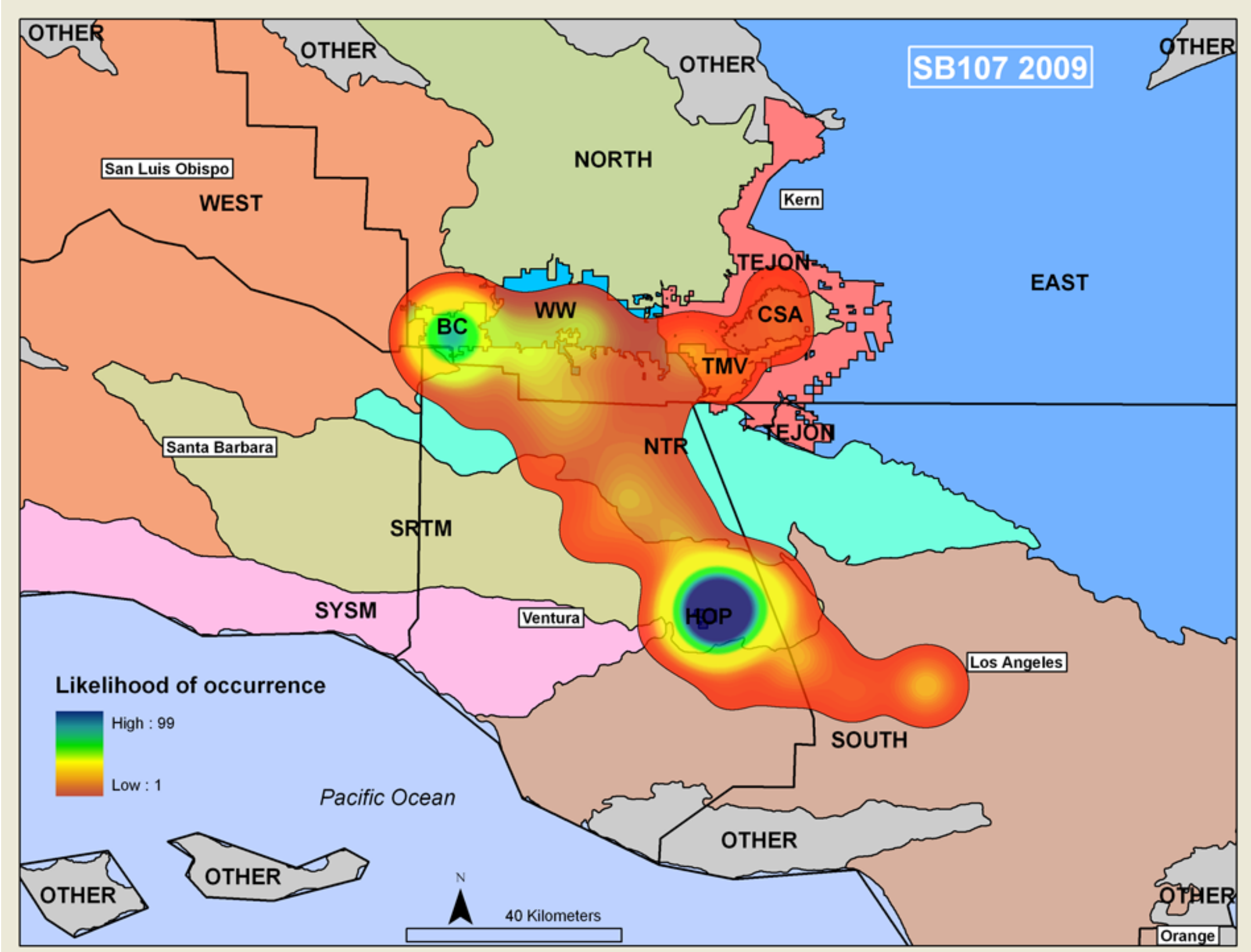




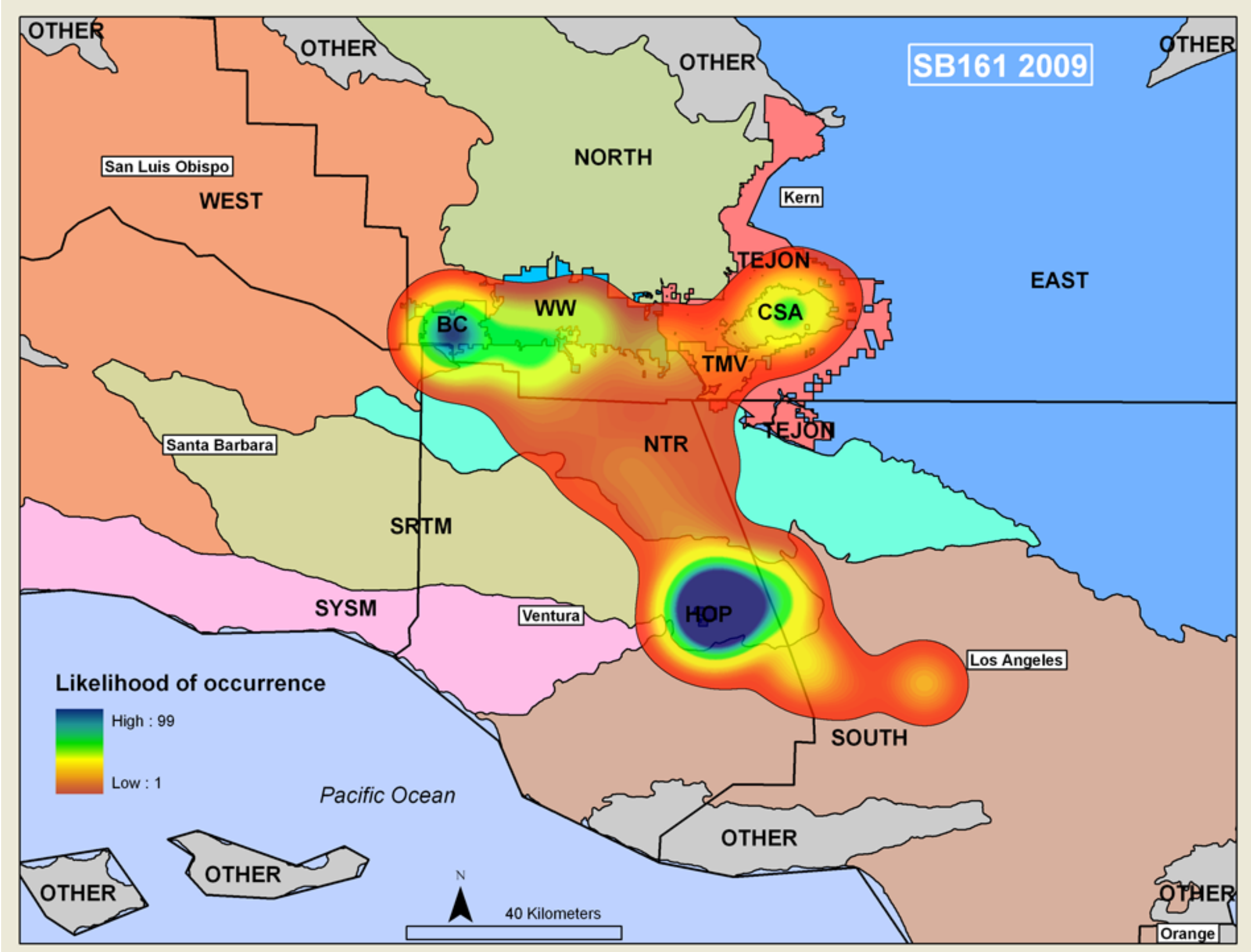




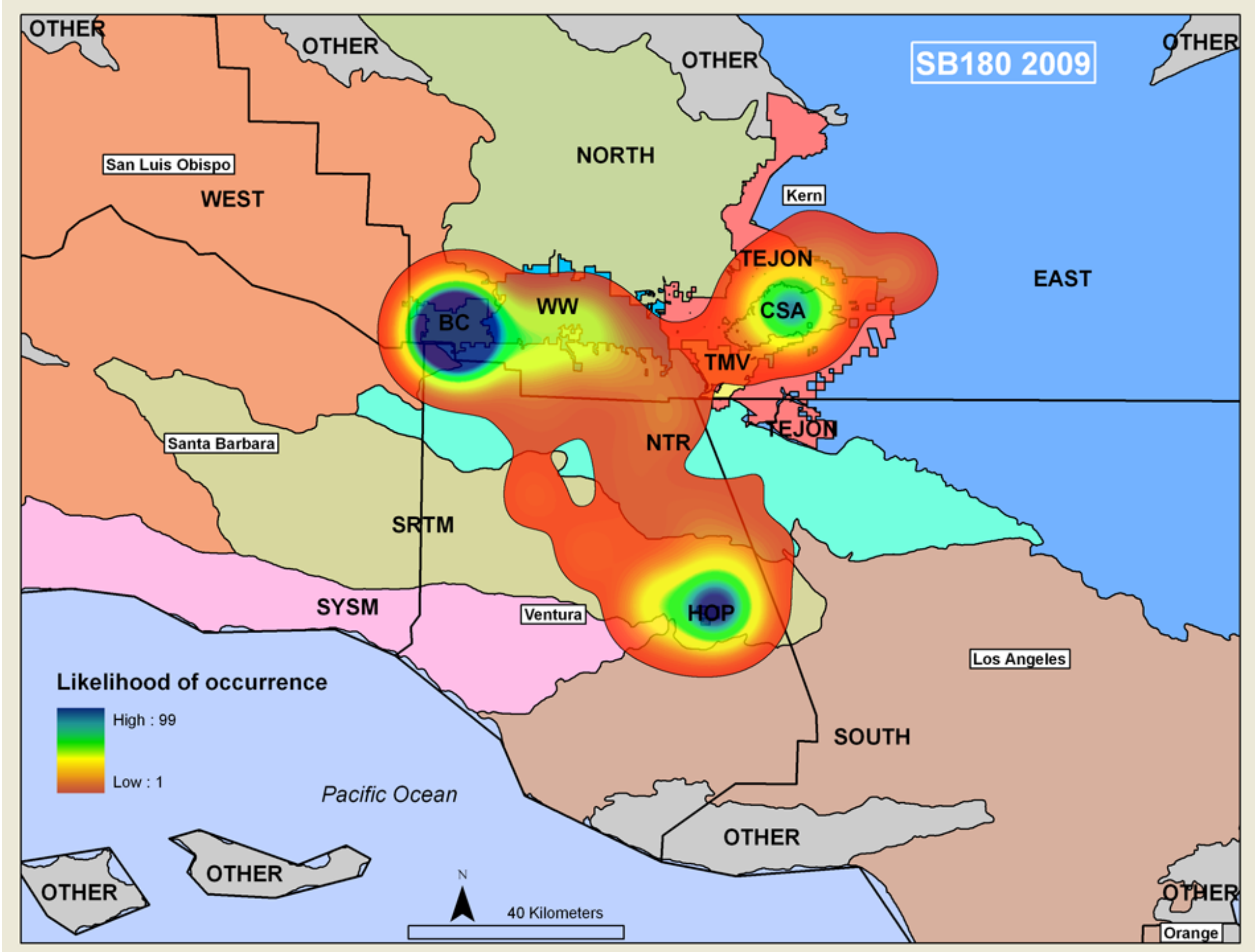




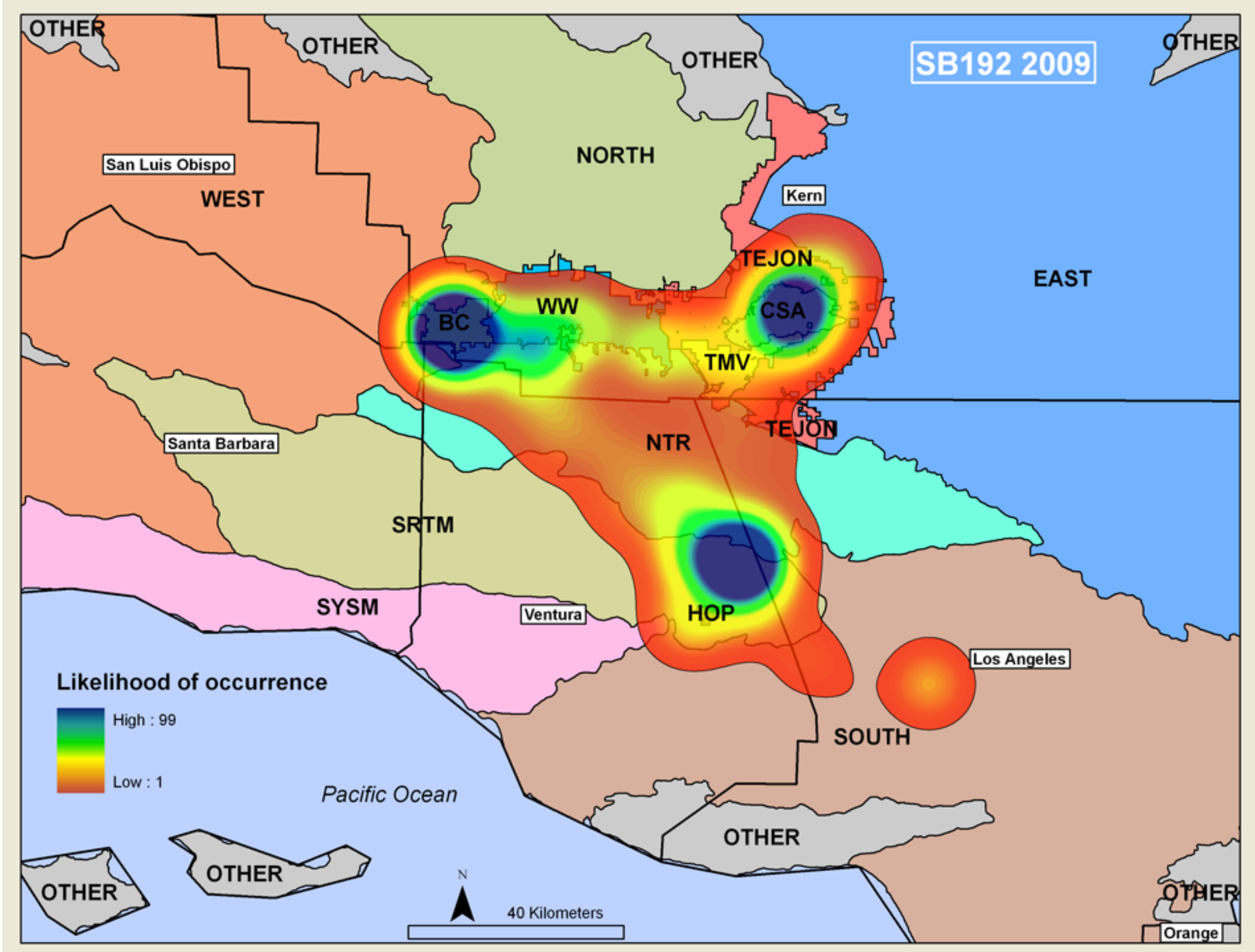




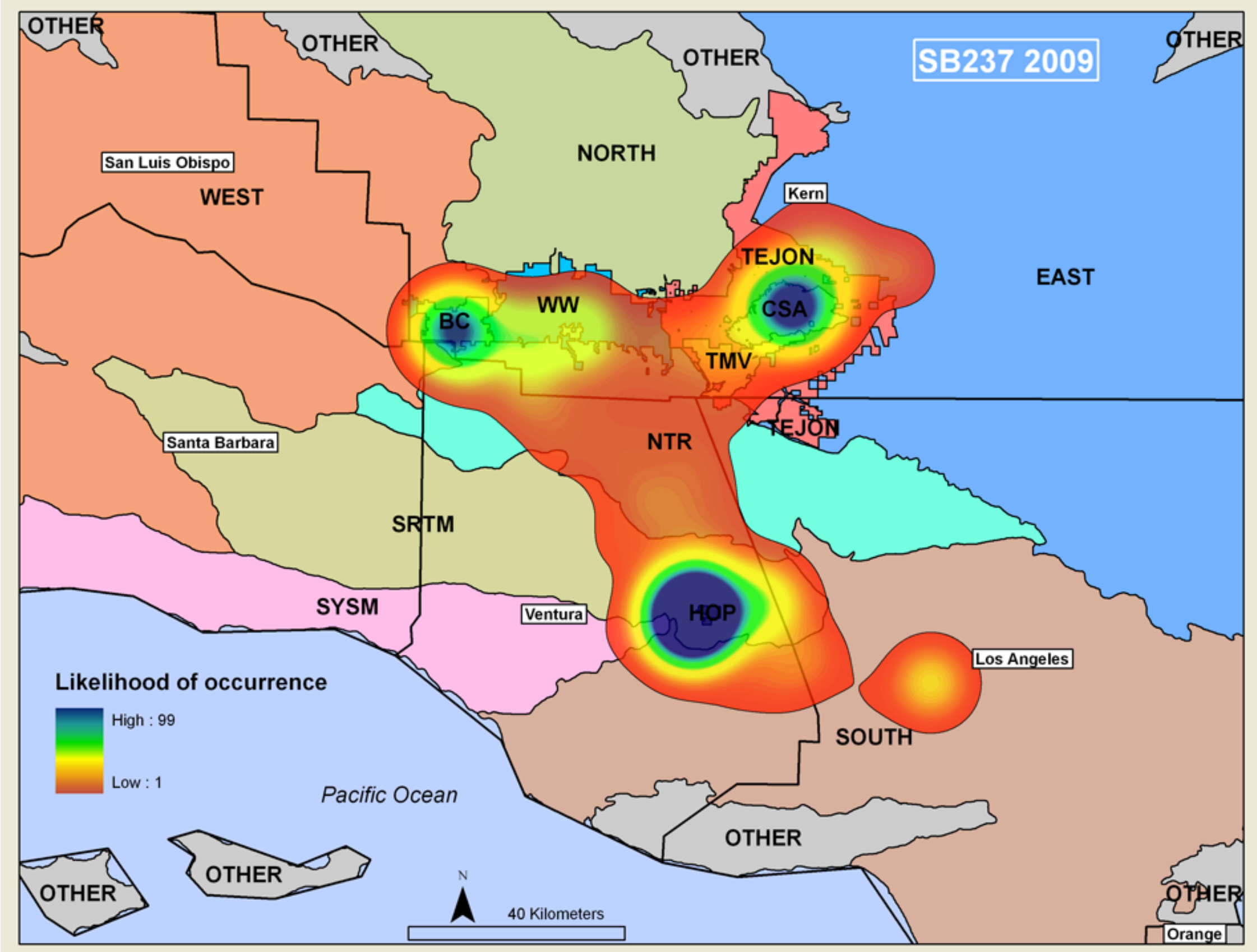




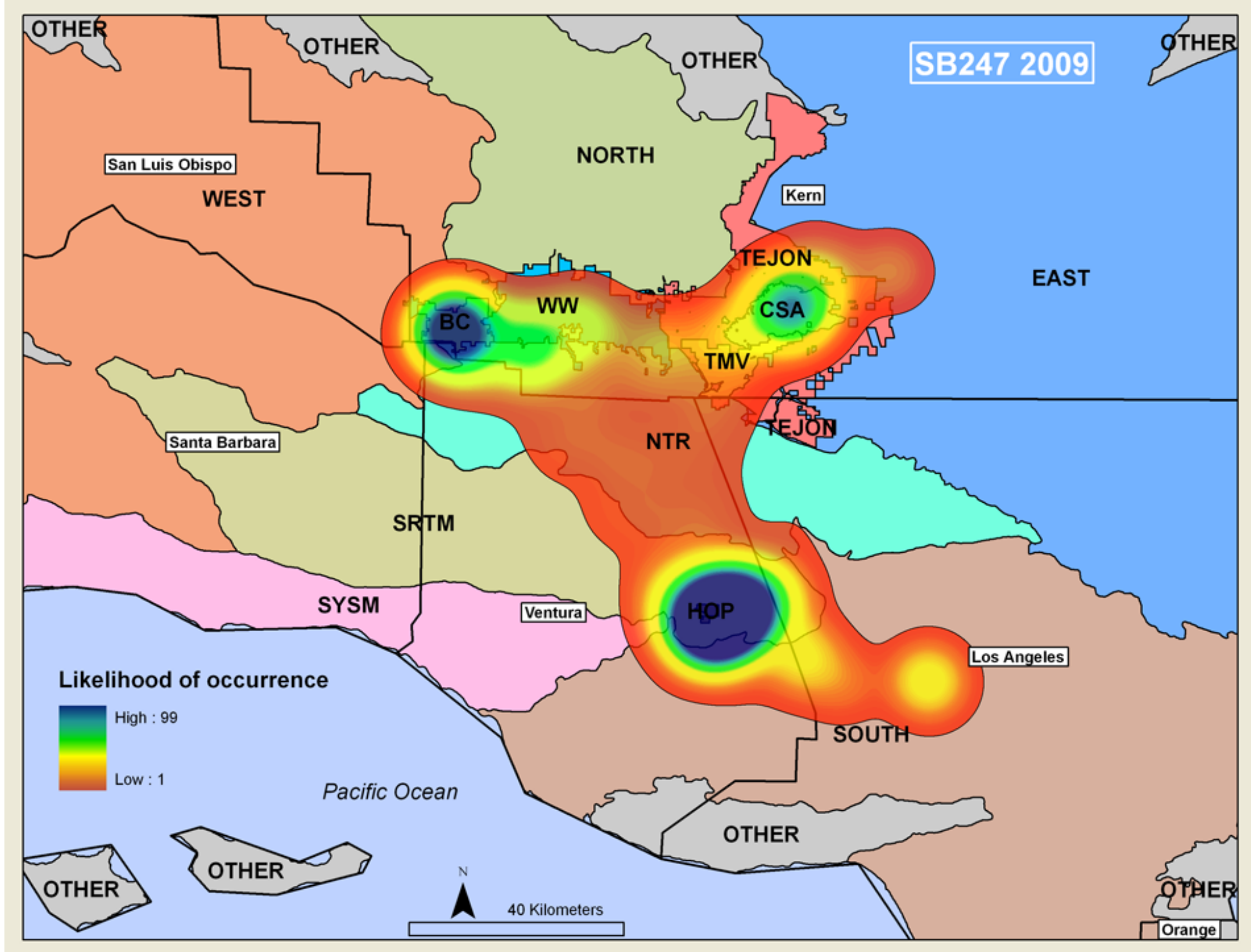




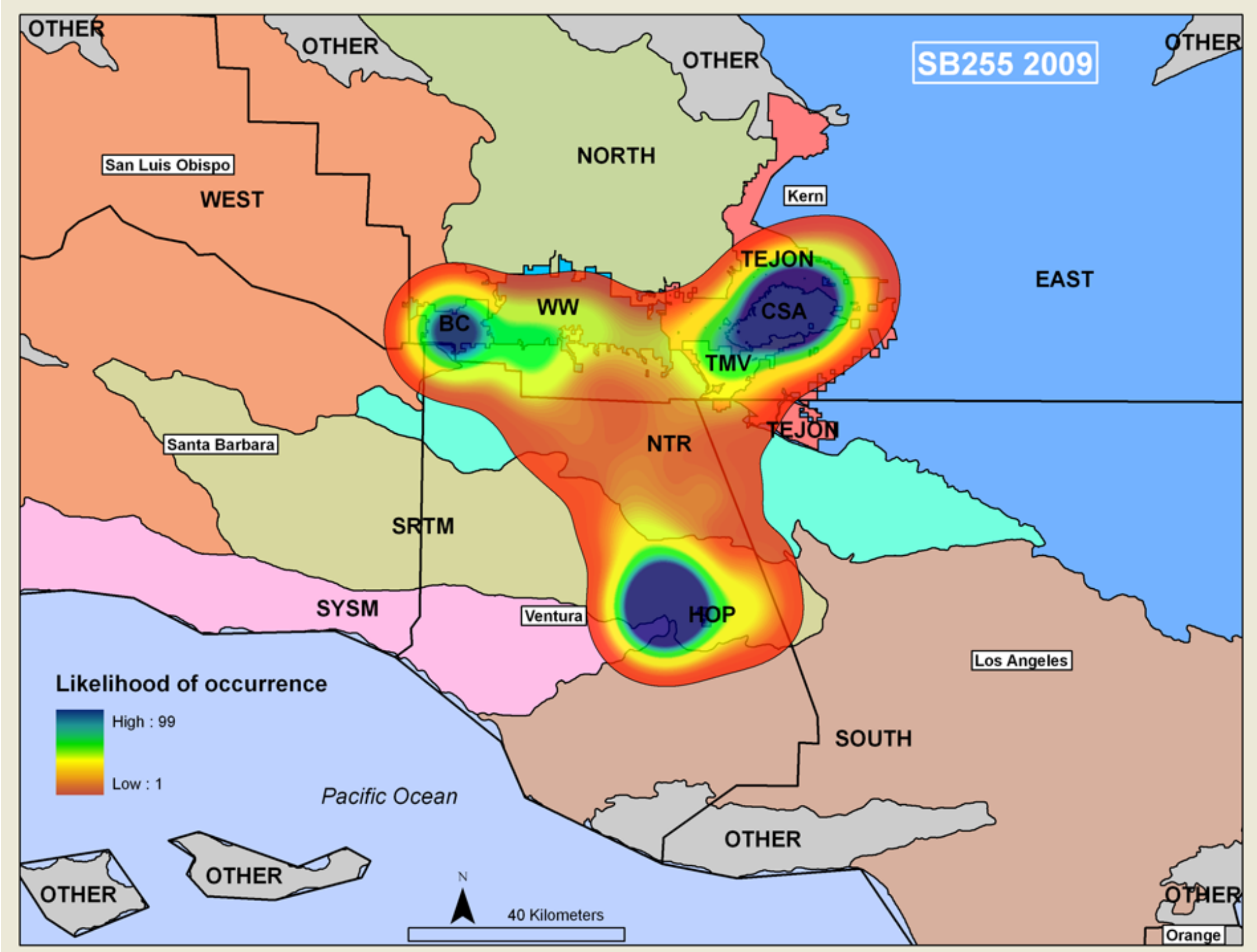




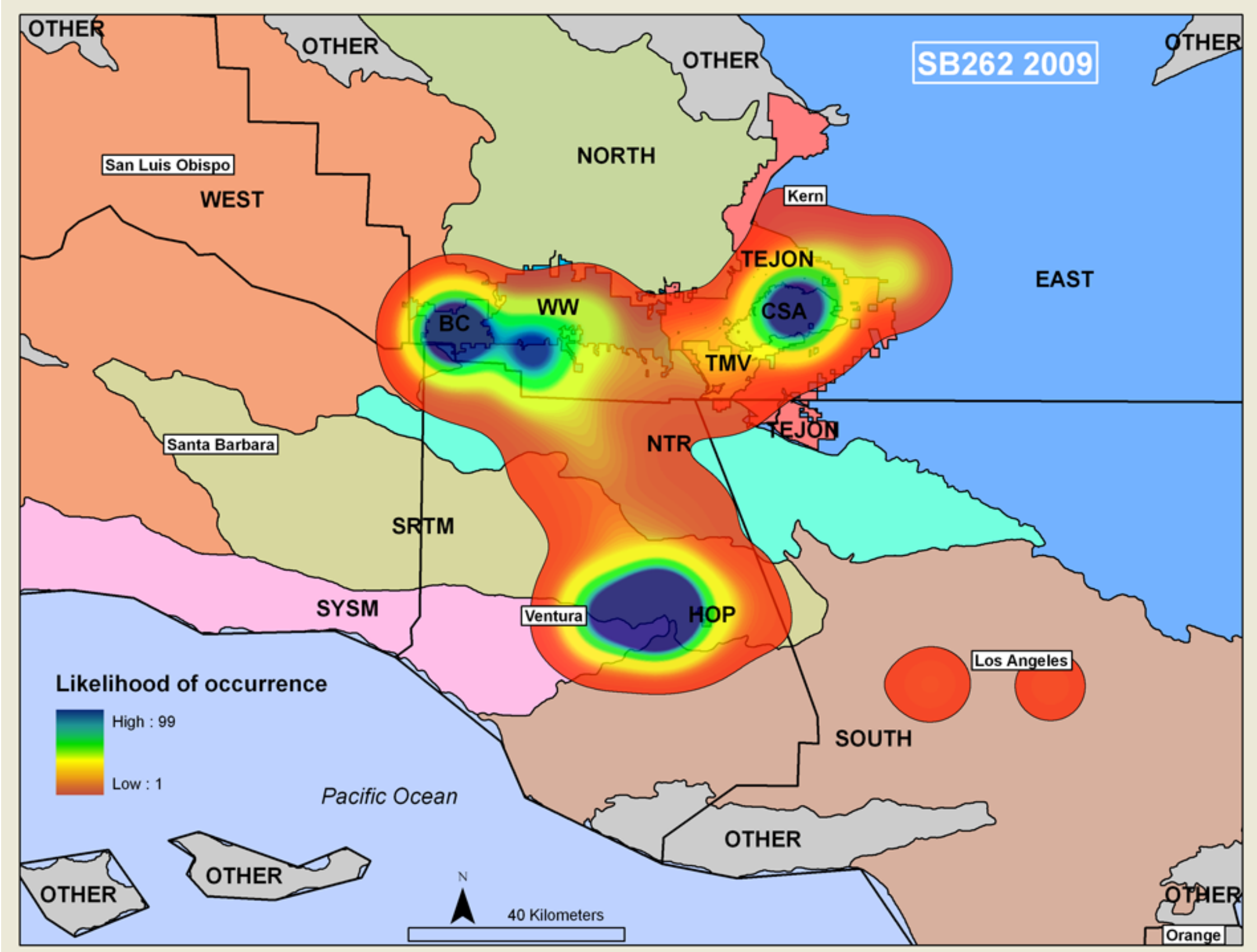




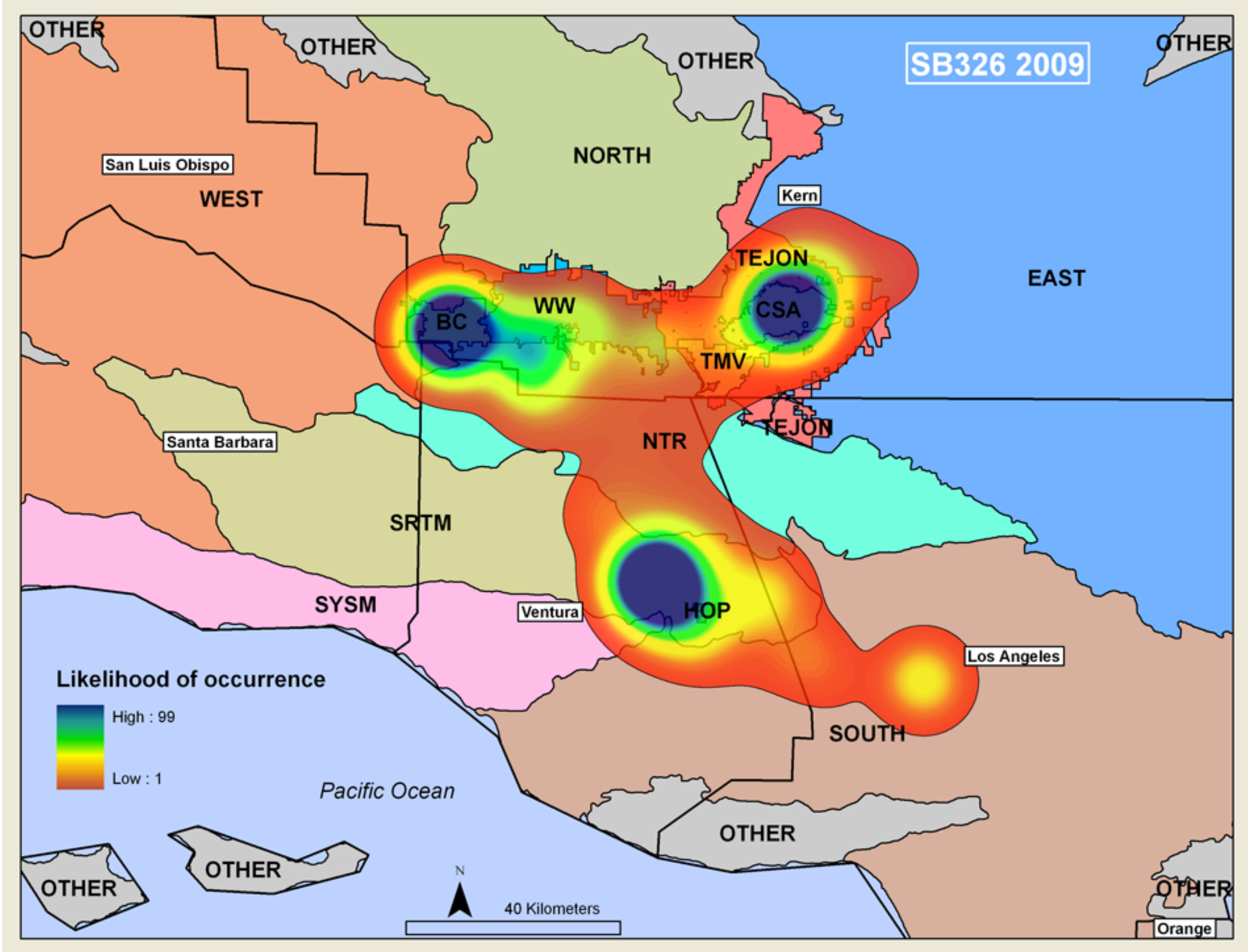




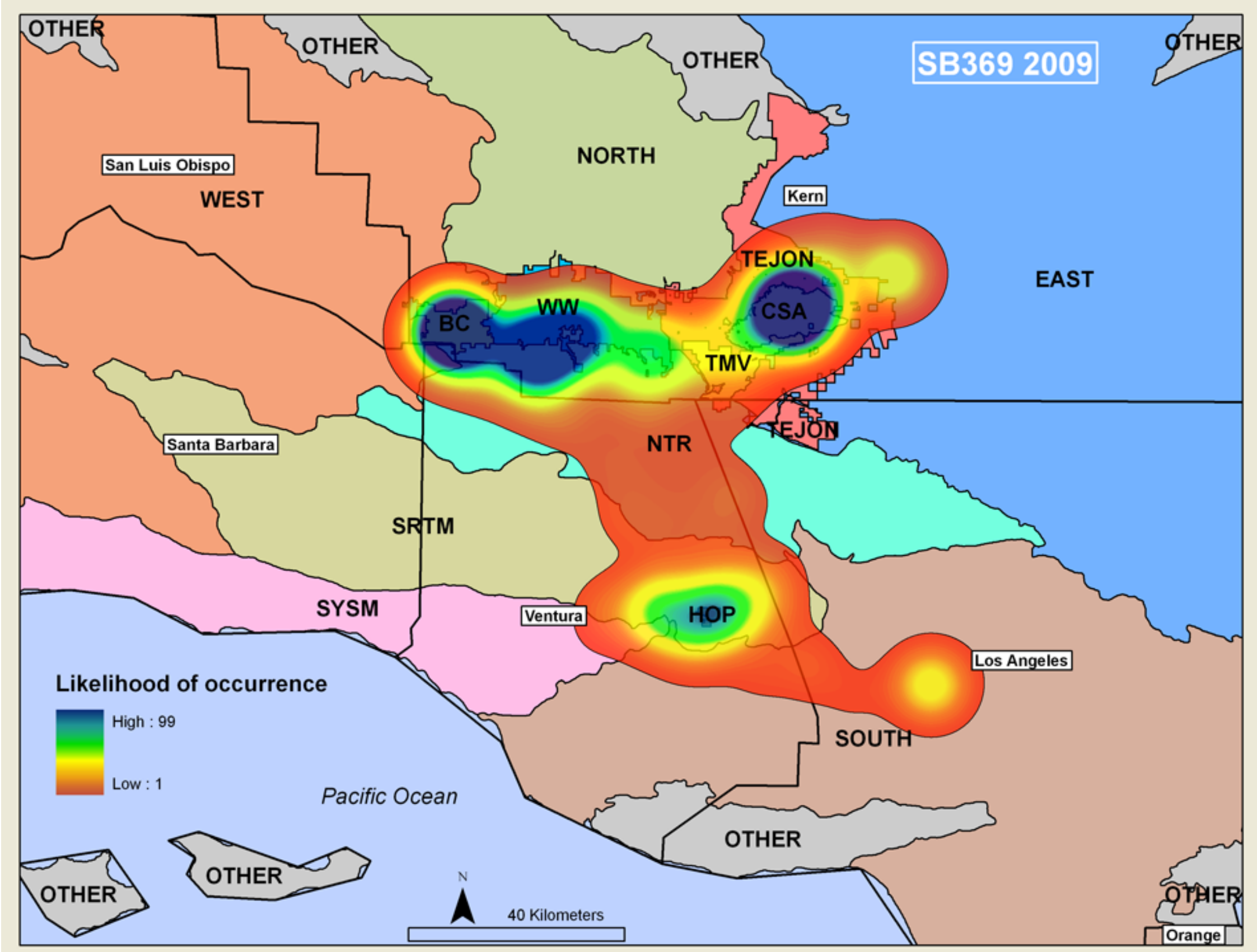




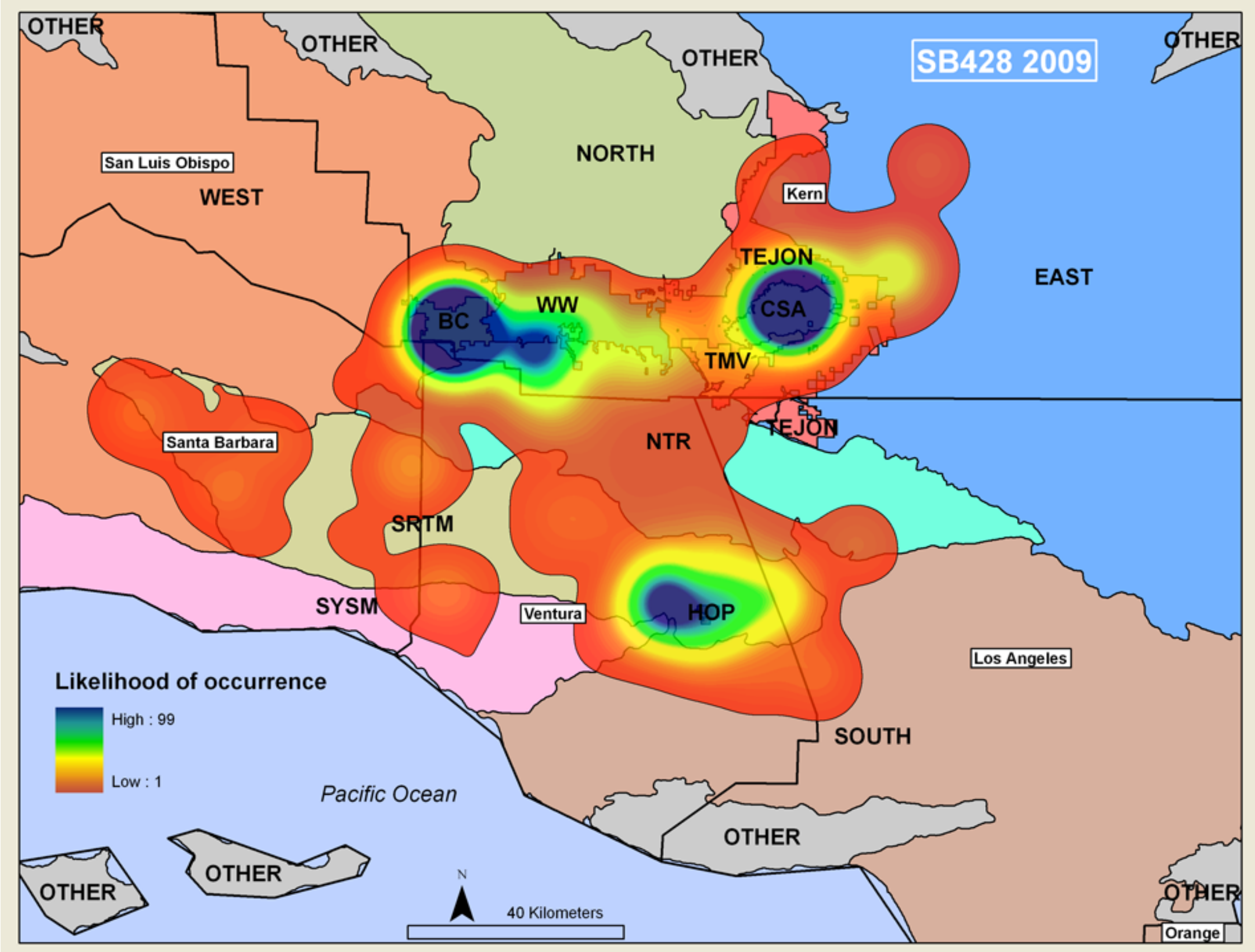




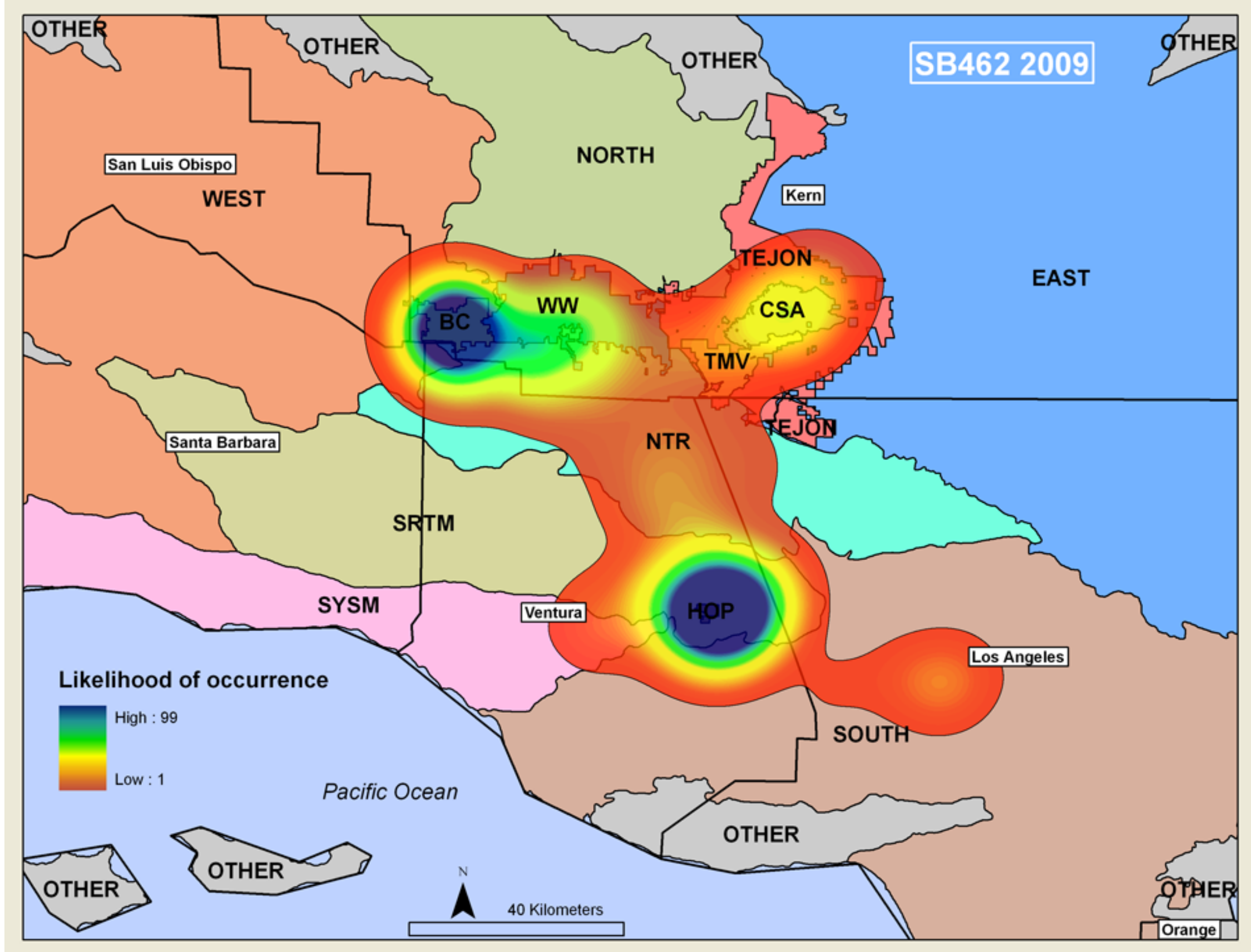


Publishing support provided by the U.S. Geological Survey Publishing Network, Tacoma Publishing Service Center

For more information concerning the research in this report, contact the Director, Forest and Rangeland Ecosystem Science Center

U.S. Geological Survey

777 NW 9th Street, Suite 400

Corvallis, Oregon, 97330

http://fresc.usgs.gov/ 
